\title{
Targeting BMI-1 in B cells restores effective humoral immune responses and controls chronic viral infection
}

\author{
Andrea Di Pietro ${ }^{1,2}$, Jack Polmear $\mathbb{1}^{1,2}$, Lucy Cooper ${ }^{1,2}$, Timon Damelang ${ }^{\circledR}{ }^{3}$, Tabinda Hussain ${ }^{1,2}$, \\ Lauren Hailes ${ }^{1,2}$, Kristy O'Donnell ${ }^{4}$, Vibha Udupa ${ }^{2,3,5}$, Tian $\mathrm{Mi}^{6}$, Simon Preston ${ }^{7,8}$, Areen Shtewe ${ }^{9}$, \\ Uri Hershberg 9 , Stephen J. Turner $\mathbb{C}^{2,5}$, Nicole L. La Gruta $\mathbb{1}^{1,2}$, Amy W. Chung $\mathbb{C}^{3}$, David M. Tarlinton $\mathbb{1}^{4}$, \\ Christopher D. Scharer ${ }^{6}{ }^{6}$ and Kim L. Good-Jacobson ${ }^{1,2} \bowtie$
}

\begin{abstract}
Ineffective antibody-mediated responses are a key characteristic of chronic viral infection. However, our understanding of the intrinsic mechanisms that drive this dysregulation are unclear. Here, we identify that targeting the epigenetic modifier BMI-1 in mice improves humoral responses to chronic lymphocytic choriomeningitis virus. BMI-1 was upregulated by germinal center B cells in chronic viral infection, correlating with changes to the accessible chromatin landscape, compared to acute infection. B cell-intrinsic deletion of Bmi1 accelerated viral clearance, reduced splenomegaly and restored splenic architecture. Deletion of Bmi1 restored c-Myc expression in B cells, concomitant with improved quality of antibody and coupled with reduced antibody-secreting cell numbers. Specifically, BMI-1-deficiency induced antibody with increased neutralizing capacity and enhanced antibody-dependent effector function. Using a small molecule inhibitor to murine BMI-1, we could deplete antibody-secreting cells and prohibit detrimental immune complex formation in vivo. This study defines BMI-1 as a crucial immune modifier that controls antibody-mediated responses in chronic infection.
\end{abstract}

C hronic viral infections, such as human immunodeficiency virus and hepatitis $\mathrm{C}$, are long-standing global health burdens that have evaded control by an antibody-mediated vaccine. The inability to clear virus from the body can cause irreparable and potentially fatal organ damage if left untreated. SARS-CoV-2 is the newest virus with the potential to cause a persisting infection $^{1}$, with severe disease correlating to dysregulation in antibody responses ${ }^{2}$. Efficiently treating patients who battle to clear the infection has proven problematic. Thus, it is critical to understand why the immune system fails to produce effective adaptive responses to chronic virus. While progress in this area has focused on $\mathrm{T}$ cell dysfunction, the mechanistic changes that lead to sustained B cell dysfunction have remained elusive.

Antibody production is a critical component of effective antiviral immune responses. During a $\mathrm{T}$ cell-dependent response, antigen-activated $\mathrm{B}$ cells form an early wave of antibody-secreting cells (ASCs), followed by a germinal center (GC) reaction within which $\mathrm{B}$ cells undergo affinity maturation. The generation of a high-affinity repertoire is a finely regulated process driven by transcription factors. Among them, c-Myc is transiently expressed in the GClight zone (LZ) and is responsible for selection of antigen-specific clones for further expansion in the dark zone $(\mathrm{DZ})^{3-5}$, followed by differentiation into high-affinity ASCs and memory B cells. Antibodies help clear infections through several key mechanisms: direct neutralization, non-neutralizing functions and mediating affinity maturation of GC B cells. However, antibodies can be a double-edged sword during chronic infection. Ineffective humoral responses are underpinned by three major alterations: polyclonal B cell expansion ${ }^{6-8}$, altered B cell memory $\mathrm{y}^{9}$ and changes to the quantity and quality of antibody. Excessive IgG in the serum leads to an overload of immune complexes ${ }^{6}$ (ICs) that suppress antibody-mediated innate effector functions and counterintuitively limits viral clearance ${ }^{10,11}$. IC deposition during chronic infection can cause destructive tissue pathology in both patients and in mice ${ }^{12,13}$. However, quantity is not the sole consideration for understanding how antibodies contribute to protection versus pathogenicity, as it does not necessarily correlate with antibody efficacy ${ }^{10,14}$. Efficacy arises from neutralizing capacity and Fc-mediated functions, both critical for clearing viral infection ${ }^{15-18}$. Despite the evidence of humoral dysregulation during chronic infection, few therapeutic options exist for modulating humoral responses to recover functionality and drive viral clearance in chronic infection.

Epigenetic modifiers, such as chromatin-remodeling histone modifiers and DNA methyltransferases, are vital regulators underpinning B cell fate ${ }^{19,20}$. During chronic viral infection, histone modifiers regulate functional differences between exhausted $\mathrm{CD} 8^{+} \mathrm{T}$ cells and effector memory subsets ${ }^{21,22}$. Epigenetic regulators have been shown to dysregulate B cells in lymphomas ${ }^{23,24}$ and in autoimmune

\footnotetext{
'Department of Biochemistry and Molecular Biology, Monash University, Clayton, Victoria, Australia. ${ }^{2}$ Infection and Immunity Program, Biomedicine Discovery Institute, Monash University, Clayton, Victoria, Australia. ${ }^{3}$ Department of Microbiology and Immunology, Peter Doherty Institute for Infection and Immunity, University of Melbourne, Parkville, Victoria, Australia. ${ }^{4}$ Department of Immunology \& Pathology, Alfred Research Alliance, Monash University, Melbourne, Victoria, Australia. ${ }^{5}$ Department of Microbiology, Monash University, Clayton, Victoria, Australia. ${ }^{6}$ Department of Microbiology and Immunology, School of Medicine, Emory University, Atlanta, GA, USA. 'DDivisions of Immunology and Molecular Immunology, Walter and Eliza Hall Institute of Medical Research, Parkville, Victoria, Australia. ${ }^{8}$ Department of Medical Biology, University of Melbourne, Parkville, Victoria, Australia. ${ }^{9}$ Department of Human Biology, Faculty of Science, University of Haifa, Haifa, Israel. Twitter: @KimLJacobson;

凶e-mail: kim.jacobson@monash.edu
} 
conditions $^{25}$. Yet, the B cell-intrinsic roles of epigenetic regulators in humoral dysfunction during chronic infection are undetermined. We hypothesized that the chronic inflammatory environment generated by persistent infections could perturb the expression and activity of epigenetic modifiers in the GC during the production of high-affinity ASCs. Using a combination of deep-sequencing, genetic tools and small molecule inhibitors, we demonstrate that a dysfunctional B cell fate in viral infection is dictated by the histone modifier BMI-1.

\section{Results}

BMI-1 is increased in B cells during chronic viral infection. To elucidate how chronic viral infection disrupts $\mathrm{B}$ cell differentiation and identify key intrinsic determinants of dysfunction, we used the comparative lymphocytic choriomeningitis virus (LCMV) model. C57BL/6 mice were infected with either LCMV-WE or LCMV-Docile, two closely related strains of LCMV, to induce either an acute (WE) or chronic (Docile) infection. Using this model, we investigated whether chronic infection resulted in changes to the epigenomic landscape within responding B cells. GC B cells $\left(\mathrm{CD} 19^{+} \mathrm{IgD}{ }^{\mathrm{lo}} \mathrm{CD} 95^{+} \mathrm{CD} 38^{\mathrm{lo}} \mathrm{CD} 138^{-}\right)$were isolated $14 \mathrm{~d}$ after infection and both assay for transposase-accessible chromatin using sequencing (ATAC-seq) and RNA-seq was undertaken (Fig. 1a). ATAC-seq was used to determine regions of chromatin accessibility within the genome that may be altered during chronic infection and correlated to changes in gene expression as determined by RNA-seq. Principal-component analysis (PCA) showed that samples within the same group (WE or Docile) clustered together. Overall, 889 differentially accessible regions (DARs) were identified between acute and chronic GC B cells, with an overall increase (561 DARs) in accessibility in chronic infection (Fig. 1b,c and Extended Data Fig. 1a-c). The frequency of DARs in the promoter-transcription start site region was $11 \%$, with the majority of DARs within the intergenic and intron regions (Extended Data Fig. 1b). In accordance with increased chromatin accessibility, RNA-seq identified 545 differentially expressed genes (DEGs), with 505 genes upregulated in chronic GC B cells compared to acute GC B cells (Fig. 1d and Extended Data Fig. 1d-h; select ASCs and interferon (IFN)-regulated genes indicated). To determine which of these DEGs may be directly regulated by changes to chromatin accessibility at their loci, overlap analysis of the datasets was performed. A total of 39 DEGs in GC B cells responding to LCMV-WE or LCMV-Docile had corresponding DARs identified by ATAC-seq (Extended Data Fig. 1i,j; several different DARs were identified for individual genes). Ingenuity Pathway Analysis (IPA) was then utilized to gain further insight into the gene networks altered in chronic infection. In accordance with an increase of ASCs in chronic infection, IPA revealed differentiation and quantity of plasma cells, as well as GC B cells, in the top ten disease and biological functions altered across the two conditions (Fig. 1e,f). This was despite excluding CD138 ${ }^{+}$cells from the sort-purified GC B cells used for ATAC-seq and RNA-seq analyses.

The increase in chromatin accessibility regions led us to hypothesize that epigenetic modifiers that repress gene expression may be dysregulated during chronic viral infection. Two important complexes that are known regulators of $\mathrm{B}$ cell fate are the Polycomb repressive complexes (PRCs). PRC1 and PRC2 consist of several subunits with the ability to support and deposit H2AK119Ub1 and $\mathrm{H} 3 \mathrm{~K} 27 \mathrm{me} 3$, respectively, regulating expression of target genes required for formation and maintenance of $\mathrm{GCs}^{23,24,26}$. We observed 49 PRC1 targets (Fig. 1g) and 80 PRC2 targets (Extended Data Fig. 1k) with altered chromatin accessibility in chronic GC B cells. In our DEG dataset, 63 PRC1 targets (Fig. 1g) and 74 PRC2 targets were differentially expressed (Extended Data Fig. 1k). Among the overlapped targets from the two datasets, the analysis identified seven altered PRC1 targets (Gfil, Gnaz, Ifi27, Oas3, Sclo4a1, Stat1 and Tmem184b) and eight altered PRC2 targets (Evc, Gnaz, Max, Mx1, Oas3, Plk2, Stat1 and Xaf1).

We next assessed whether expression of PRC components themselves was altered in chronic GC B cells. Expression of components of the canonical PRC1 (Fig. 1h), non-canonical PRC1, canonical PRC2 or PRC2 co-factors (Extended Data Fig. 11) were mostly unchanged in chronic infection, with Ring1b, Suz12, Rbbp4 and $B$ cor decreased, whereas Bmil was increased compared to acute GC B cells. The increase in Bmi1 was a surprising finding. Previous reports have not observed BMI-1 in murine GC B cells ${ }^{26}$, although it has been detected in the LZ of GC in human tonsils ${ }^{27}$ and is expressed in human ASCs ${ }^{28}$. BMI-1 is a Polycomb group protein that activates the catalytic component RING1B of PRC1 (ref. ${ }^{29}$ ), which in turn deposits monoubiquitin at lysine 119 of histone $\mathrm{H}_{2} \mathrm{~A}^{30}$. Functionally, BMI-1 allows stable silencing of gene expression, regulating lineage commitment, self-renewal, proliferation and survival ${ }^{31-36}$. BMI-1 was originally identified as an oncogenic collaborator of $\mathrm{c}-\mathrm{Myc}^{37,38}$ that is upregulated in Myc-induced B cell malignancies $^{39}$ and myeloma ${ }^{34,40}$; however, its role during humoral responses to infection has not been determined.

We proposed that Bmil upregulation in chronic GC B cells may be connected to the increase in plasma cell gene networks. To understand murine Bmil expression dynamics, we used a tamoxifen-inducible Bmi $1^{\text {CreERT2}}$ Rosa $26^{\mathrm{EYFP}}$ reporter mouse to temporally examine Bmil expression on a per-cell basis. We first assessed which B cell subsets express BMI-1 in a tractable, non-infectious model, the hapten carrier 4-hydroxy-3-nitrophenylacetyl-keyhole limpet hemocyanin (NP-KLH). Bmi1 ${ }^{\text {CreERT2}}$ Rosa $26^{\text {EYFP }}$ mice were immunized with NP-KLH precipitated in the adjuvant alum,

Fig. 1 | Gene expression and chromatin accessibility regions in GC B cells during chronic viral infection are distinct from acute viral infection.

a, Schematic of experimental setup. GC B cells were sort-purified from wild-type mice infected with either LCMV-WE or LCMV-Docile $14 \mathrm{~d}$ previously.

b, PCA in two dimensions of DARs in acute (salmon) and chronic (green) GC B cells. c, Heat map of ATAC-seq signals for unique and shared peak groups; $n=4$ mice per group. $\mathbf{d}$, Heat map of gene expression by RNA-seq for differential expressed genes in the two clusters; $n=2$ mice per group.

e, Bar charts of significantly enriched top ten list of IPA-based diseases and bio function in chronic GC B cells. Each bar represents a high-level functional category as calculated from the Fisher's exact test $(P \leq 0.05)$. f, IPA analysis: upregulated or downregulated genes predicted to affect the differentiation of plasma cells. $\mathbf{g}$, Accessibility changes in PRC1 targets within DARs (ATAC-seq; reads per million (RPM); top) and PRC1 targets within the DEG dataset (RNA-seq; counts per million (CPM); bottom); ${ }^{\star \star \star} P=0.0001$, ${ }^{\star \star \star \star} P<0.0001$ (top); $P=0.0312,{ }^{\star \star \star \star} P<0.0001$ (Wilcoxon matched-pairs signed-rank test, two-tailed $P$ value) (bottom). h. Plots of normalized counts for canonical PRC1 genes (RNA-seq); $n=2$ mice per group, data represent mean \pm s.e.m. i, Schematic of infection and tamoxifen administration of Bmi $7^{\text {CreERT2}}$ Rosa26 $6^{\text {EYFP }}$ reporter mice. Wild-type (WT) and Bmi ${ }^{\text {CreERT2}}$ Rosa26 $6^{\text {EYFP }}$ reporter mice were infected with either LCMV-WE or LCMV-Docile. Tamoxifen was administered every $24 \mathrm{~h}$ from $\mathrm{d} 9$-d11 and EYFP+ cells were assessed in B cell subsets at d14. j, Flow cytometric representative histograms of EYFP+ cells within the lymphocyte population. $\mathbf{k}$ EYFP+ lymphocytes (frequency of live cells); $n=3$ WT (WE or Docile), $n=9$ reporter (WE) and $n=7$ reporter (Docile), combined from three independent experiments. I, Frequency of EYFP+ GC B cells; $\mathrm{EYFP}^{+} \mathrm{B} 22 \mathrm{O}^{\mathrm{lo}} \mathrm{CD} 138^{\mathrm{hi}} \mathrm{ASC} ; n=3 \mathrm{WT}$ mice (WE or Docile), $n=9$ reporter mice (WE) and $n=7$ reporter mice (Docile), combined from three independent experiments. $\mathbf{m}$, Uninfected reporter mice received three doses of tamoxifen, $24 \mathrm{~h}$ apart and assessed $48 \mathrm{~h}$ after the final dose. Frequency of B220 ${ }^{\circ} \mathrm{CD} 138^{\mathrm{hi}}$ ASCs in mesenteric lymph nodes ( $\mathrm{mLNs}$ ), spleen and bone marrow $(B M) ; n=8$, combined from two individual experiments. Data represent mean \pm s.e.m. $(\mathbf{k}-\mathbf{m}) ;{ }^{\star} P<0.05,{ }^{\star \star} P<0.01,{ }^{\star \star \star} P<0.001$ (Mann-Whitney U-test, two-tailed $P$ value). 
administered with tamoxifen at $\mathrm{d} 3-5$ and assessed at $\mathrm{d} 7$ to detect the yellow fluorescent protein (YFP) expressed under the control of Rosa26 regulatory sequences in BMI- $1^{+}$cells (Extended Data a

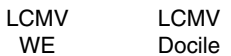

(acute) (chronic)
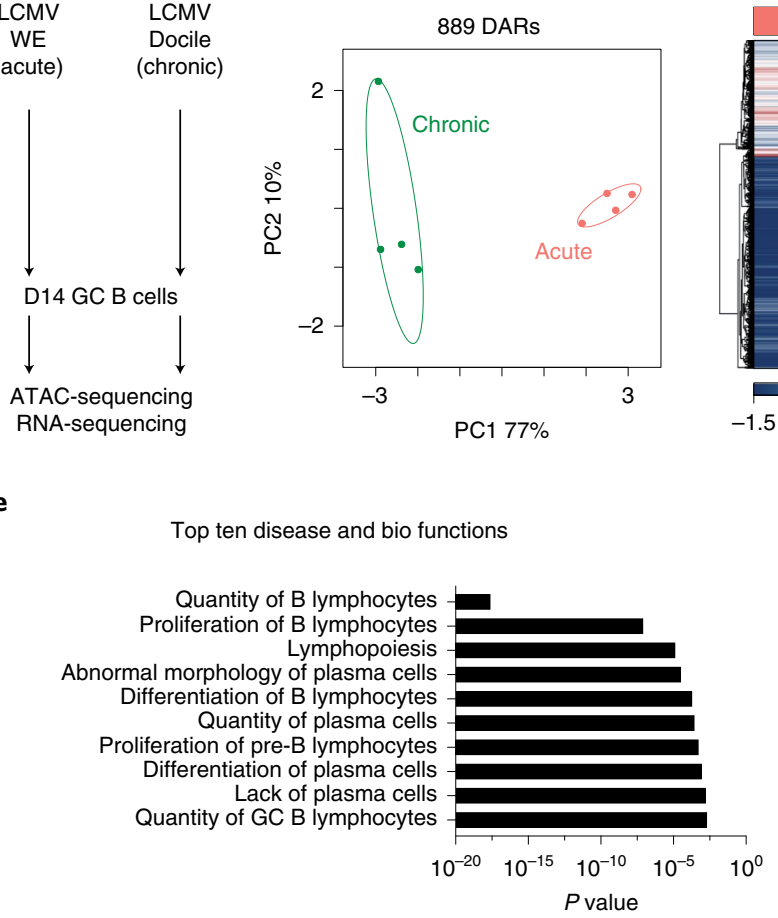

h

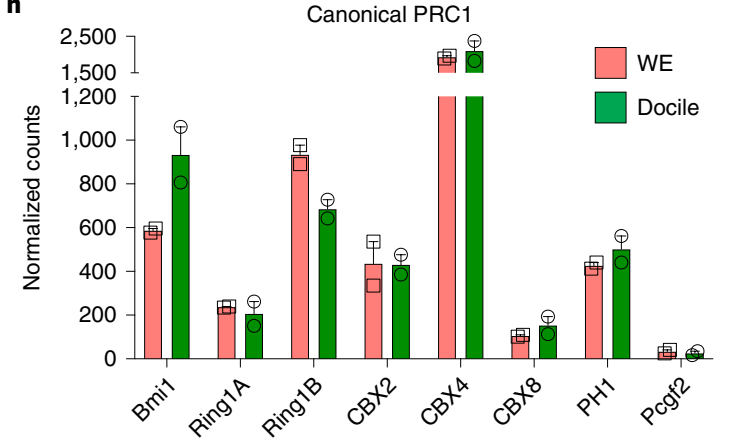

i
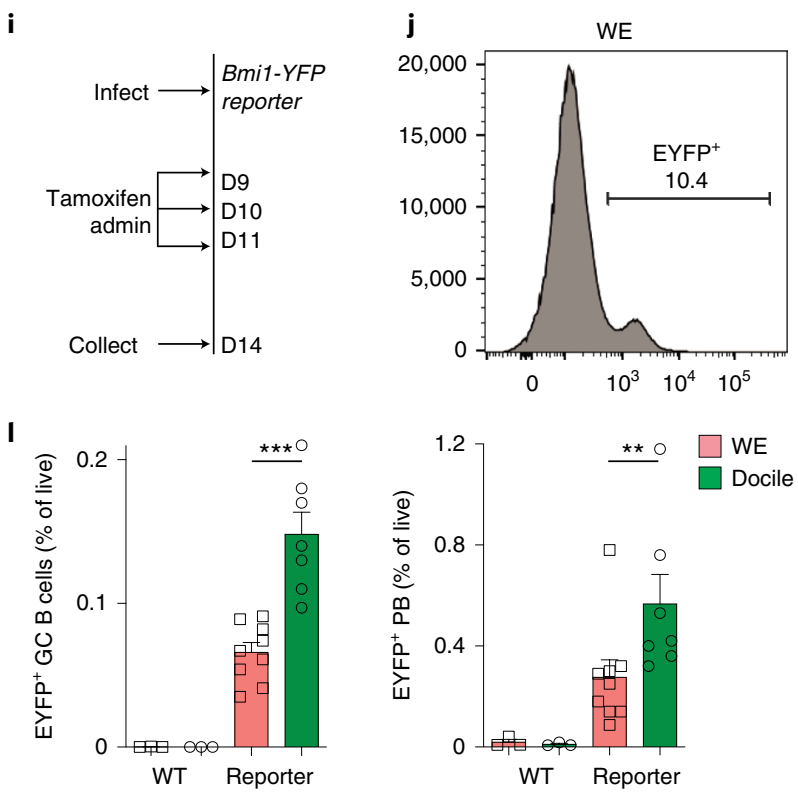

b
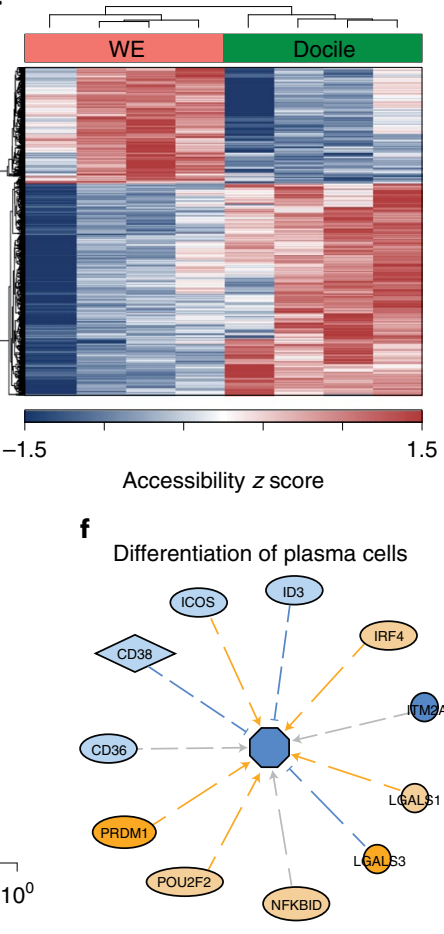

Fig. 2a). Flow cytometric analyses revealed that $\mathrm{B} 220^{\mathrm{lo}} \mathrm{CD} 138^{\mathrm{hi}}$ ASCs upregulated Bmil (Extended Data Fig. 2b). We undertook further analysis to determine whether BMI-1-expressing cells were 


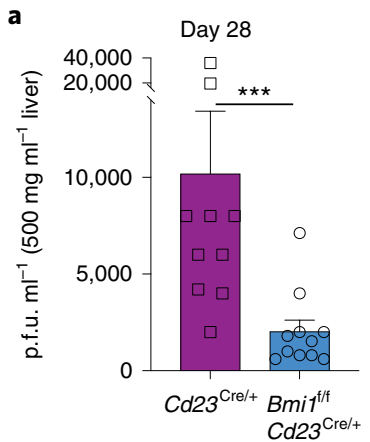

b

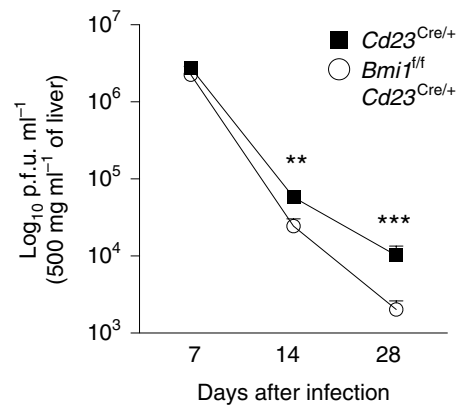

C Spleen
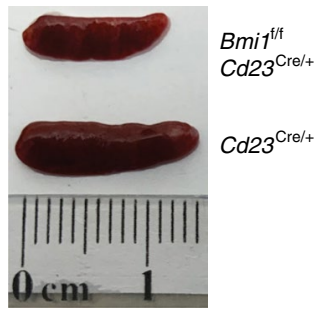

d

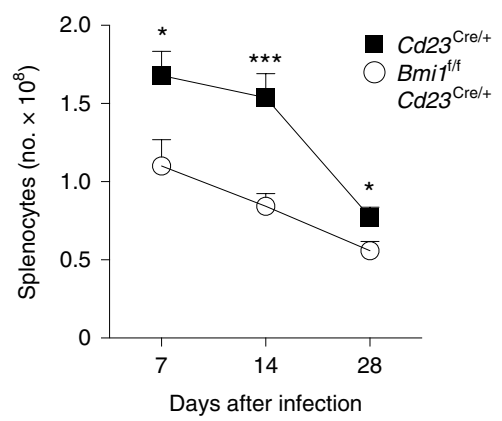

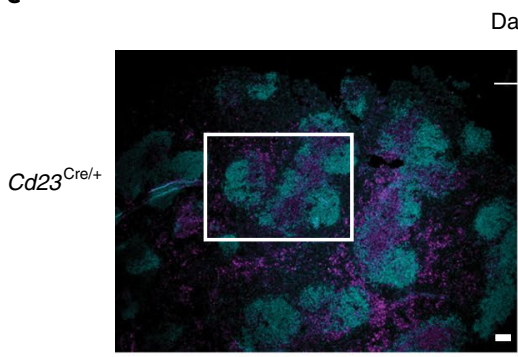

Day 7
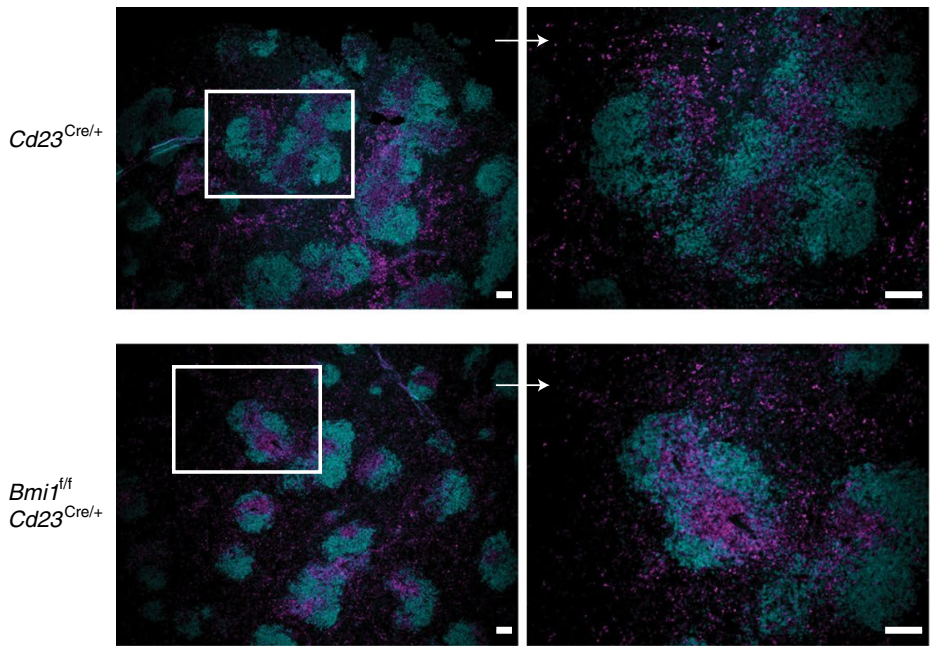

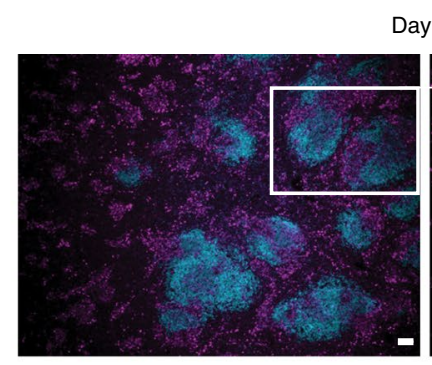

Day 21
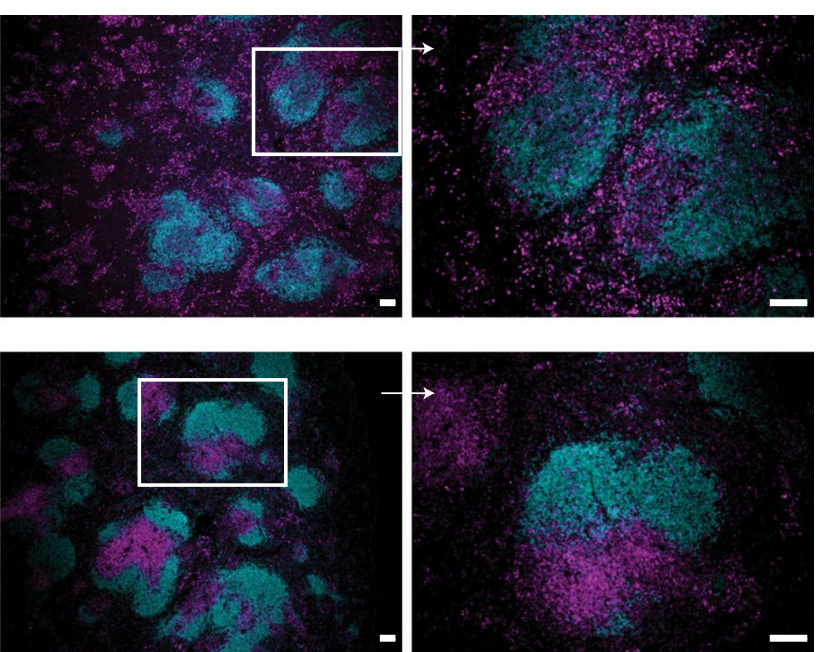

Fig. 2 | Conditional deletion of Bmi1 in B cells results in accelerated clearance of chronic viral infection. a, $C d 23^{\mathrm{Cre} /+}$ and $\mathrm{Bmit}{ }^{1 / 4} \mathrm{Cd} 23^{\mathrm{Cre} /+}$ mice were infected with LCMV-Docile and livers were assessed for viral plaque-forming units (p.f.u.) at $d 28, n=10 \mathrm{Cd} 23^{\mathrm{Cre} /+}$ and $n=11 \mathrm{Bmi} 7^{\mathrm{f} / \mathrm{C}} \mathrm{Cd} 23^{\mathrm{Cre} /+}$ mice, combined from three independent experiments. Data represent mean \pm s.e.m. ${ }^{\star \star \star} P=0.000264$ (Mann-Whitney $U$-test, two-tailed $P$ value). $\mathbf{b}$, Time course of viral p.f.u. of the indicated time points after infection ( $d 7, n=3 ; d 14$ and $d 28, n=10 \mathrm{Cd} 23^{\mathrm{Cre} /+}$ and $n=11 \mathrm{Bmi} \mathrm{i}^{\mathrm{t} / \mathrm{C}} \mathrm{Cd} 23^{\mathrm{Cre} /+}$ mice, combined from 1-3 experiments per time point). Data represent mean \pm s.e.m. $\mathrm{d} 7, P=0.234 ; \mathrm{d} 14,{ }^{\star \star} P=0.0095 ; \mathrm{d} 28,{ }^{\star \star \star} P=0.000264$ (Mann-Whitney $U$-test, two-tailed $P$ value). $\mathbf{c}$, Representative spleens from $\mathrm{Cd} 23^{\mathrm{Cre} /+}$ and $\mathrm{Bmi} \mathrm{T}^{\mathrm{ft} \mathrm{f}} \mathrm{Cd} 23^{\mathrm{Cre} /+}$ mice infected with LCMV-Docile at d14 after infection. d, Splenocyte number at the indicated time points after infection;

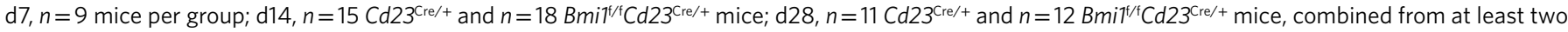
individual experiments per time point. Data represent mean \pm s.e.m. $\mathrm{d} 7,{ }^{\star} P=0.0244 ; \mathrm{d} 14,{ }^{\star \star \star} P=0.001 ; \mathrm{d} 28,{ }^{\star} P=0.0214$ (Mann-Whitney $U$-test, two-tailed

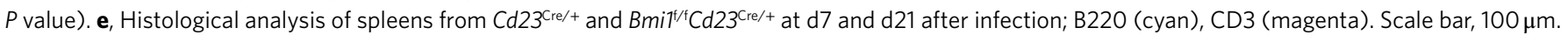
$\mathrm{d} 7, n=3 \mathrm{Cd} 23^{\mathrm{Cre} /+}$ spleens and $n=4 \mathrm{Bmit}^{\mathrm{t} / \mathrm{f}} \mathrm{Cd} 23^{\mathrm{Cre} /+}$ spleens; $d 21, n=3$ spleens per group. One experiment per time point.

enriched in a particular subset of ASCs. Enhanced YFP (EYFP) expression was modulated in the $\operatorname{IgA}{ }^{+}$and $\operatorname{IgG} 1^{+}$populations in secondary lymphoid tissues (Extended Data Fig. 2c) and EYFP ${ }^{+}$ was significantly enriched in plasma cells compared to plasmablasts (Extended Data Fig. 2d).

$B m i 1^{\text {CreERT2}}$ Rosa26 $6^{\text {EYFP }}$ reporter mice were infected with LCMV-WE or LCMV-Docile and tamoxifen was administered every $24 \mathrm{~h}$ from d9-11 (Fig. 1i). Infection with LCMV-Docile induced a significant increase in the frequency of EYFP ${ }^{+}$lymphocytes, compared to LCMV-WE (Fig. 1j,k). In both GC B cells and in $\mathrm{B} 220^{\mathrm{lo}} \mathrm{CD} 138^{\text {hi }}$ ASCs, BMI-1 was increased $\sim$ threefold in chronically infected mice, compared to acutely infected mice, with a higher proportion within the ASC population (Fig. 11). Within the GC population, the increase in $\mathrm{EYFP}^{+}$cells in LCMV-Docile-infected mice was localized to the LZ population, whereas DZ cells had an equivalent frequency of $\mathrm{EYFP}^{+}$cells following acute or chronic infection (Extended Data Fig. 2e). Furthermore, when steady-state ASCs were assessed for EYFP expression, $\mathrm{EYFP}^{+}$cells were significantly increased in the bone marrow compared to the spleen and mesenteric lymph nodes (Fig. $1 \mathrm{~m}$ ). Thus, Bmil expression was enriched in the ASC population compared to GC B cells, correlating with an increase in tissues with higher frequencies of long-lived plasma cells. The increase in Bmil transcript in $\mathrm{EYFP}^{+}$subsets, as well as increased Bmil transcript and BMI-1 protein in B cell subsets responding to LCMV-Docile compared to LCMV-WE from wild-type mice, was confirmed by quantitative PCR with reverse transcription (RT-qPCR) and immunoblot analyses (Extended Data Fig. 2f-k). Combined, BMI-1 is conventionally enriched in ASCs and differentially expressed in GC B cells responding to either acute or chronic strains of LCMV.

Bmi1 deletion in B cells accelerates LCMV-Docile clearance. We next asked whether modulation of BMI-1 in B cells in chronic infection determined productive outcomes to viral infection. To delete Bmil in mature B cells, we generated $B m i 1^{\mathrm{f/f}} \mathrm{C} d 23^{\mathrm{Cre} /+}$ mice by crossing mice that carry floxed alleles of Bmil with mice expressing a Cre recombinase under the control of the $\mathrm{B}$ cell-specific $C d 23$ promoter. $\mathrm{Bmil}^{\mathrm{f} / \mathrm{f}} \mathrm{Cd} 23^{\mathrm{Cre} /+}$ and control $\mathrm{Cd} 23^{\mathrm{Cre} /+}$ mice were infected with LCMV-Docile and assessed throughout infection. Notably, Bmil $\mathrm{f}^{\mathrm{f} /}$ ${ }^{\mathrm{f}} \mathrm{Cd} 23^{\mathrm{Cre} /+}$ mice had significantly reduced viral titers (fivefold change) 
compared to controls at d28 after infection (Fig. 2a). Time-course analyses demonstrated that viral titers were similar between control and BMI-1-deficient mice at d7; however, a 2.4-fold decrease was detected by d14 (Fig. 2b), concomitant with a significant increase in weight gain compared to $C d 23^{\mathrm{Cre} /+}$ mice (Extended Data Fig. 3a). At $\mathrm{d} 14$ after infection, spleens from $\mathrm{Bmil}^{\mathrm{f} / \mathrm{f}} \mathrm{Cd} 23^{\mathrm{Cre} /+}$ mice were noticeably smaller than control mice (Fig. 2c) and splenocyte numbers were reduced (Fig. $2 \mathrm{~d}$ ). Frequencies of innate, $\mathrm{CD} 4^{+}$and $\mathrm{CD}^{+} \mathrm{T}$ cell populations were comparable between $\mathrm{Cd} 23^{\mathrm{Cre} /+}$ and $\mathrm{Bmil}{ }^{\mathrm{f} / \mathrm{f}} \mathrm{Cd}$ $23^{\mathrm{Cre} /+}$ mice (Extended Data Fig. 3b-f). Functionally, there was no difference in killing capacity of gp $33^{+} \mathrm{CD} 8^{+} \mathrm{T}$ cells (Extended Data Fig. $3 g$ ) or production of IFN- $\gamma$ on a per-cell basis (Extended Data Fig. 3h). Infection with LCMV disrupts splenic architecture ${ }^{41-43}$, particularly B cell follicles and $\mathrm{T}$ cell zones (Fig. 2e; $C d 23^{\mathrm{Cre} /+}$ mice; spleens from uninfected mice are shown in Extended Data Fig. 3i). In contrast, spleens from $B m i 1^{\mathrm{f} / \mathrm{f}} \mathrm{Cd} 23^{\mathrm{Cre} /+}$ mice displayed intact follicular structures and $\mathrm{T}$ cell areas (Fig. $2 \mathrm{e} ; \mathrm{Bmil} 1^{\mathrm{f} / \mathrm{f}} \mathrm{Cd} 23^{\mathrm{Cre} /+}$ ). Thus, depletion of BMI-1 in mature B cells resulted in normalized splenic size and architecture and accelerated viral clearance.

Increase in antibody function in the absence of BMI-1. Changes to antibody quality and quantity contribute to ineffective humoral responses during chronic viral infection. Given that B cell-specific deletion of BMI-1 led to accelerated viral clearance, we hypothesized that the efficacy of antibody, either through neutralizing or non-neutralizing effector function, was increased in $B m i 1^{\mathrm{f} / \mathrm{f}} \mathrm{Cd}$ $23^{\mathrm{Cre} /+}$ mice. To test this, LCMV-Docile-infected $\mathrm{Bmil}{ }^{\mathrm{f} / \mathrm{f}} \mathrm{Cd} 23^{\mathrm{Cre} /+}$ and $C d 23^{\mathrm{Cre} /+}$ mice were assessed for neutralizing antibody capacity. Neutralizing antibodies formed to chronic LCMV emerge late in the response, increasing approximately 2 months after infection ${ }^{44}$. By contrast, antibodies from $B m i 1^{\mathrm{f} / \mathrm{f}} \mathrm{Cd} 23^{\mathrm{Cre} /+}$ mice had an increased capacity to reduce plaque formation in vitro at $\mathrm{d} 14$, compared to antibodies from control mice (Fig. 3a).

The tuning of antibody quality occurs by glycosylation of a conserved $N$-linked glycan of the IgG constant region $(\mathrm{Fc})$, which can be dynamically modulated by the pathogen-influenced microenvironment during an immune response ${ }^{45,46}$. Shifts in glycosylation can have antiviral or anti-inflammatory effects, regulate complement activation and enhance the effectiveness of neutralizing antibodies $^{16,47}$. Therefore, to elucidate the efficacy of antibody produced in BMI-1-deficient mice, we assessed IgG Fc $\mathrm{N}$-linked glycan profiles. While most glycosylation patterns remained unchanged in the absence of BMI-1 (Extended Data Fig. 4a), there was a significant decrease in G2Z1F, whereas the corresponding G2Z1 remained unchanged (Fig. 3b). Afucosylated forms of IgG can increase antibody efficacy ${ }^{48}$, enhance antibody-dependent cellular cytotoxicity $(\mathrm{ADCC})^{49}$ and induce effective innate cell function during chronic viral infection ${ }^{50}$. Specifically, the G2Z1F glycoform has been shown to be enriched in the IgG2c subset and is thought to act as a dampener of this pro-inflammatory isotype ${ }^{51}$. To determine whether antibody efficacy was increased by reduction of this glycoform, we compared the ability of antibody from $B m i 1^{\mathrm{f} / \mathrm{f}} \mathrm{Cd} 23^{\mathrm{Cre} /+}$ and $C d 23^{\mathrm{Cre} /+}$ mice to induce ADCC. Using natural killer (NK) cells from wild-type mice, ADCC was significantly enhanced using sera collected from LCMV-Docile-infected $\mathrm{Bmil}^{\mathrm{f} / \mathrm{f}} \mathrm{Cd} 23^{\mathrm{Cre} /+}$ mice, compared to sera from $C d 23^{\mathrm{Cre} /+}$ mice (Fig. $3 \mathrm{c}$ ). Taken together, these data reveal BMI-1 as a key regulator of antibody efficacy in chronic viral infection.

We next investigated the kinetics of ASC production. The frequency of $\mathrm{CD}_{1} 9^{+} \mathrm{IgD}^{+}$cells (enriched in naive B cells) was comparable between $\mathrm{Bmil}^{\mathrm{f/f}} \mathrm{Cd} 23^{\mathrm{Cre} /+}$ mice and controls, as was the ability of $\mathrm{CD}_{1} \mathrm{IgD}^{+}$to form GC B cells (Extended Data Fig. 4b-e). At $\mathrm{d} 14$, the total number of $\mathrm{CD}_{19}{ }^{+} \mathrm{IgD} \mathrm{D}^{+}$and GC B cells was significantly reduced. BMI-1-deficient GC B cells were able to isotype switch to IgG2c and to maintain detectable virus-specific IgG2c (Extended Data Fig. 4f,g). In contrast, B cell-specific deletion of BMI-1 altered the dynamics of ASCs. In LCMV-Docile-infected $C d 23^{\mathrm{Cre} /+}$ mice, ASC formation peaked at $\mathrm{d} 14$ before declining to low levels by d21 (Fig. 3d-f). In comparison, ASC frequency, but not total number, was increased in $\mathrm{Bmil}^{\mathrm{f} / \mathrm{f}} \mathrm{Cd} 23^{\mathrm{Cre} /+}$ mice at $\mathrm{d} 7$, before a significant decrease in both frequency and number at d14 compared to controls (Fig. 3f). Notably, there was not a complete absence of ASCs; in fact, the reduction of d14 ASC frequency and number (Fig. 3e) resembled that observed in LCMV-WE (acute)-infected mice. Similarly, GC B cell frequency and number (Fig. 3g) and circulating ICs (Fig. 3h) in BMI-1-deficient mice infected with LCMV-Docile, resembled that observed in control mice infected with LCMV-WE. To confirm that changes to the ASC population were B cell-intrinsic, 1:1 mixed bone-marrow chimeras were established with Ly5.1 and $B m i 1^{\mathrm{f} / \mathrm{f}} \mathrm{Cd} 23^{\mathrm{Cre} /+}$ bone marrow (Fig. 3i). Infected chimeras showed a significant reduction in BMI-1-deficient ASCs compared to Ly5.1 (Fig. 3j). Thus, induction of neutralizing antibodies, augmentation of antibody-dependent effector function and reduction in circulating ICs are consistent with more potent immune responses in LCMV-Docile-infected $B m i 1^{\mathrm{f} / \mathrm{f}} \mathrm{Cd} 23^{\mathrm{Cre} /+}$ mice.

Fig. 3 | Pleiotropic function of BMI-1 in the humoral response to chronic viral infection. a, $C d 23^{\mathrm{Cre} /+}$ or $B m i 7^{\mathrm{f} / \mathrm{f}} \mathrm{Cd} 23^{\mathrm{Cre} /+}$ mice were infected with LCMV-Docile. Assessment of the ability of serum at d14 post-infection to reduce viral infectivity in vitro (no serum, no s.); $n=6 \mathrm{Cd} 23^{\mathrm{Cre} /+}$ and $n=9$ $B \mathrm{mi}^{7 / / \mathrm{C}} \mathrm{Cd} 23^{\mathrm{Cre} /+}$ mice, combined from three independent experiments. Data represent mean \pm s.e.m. ${ }^{\star} P<0.05$ (Mann-Whitney U-test, two-tailed $P$ value). b. Purified lgG from infected $\mathrm{Cd} 23^{\mathrm{Cre} /+}$ or $\mathrm{Bmi} 7^{1 / \mathrm{f}} \mathrm{Cd} 23^{\mathrm{Cre} /+}$ mice was assessed for $\mathrm{N}$-glycan structures by capillary electrophoresis. Relative abundance of specific types of $\mathrm{N}$-glycan structures of total IgG at d14 after infection (G2, digalactosylated; F, fucosylated; Z1, sialylated); $n=5$ mice per group, data combined from two independent experiments. Data represent mean \pm s.e.m. ${ }^{\star \star} P=0.0079$ (Mann-Whitney $U$-test, two-tailed $P$ value). c, ADCC assay used to determine frequency of dead target MC57G cells after incubation with WT NK cells and sera from d14 post-LCMV-Docile-infected mice, assessed by flow cytometry; $n=7$ mice per group, data combined from two independent experiments. Data represent mean \pm s.e.m. ${ }^{\star \star} P=0.0023($ Mann-Whitney $U$-test, two-tailed $P$ value). d, Representative flow cytometric plot of $B 220^{\circ} \mathrm{CD} 138^{\text {hi }}$ ASC in LCMV-Docile-infected mice. e,f, Frequency and number of ASCs in mice infected with either LCMV-WE or LCMV-Docile at d14 (WE, $n=5 \mathrm{Cd} 23^{\mathrm{Cre} /+}$ and $n=6 \mathrm{Bmit}^{\mathrm{f/f}} \mathrm{Cd} 23^{\mathrm{Cre} /+}$ mice; Docile, $n=14 \mathrm{Cd} 23^{\mathrm{Cre} /+}$ and $n=15 \mathrm{Bmit}^{1 / \mathrm{C}} \mathrm{Cd} 23^{\mathrm{Cre} /+}$ mice) (e) and in LCMV-Docile-infected mice at indicated time points (d7, $n=6$ mice per group; $d 14, n=14 \mathrm{Cd} 23^{\mathrm{Cre} /+}$ and $n=15$ $\mathrm{Bmit}^{1 / \mathrm{f}} \mathrm{Cd} 23^{\mathrm{Cre} /+}$ mice; $\mathrm{d} 21, n=6$ mice per group; $\mathrm{d} 28, n=8 \mathrm{Cd} 23^{\mathrm{Cre} /+}$ and $n=9 \mathrm{Bmi} 7^{1 / \mathrm{f}} \mathrm{Cd} 23^{\mathrm{Cre} /+}$ mice, combined from at least two experiments per time point) (f). Data represent mean \pm s.e.m. Frequency of live cells: $\mathrm{d} 7,{ }^{\star \star} P=0.0022 ; \mathrm{d} 14,{ }^{\star} P=0.0102 ; \mathrm{d} 21,{ }^{\star} P=0.0411 ; \mathrm{d} 28, P=0.8884$ (Mann-Whitney $U$-test, two-tailed $P$ value); cell number: $\mathrm{d} 7, P=0.8182 ; \mathrm{d} 14,{ }^{\star \star} P=0.0012 ; \mathrm{d} 21,{ }^{\star} P=0.026 ; \mathrm{d} 28, P=0.4907$ (Mann-Whitney $U$-test, two-tailed $P$ value).

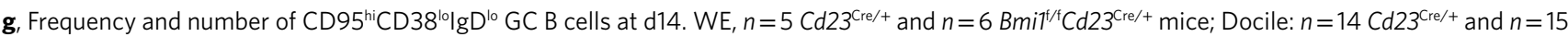
$B \mathrm{mit}^{1 / 4} \mathrm{Cd} 23^{\mathrm{Cre} /+}$ mice. Data were combined from at least two experiments and represent mean \pm s.e.m. Frequency of live cells: ${ }^{\star} P=0.0194,{ }^{\star \star} P=0.0015$, ${ }^{\star \star \star} P=0.0005$; cell number: ${ }^{\star} P=0.0418,{ }^{\star \star} P=0.0024$ (Mann-Whitney $U$-test, two-tailed $P$ value). $\mathbf{h}$, Assessment of total lgG2c immune complexes at d14 after infection; $n=2$ mice per group, data are representative of three independent experiments and represent mean \pm s.e.m. (Mann-Whitney $U$-test, two-tailed $P$ value). i,j, BM of Ly5.1 and $B m i 7^{1 / f} \mathrm{Cd} 23^{\mathrm{Cre} /+}$ were mixed in a 1:1 ratio and used to reconstitute irradiated recipients; mice were infected and assessed for ASCs as per schematic; $n=9$ per group, data were combined from two independent experiments and represent mean \pm s.e.m. ${ }^{\star \star \star} P=0.002$ (Mann-Whitney U-test, two-tailed $P$ value) 
Relationship of c-Myc and BMI-1 in chronic viral infection. Affinity maturation is highly regulated to avoid the survival and expansion of potentially autoreactive or cancerous clones. A critical regulator of the selection process is $\mathrm{c}-\mathrm{Myc}^{3,4}$. Given the role of BMI-1 in Myc-induced $\mathrm{B}$ cell malignancies ${ }^{39}$ and the heterogeneity of both Bmil and $\mathrm{Myc}^{3,4}$ expression in the GC, we hypothesized that BMI-1 and c-Myc may collaborate to regulate the efficacy of the antibody response to infection. $\mathrm{EYFP}^{+}$and $\mathrm{EYFP}^{-}$GC B cells were isolated from BMI-1 reporter mice infected with either LCMV-WE or LCMV-Docile (Fig. 4a). Of note, $M y c$ expression was selectively expressed in the $\mathrm{EYFP}^{+} \mathrm{GC}$ B cell subset, with a 21-fold increase compared to EYFPGC B cells (Fig. 4b). The fold change of $M y c$ expression in $\mathrm{EYFP}^{+}$
GC B cells responding to chronic infection was considerably higher compared to the acute WE-infected cohort, in which there was a twofold, nonsignificant increase in $\mathrm{EYFP}^{+}$over $\mathrm{EYFP}^{-}$(Fig. 4b). We next investigated whether Bmil deletion affected $M y c$ expression. Total GC B cells from LCMV-Docile-infected $C d 23^{\text {Cre/+ }}$ mice had increased expression of $M y c$ compared to LCMV-WE (Fig. 4c). $\mathrm{B}$ cell-specific BMI-1 deletion selectively reduced $M y c$ expression in LCMV-Docile-infected mice to the level observed in LCMV-WE infection (Fig. 4c). In contrast, there was no significant change in gene expression of other reported targets of BMI-1, Bcl2l11 (encoding Bim) ${ }^{34}$ and Pmaip1 (encoding Noxa) ${ }^{33}$ in acute or chronically infected $\mathrm{Bmil}{ }^{\mathrm{f/f}} \mathrm{Cd} 23^{\mathrm{Cre} /+}$ mice (Extended Data Fig. $4 \mathrm{~h}$ ).

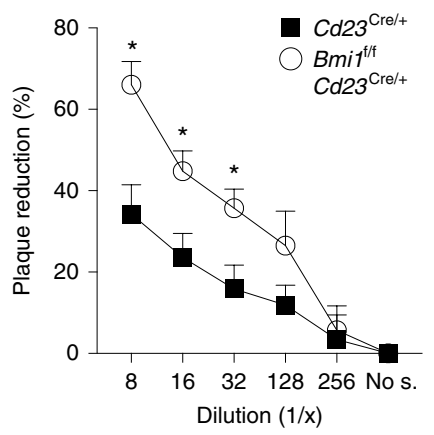

d
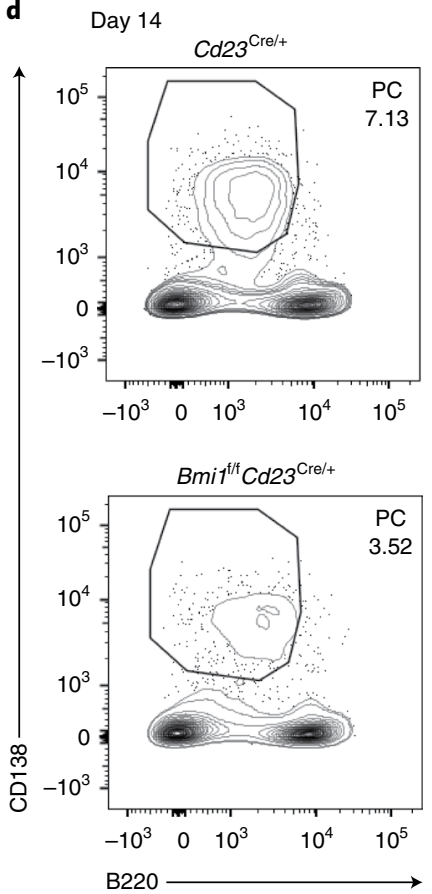

b
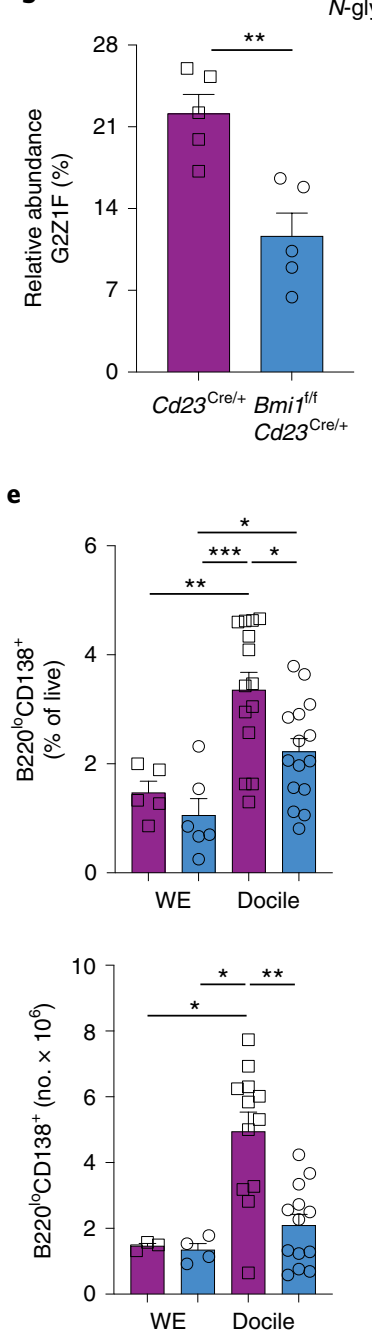

$N$-glycan structure

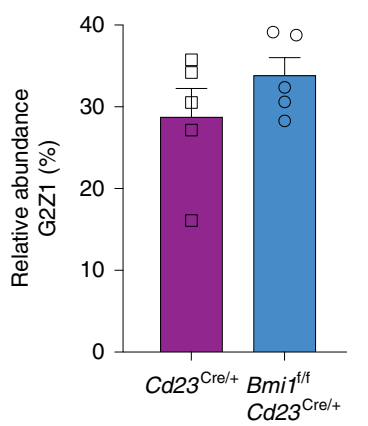

$\mathbf{f}$
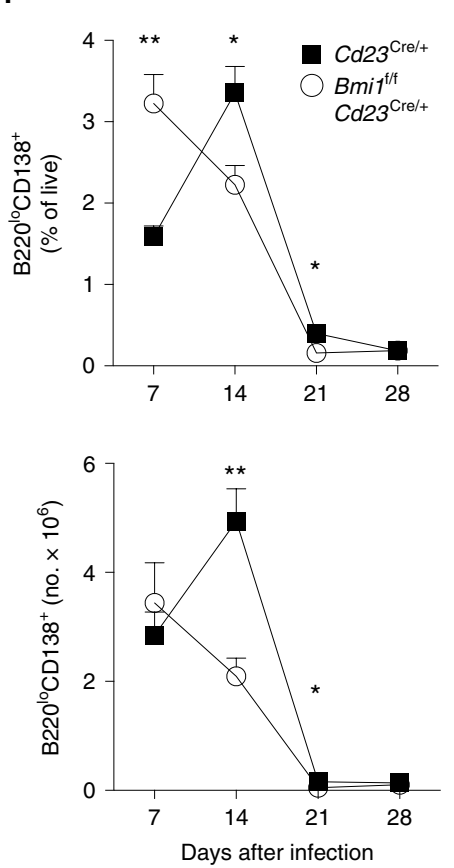

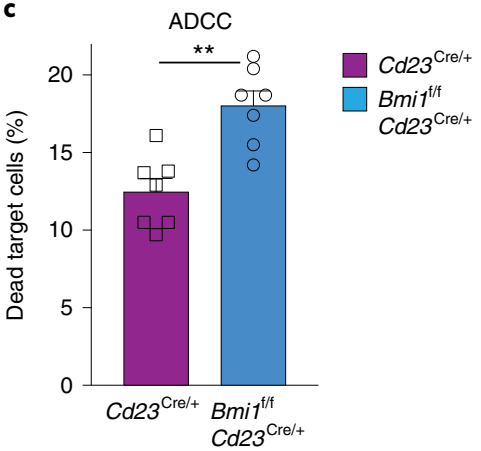

g

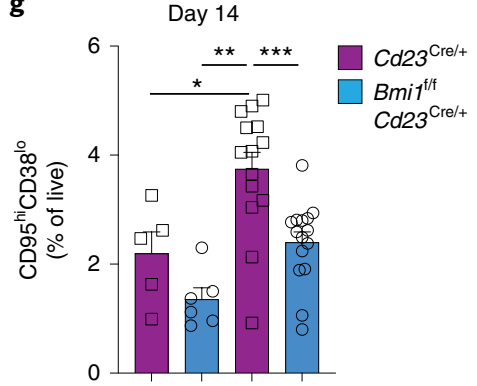

h

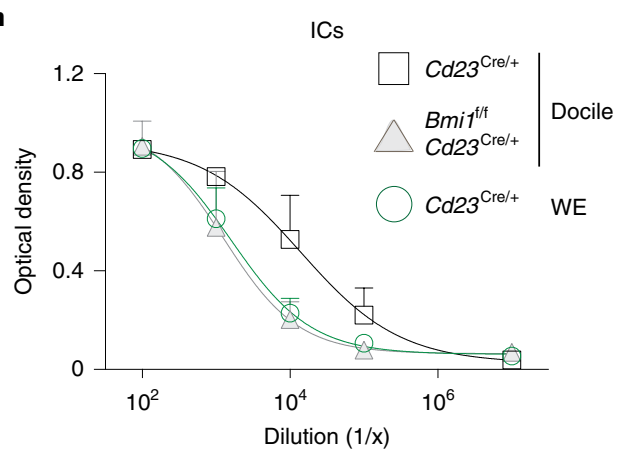

i

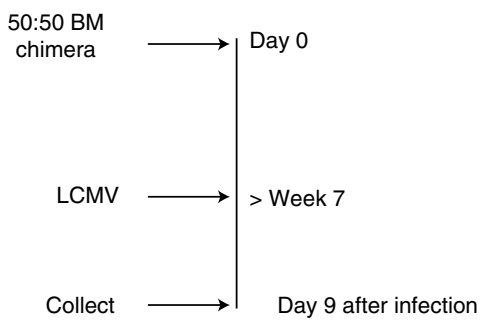

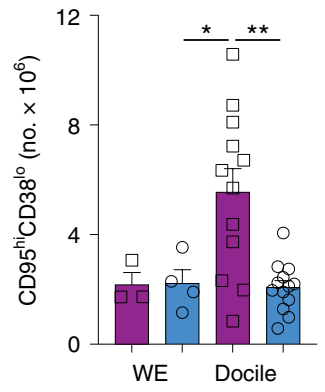

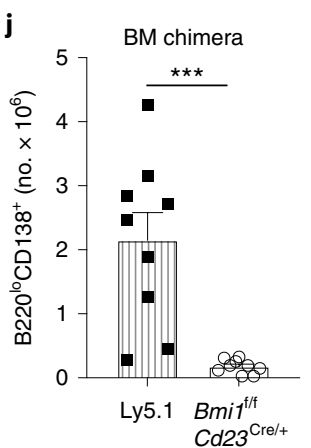


Within the GC, c-Myc is localized to the LZ in immunization models ${ }^{3,4}$. Given the increase in $M y c$ in chronic infection, we hypothesized that c-Myc would no longer be tightly regulated within the GC. Indeed, histological analyses of $C d 23^{\mathrm{Cre} /+}$ mice infected with LCMV-Docile revealed c-Myc expression throughout the GC (Fig. 4d and Extended Data Fig. 5a). In contrast, GCs in $\mathrm{Bmil}^{\mathrm{f/f}} \mathrm{Cd} 23^{\mathrm{Cre} /+}$ mice were mostly absent of c-Myc expression, with only a few cells evidently expressing c-Myc (Fig. 4d,e and Extended Data Fig. 5b). Therefore, conditional deletion of BMI-1 restored regulated expression of $\mathrm{c}-\mathrm{Myc}$ within the GC.

Given the changes in expression and distribution of c-Myc, we next examined whether somatic hypermutation and/or affinity maturation of GC B cells was altered at d14 post-infection (Extended Data Fig. $5 c-f)$. No clear differences were observed in mutation levels (Extended Data Fig. 5c). To examine affinity maturation in BMI-1-sufficient versus BMI-1-deficient GC B cells, the ratio of non-synonymous to synonymous mutations (N/S) (Extended Data Fig. 5d) and selection pressure (Extended Data Fig. 5e,f) was assessed. The ratio of N/S in the complementarity-determining regions (CDRs) was decreased in GC B cells isolated from $C d 23^{\mathrm{Cre} /+}$ mice responding to chronic infection, compared to acute infection, suggestive of reduced affinity maturation. In contrast, GC B cells isolated from LCMV-Docile-infected $\mathrm{Bmil}^{\mathrm{fff}} \mathrm{Cd} 23^{\mathrm{Cre} /+}$ mice had a N/S ratio comparable to that of $C d 23^{\mathrm{Cre} /+}$ mice infected with LCMV-WE (Extended Data Fig. 5d). We then quantified the link to selection pressure more precisely with BASELINe (Extended Data Fig. 5e,f). B cell receptor (BCR) sequences from either $C d 23^{\mathrm{Cre} /+}$ or $B m i 1^{\mathrm{f} / \mathrm{f}} \mathrm{Cd} 23^{\mathrm{Cre} /+}$ mice infected with LCMV-WE had more positive selection in the CDR region than those infected with LCMV-Docile; however, the trend toward positive selection returned in $\mathrm{Bmil}^{\mathrm{f} / \mathrm{f}} \mathrm{Cd}$ $23^{\mathrm{Cre} /+}$ mice responding to chronic infection, compared to $\mathrm{Cd} 23^{\mathrm{Cre} /+}$ mice, although it was not completely restored to that of acute infection. In contrast to the CDR, there was little change in the negative selection detected in the framework regions (Extended Data Fig. 5f). Taken together, affinity maturation seemed to be improved in $\mathrm{Bmil}^{\mathrm{f} /}$ ${ }^{\mathrm{f}} \mathrm{Cd} 23^{\mathrm{Cre} /+}$ mice during chronic infection.

The elevation in BMI-1 and c-Myc expression in chronic GC B cells prompted us to ask whether there was a particular pathogen-influenced microenvironmental change that may induce these differences in B cell transcriptional programs. A key candidate was IL-21, a cytokine that regulates B cell behavior ${ }^{52,53}$ and can induce context-specific Myc expression ${ }^{54}$. Notably, IL-21 production by helper $\mathrm{T}$ cells in chronic viral infection is substantially higher than in acute viral infection ${ }^{55}$. We therefore tested whether there was a dose-dependent induction of Bmil and $M y c$ in in vitro-stimulated $B$ cells, co-cultured with increasing concentrations of IL-21 (Fig. 4f-h). While B cells cultured with low IL-21 concentrations did not increase Bmil (Fig. 4f) or Myc (Fig. 4g) over the baseline stimuli (CD40L, IL-4 and IL-5), significant upregulation was evident at high IL-21 levels (Fig. 4f,g). The observed increase was not simply due to a change in plasmablast frequency within the cultures, as there was no significant change in plasmablast frequency between
25-50 $\mathrm{ng} \mathrm{ml}^{-1}$ IL-21 (Fig. 4h). Together, these data reveal that the disruption in $\mathrm{c}-\mathrm{Myc}$ regulation during chronic infection correlated with increased IL-21 and that conditional deletion of BMI-1 restores expression and localization of c-Myc-expression in GC B cells.

H2AK119Ub1 is decreased at key loci in chronic infection. The non-canonical form of PRC1 (which excludes BMI-1) and PRC2 are required for GC formation ${ }^{26}$. The ability of BMI-1-deficient B cells to form GCs and upregulation of BMI-1 in ASCs, suggest a switch between the non-canonical and the canonical forms of PRC1 to regulate B cell fate. This switch seemed to be disrupted in chronic GC B cells, with upregulation of Bmi1, Myc and ASC-related genes (Fig. 5a). Accordingly, c-Myc-target genes were significantly enriched in chronic GC B cells, compared to the acute gene expression profile (Fig. 5b,c), concomitant with identification of several c-Myc targets within DARs (Fig. 5c).

Given that the non-canonical PRC1 deposits H2AK119Ub1 at key loci in GC B cells, it was unclear how changes in BMI-1 expression affected PRC1 function, if at all. We first asked whether changes in $\mathrm{H} 2 \mathrm{AK} 119 \mathrm{Ub} 1$ and $\mathrm{H} 3 \mathrm{~K} 27 \mathrm{me} 3$, the histone marks regulated by PRC1 and PRC2, respectively, were altered at key loci in acute versus chronic GC B cells. There was a clear change in H2AK119Ub1 in control GC B cells between LCMV-WE- and LCMV-Docile-infected mice (Fig. 5d). B cells from LCMV-Docile mice had a significant decrease in H2AK119Ub1 at Myc and Prdm1 loci (Fig. 5d), whereas H2K27me3 was unchanged (Fig. 5e). B cell-specific BMI-1 deletion in chronically infected mice elevated H2AK119Ub1 at Myc and $\operatorname{Prdm} 1$ loci in unswitched B cells, with a less prominent increase at Irf4 in $\mathrm{IgD}^{-} \mathrm{B}$ cells. While there was a trend increase in $\mathrm{H} 3 \mathrm{~K} 27 \mathrm{me} 3$ in the absence of BMI-1, in most cases this change was not significant (Fig. 5e). Thus, conditional deletion of BMI-1 restored monoubiquitination at H2AK119 in chronic B cells to similar levels as control B cells responding to acute viral infection.

To determine whether the BMI-1-dependent change in H2AK119Ub1 regulated gene expression, we performed RNA-seq analysis of acute versus chronic GCB from $\mathrm{Cd} 23^{\mathrm{Cre} /+}$ or $\mathrm{Bmil}$ $C d 23^{\mathrm{Cre} /+}$ mice (Extended Data Fig. 6a). Using the DEGs identified in both Fig. 1 and Extended Data Fig. 6 datasets to explore whether BMI-1-deficiency restored chronic GC B cell gene expression to resemble that of acute GCB, we identified five distinct signatures (Fig. 5f). BMI-1 deletion partially restored gene profiles to that of control GCB responding to acute infection. Among these five clusters (C1-5), genes listed in $\mathrm{C} 1$ and $\mathrm{C} 4$ showed similar expression patterns between BMI-1-sufficient acute GC B cells and BMI1-deficient chronic GC B cells (magnified heat maps; Fig. 5f). Taken together, these results underscore the crucial role of BMI-1 in regulating gene expression in $\mathrm{B}$ cells responding to chronic infection.

BMI-1 regulates ASCs in response to NP-KLH immunization. The differences observed in BMI-1 expression and function in $B$ cells responding to acute versus chronic viral infection prompted us to investigate the specific role of BMI-1 during B cell differentiation

Fig. 4 | Regulation of c-Myc in BMI-1-deficient mice. a, Schematic of infection and tamoxifen administration of Bmi7CreERT2Rosa26 $6^{\text {EYFP }}$ reporter mice. $\mathbf{b}$, RTQPCR analyses of Myc expression in EYFP- and EYFP+ GC B cells from Bmi ${ }^{\text {CreeRT2 }}{ }^{2}$ Rosa26 $6^{\text {EYF }}$ reporter mice infected with LCMV-Docile (d7 after infection; $2^{-\Delta \Delta C \mathrm{t}}$ method relative to EYFP-; reference gene is Ku70). WE, $n=7 \mathrm{EYFP}^{-}$and $n=5 \mathrm{EYFP}^{+}$; Docile, $n=10 \mathrm{EYFP}^{-}$and $n=8 \mathrm{EYFP}^{+}$; combined from two (WE) and four (Docile) experiments. Data represent mean \pm s.e.m. ${ }^{\star \star} P=0.0016,{ }^{\star \star \star \star} P<0.0001$ (Mann-Whitney $U$-test, two-tailed $P$ value). c, Myc expression

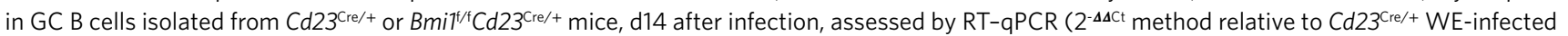
mice), $n=4$ mice per group. Data represent mean \pm s.e.m. ${ }^{\star} P=0.0286$ (Mann-Whitney U-test, two-tailed $P$ value). $\mathbf{d}$, Histological analysis of spleens from Cd23Cre/+ and Bmit ${ }^{1 / 4} C d 23^{C r e /+}$ at d7 after infection; IgD (cyan), CD3 (red), Myc (yellow), PNA (magenta). Scale bar, $100 \mu \mathrm{m}$. Orange arrows indicate c-Myc-expressing cells. e, Quantification of $\mathrm{Myc}^{+} \mathrm{PNA}^{+}$cells per IgD ${ }^{10}$ regions within a follicle; data are combined from ten individual regions from $n=4$ mice per group, combined from two independent experiments and represent mean \pm s.e.m. ${ }^{\star \star \star \star} P<0.0001$ (Mann-Whitney U-test, two-tailed $P$ value). $\mathbf{f}-\mathbf{h}$, B cells were stimulated in vitro with CD4OL, IL-4, IL-5 and with increasing concentrations of IL-21 as indicated and assessed for Bmil (f), Myc ( $(\mathbf{g})$ and plasmablast frequency $(\mathbf{h}) ; n=4-5$ mice per group, combined from two independent experiments. Data represent mean \pm s.e.m. $(\mathbf{f}-\mathbf{h})$. ${ }^{\star} P<0.05($ MannWhitney U-test, two-tailed $P$ value) 
in a tractable, non-infectious model. Thus, $\mathrm{Bmil}^{\mathrm{f} / \mathrm{f}} \mathrm{Cd} 23^{\mathrm{Cre} /+}$ and $C d 23^{\mathrm{Cre} /+}$ mice were immunized with $\mathrm{NP}-\mathrm{KLH}$ in alum and humoral responses were assessed. Histological analyses revealed the loss of splenic IgG1 ${ }^{\text {bright }}$ cells at $\mathrm{d} 7$ after immunization (Fig. 6a). Correspondingly, there was a significant decrease in the total frequency of BMI-1-deficient ASCs (Fig. 6b), antigen-specific IgG1+
ASCs (Fig. 6c) and antibody at d14 and d28 (Fig. 6d,e), although d7 IgG1 and IgM antibody levels were comparable between BMI1-deficient mice and controls (Extended Data Fig. 6b). As ASCs can arise from either GC-independent or GC-dependent pathways, we assessed whether the defect in ASCs was due to a loss of GC B cells. $\mathrm{Bmil}^{\mathrm{f} / \mathrm{f}} \mathrm{Cd} 23^{\mathrm{Cre} / \mathrm{+}} \mathrm{B}$ cells formed GCs, isotype switched and produced

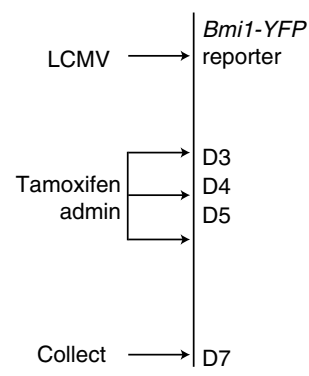

d

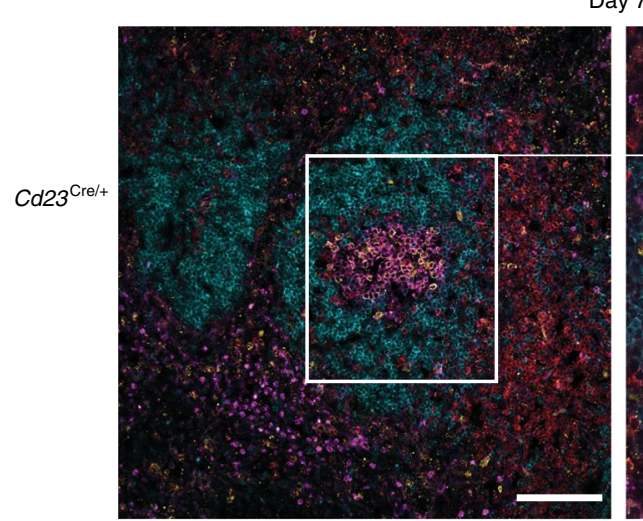

b

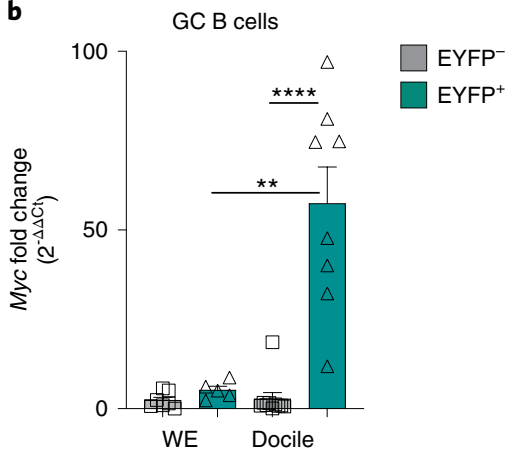

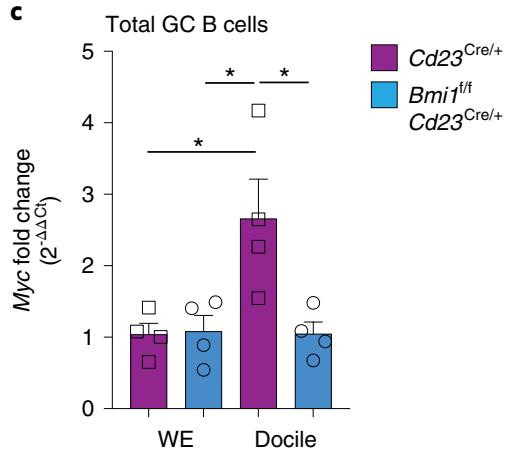

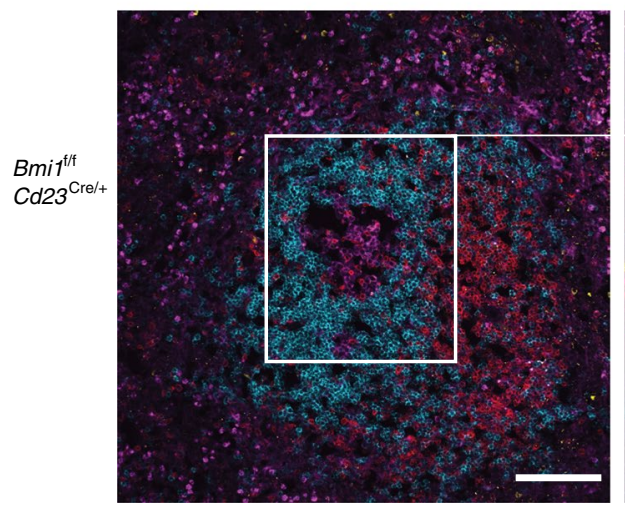

e

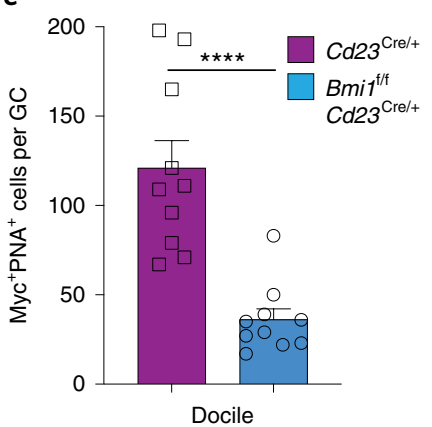

f

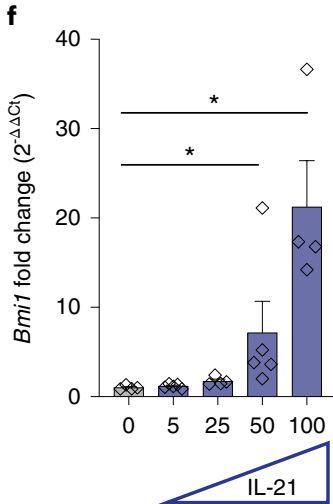

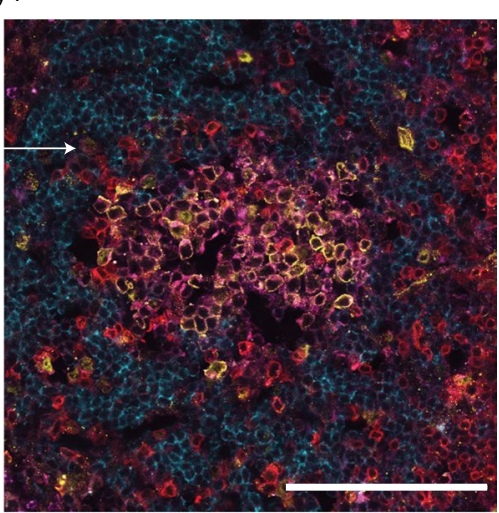

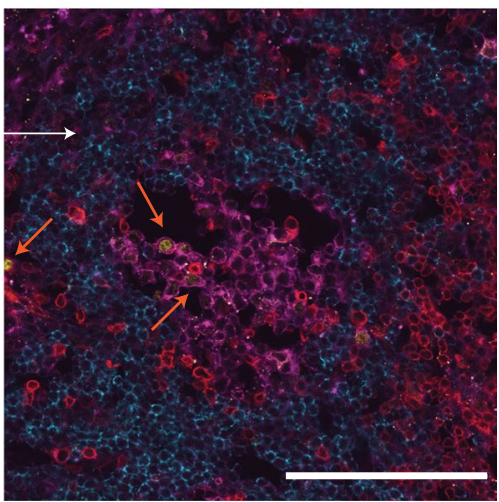

g

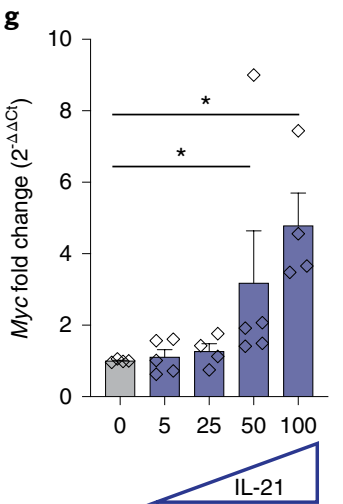

h

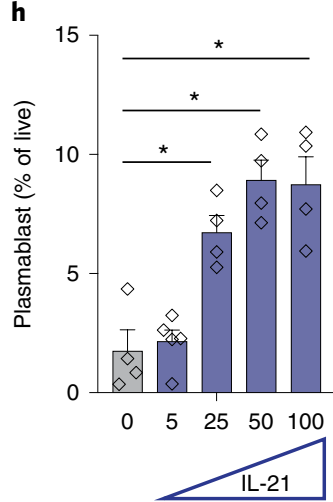


appropriate $\mathrm{DZ}$ and $\mathrm{LZ}$ ratios, in a manner comparable to $\mathrm{C} d 23^{\mathrm{Cre} /+}$ mice (Extended Data Fig. 6c-e). The ability of B cells to form GCs in $\mathrm{Bmil}^{\mathrm{f} / \mathrm{f}} \mathrm{Cd} 23^{\mathrm{Cre} /+}$ mice is consistent with a previous study demonstrating that $\mathrm{NP}^{+} \mathrm{IgD}^{\text {lo }} \mathrm{B}$ cell could expand after immunization in Bmil germline knockouts ${ }^{56}$. While only a small fraction of GC B cells was $\mathrm{EYFP}^{+}$after immunization, $M y c$ was $\sim$ sixfold upregulated in $\mathrm{EYFP}^{+}$compared to EYFP- GC B cells (Extended Data Fig. 6f). To assess whether modulating BMI-1 expression affected affinity maturation, Vh186.2 in GC B cells was sequenced (Fig. 6f,g and Extended Data Fig. 6g). The overall number of mutations (Fig. 6f) and CDR3 length (Extended Data Fig. 6g) was comparable between $B m i 1^{\mathrm{f} / \mathrm{f}} \mathrm{Cd} 23^{\mathrm{Cre} /+}$ and $\mathrm{Cd} 23^{\mathrm{Cre} /+}$ mice; however, there was an increase in mutations in CDR1 $(P=0.0594)$ and a significant decrease in mutations in CDR3 $(P=0.0448)$ in the absence of BMI-1 (Fig. 6f). Next, the affinity-enhancing replacement of the codon encoding for amino acid tryptophan by that encoding leucine at position 33 (W33L) of Vh186.2 was measured. The percentage of the W33L mutation was increased in GCB from $B m i 1^{\mathrm{f} / \mathrm{f}} \mathrm{Cd} 23^{\mathrm{Cre} /+}$ compared to $C d 23^{\mathrm{Cre} /+}$ mice ( $71 \%$ compared to $55 \%$, respectively) (Fig. $6 \mathrm{~g}$ ). Therefore, while GC B cells could form in $B m i 1^{\mathrm{f} / \mathrm{f}} \mathrm{Cd} 23^{\mathrm{Cre} /+}$ mice, B cell-specific BMI-1 deletion led to an increase of high-affinity variants within GC B cells, but a decrease in ASC output.

The data presented thus far suggested that BMI-1 was important for GC to ASC differentiation. We next asked whether BMI-1 directly regulated ASC survival independent of its role in differentiation. To specifically determine whether steady-state ASCs relied on BMI-1 for their survival, we generated $\mathrm{Bmil}^{\mathrm{f} / \mathrm{f}} \mathrm{Prdm} 1^{\text {Rosa26CreERT2 }}$ mice in which BMI-1 is inducibly deleted in Prdm1 (the gene encoding Blimp-1)-expressing cells. Uninfected $\mathrm{Bmil}^{\mathrm{f} / \mathrm{f}} \mathrm{Prdm} 1^{\text {Rosa26CreERT2 }}$ and control mice were administered with tamoxifen and ASCs were assessed 7 and $14 \mathrm{~d}$ later (Fig. 6h). Tamoxifen administration significantly reduced the frequency of ASCs at d14, and ASC number at both time points (Fig. 6i), but not GC B cells (Extended Data Fig. $6 \mathrm{~h}-\mathrm{j}$ ) demonstrating that BMI-1 is an important regulator of ASC survival.

Small molecule inhibition of BMI-1 depletes ASCs. Targeting detrimental antibodies and ICs is a therapeutic goal for chronic infectious and inflammatory disorders. Given that BMI-1 regulated ASC survival, we assessed small molecule inhibition of BMI-1 to modulate ASC and IC formation. First, naive B cells were stimulated in vitro to induce plasmablast differentiation, which was significantly reduced by PTC-209 (ref. ${ }^{57}$ ) in a dose-dependent fashion (Fig. 7a and Extended Data Fig. 7a). While plasmablasts were reduced, the ability of $\mathrm{B}$ cells to undergo division was unaffected across doses (Extended Data Fig. 7b), with the exception of $1.25 \mu \mathrm{M}$ (not shown). Next, C57BL/6 mice were infected with LCMV-Docile and after $2 \mathrm{~d}$ to allow initial activation of the immune response, were given daily administrations of PTC-028, an inhibitor that targets and degrades BMI-1 through hyperphosphorylation ${ }^{58}$ (Fig. 7b). LCMV-Docile-infected mice that received the vehicle control lost weight before stabilization at $85 \%$ of the original body weight at $\mathrm{d} 8$ after infection (Fig. $7 \mathrm{c}$ ). In contrast, LCMV-Docile-infected mice administered with PTC- 028 lost $<5 \%$ body weight up to $\mathrm{d} 3$ after infection, but then recovered by d5 (Fig. 7c). Similar to Bmil $1^{\mathrm{f} /}$ ${ }^{\mathrm{f}} \mathrm{C} d 23^{\mathrm{Cre} /+}$ mice, ASC frequency and number were significantly reduced after PTC-028 treatment, compared to controls (3.3-fold and 1.8-fold, respectively; Fig. 7d). Concomitantly, total (Fig. 7e) and LCMV-specific IgG2c IC (Fig. 7f) were significantly decreased in the PTC-028 group compared to vehicle controls. While liver viral titers were not significantly reduced with this dosage regimen (not shown), splenic architecture was restored in mice administered PTC-028, similar to that observed in $B m i 1^{1 / /} \mathrm{Cd} 23^{\mathrm{Cr} /+}$ mice (Extended Data Fig. 7c). Collectively, these data reveal BMI-1 as a viable therapeutic target to deplete ASCs and reduce IC formation in immune disorders.

\section{Discussion}

Antibodies are a key modulator of both innate and adaptive arms of an immune response. However, in chronic infections, the quality and quantity of antibodies are dysregulated and antibodies can themselves become pathogenic. Defining the mechanistic steps that shift humoral responses from effective to ineffective when viral infections persist has been elusive. Here, we identify BMI-1 as a critical regulator of $\mathrm{B}$ cell differentiation, which can be targeted therapeutically. Deletion of BMI-1 in B cells led to pleiotropic effects on the immune response: accelerated viral clearance, reduced splenomegaly coupled with improved lymphoid architecture, increased neutralizing capability and effector function of antibody. Expression of $M y c$, the transcription factor that is required for $\mathrm{B}$ cell selection in the $\mathrm{GC}^{3,4}$, was concentrated in Bmil-expressing cells and regulated by BMI-1 in chronic viral infection. Further, the preservation of lymphoid architecture, reduction in excessive IC or changes to the $N$-glycan profile of antibody within ICs may work collectively to support affinity maturation in the $\mathrm{GC}^{11,59,60}$. These results highlight the critical direct and indirect roles of B cells controlling effective versus ineffective immune responses to persistent viral infection.

c-Myc is expressed in proliferating cells but is known to be tightly regulated in cells undergoing selection in the $\mathrm{LZ}^{3,4}$. Similarly, in acute infection BMI-1 was expressed in only a small fraction of GC B cells but upregulated upon ASC differentiation. Chronic viral infection deregulated expression of both BMI-1 and c-Myc, concomitant with an increase in GC B cells and ASCs. Increased c-Myc may result in the disruption of GC B cell division and selection, skewing cells toward premature differentiation ${ }^{5}$. BMI-1 and c-Myc cooperate in lymphoid transformation ${ }^{37,38}$ and can directly and indirectly regulate each other in a context-dependent manner ${ }^{61-63}$. Although a number of pathogen-influenced changes in the microenvironment have been recorded in chronic infection ${ }^{41,64,65}$, we reasoned that cytokine differences within the GC may mediate sustained induction of BMI-1 and c-Myc. One key cytokine that is notably increased in chronic LCMV infection, compared to acute, is IL-21 (ref. ${ }^{55}$ ). Accordingly, high concentrations of IL-21, but not low levels, induced BMI-1 and c-Myc in stimulated B cells. Persisting GCs have been proposed to be beneficial in inducing broadly neutralizing antibodies ${ }^{66}$. However, we highlight the importance of appropriate regulation of this process under sustained inflammatory

Fig. 5 | H2AK119Ub1 is decreased at key loci in B cells responding to chronic viral infection. a, Heat map of selected genes in GC B cells isolated from WT mice infected with either LCMV-WE or LCMV-Docile, assessed by RNA sequencing. b, Gene set enrichment analysis (GSEA) (canonical pathway Hallmark gene set) plot of Myc targets using the RNA-seq dataset shown in Fig. 1. c, Accessibility changes in Myc targets within DARs (ATAC-seq dataset shown in Fig. 1; top) and Myc targets within the DEG dataset (RNA-seq dataset shown in Fig. 1; bottom). ${ }^{\star \star \star} P<0.0001$ (Wilcoxon matched-pairs signed-rank test, two-tailed $P$ value). d,e, Chromatin immunoprecipitation (ChIP)-qPCR analyses of H2AK119Ub1 (d) or H3K27me3 (e) in CD19+IgD- (Sw B cells) and

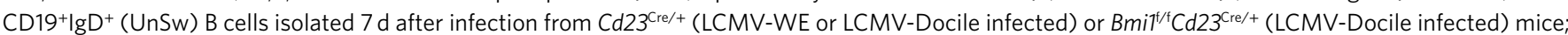
$n=3$. Data represent mean \pm s.e.m. ${ }^{\star} P<0.05,{ }^{\star \star} P<0.01$ (Unpaired Student's $t$-test, two-tailed $P$ value). f, RNA-seq analysis of GC B cells isolated $14 d$ after

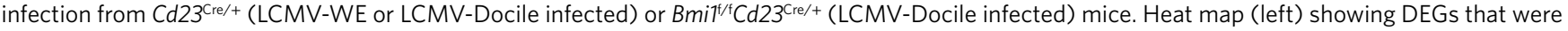
detected in both (Figs. 1 and 5) RNA-seq datasets (FDR <0.05, logFC > 0.58). Heat maps of clusters C1, C3 and C4 (right). Red denotes genes that were also identified in the ATAC-seq DARs dataset in Fig. 1. 
pressure. In particular, BMI-1 plays an essential role in dictating whether B cells recruited into a response against infection will contribute to a successful humoral response.
The specific role of BMI-1 in ASCs reveals the importance in the composition of the heterogeneous PRC1 during B cell differentiation, changing from non-canonical ${ }^{26}$ to canonical components a

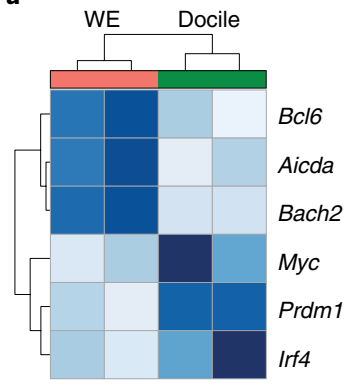

$\begin{array}{lllll}-1.0 & -0.5 & 0 & 0.5 & 1.0\end{array}$ b

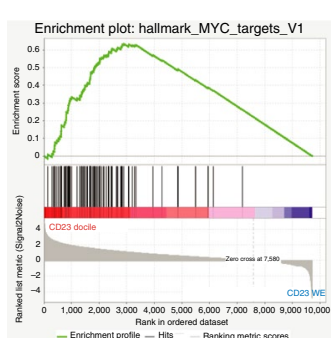

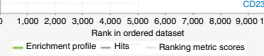
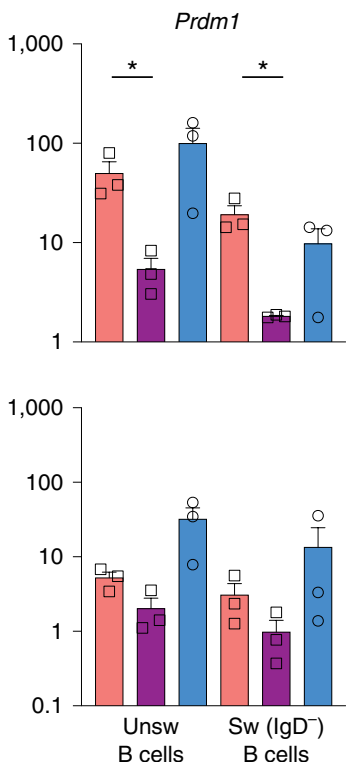

Myc targets

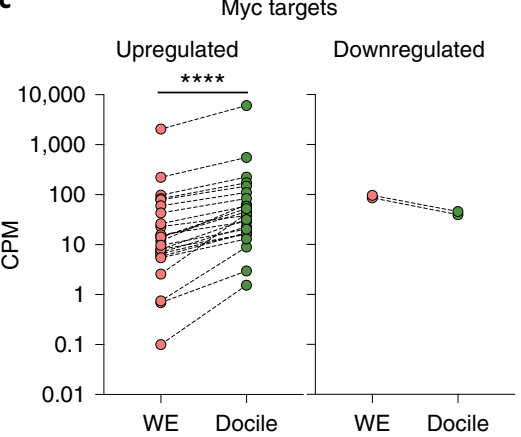

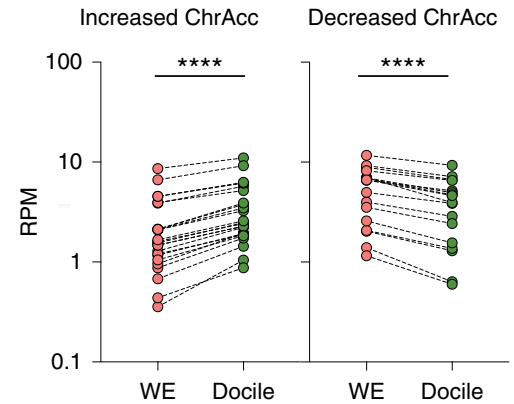

d
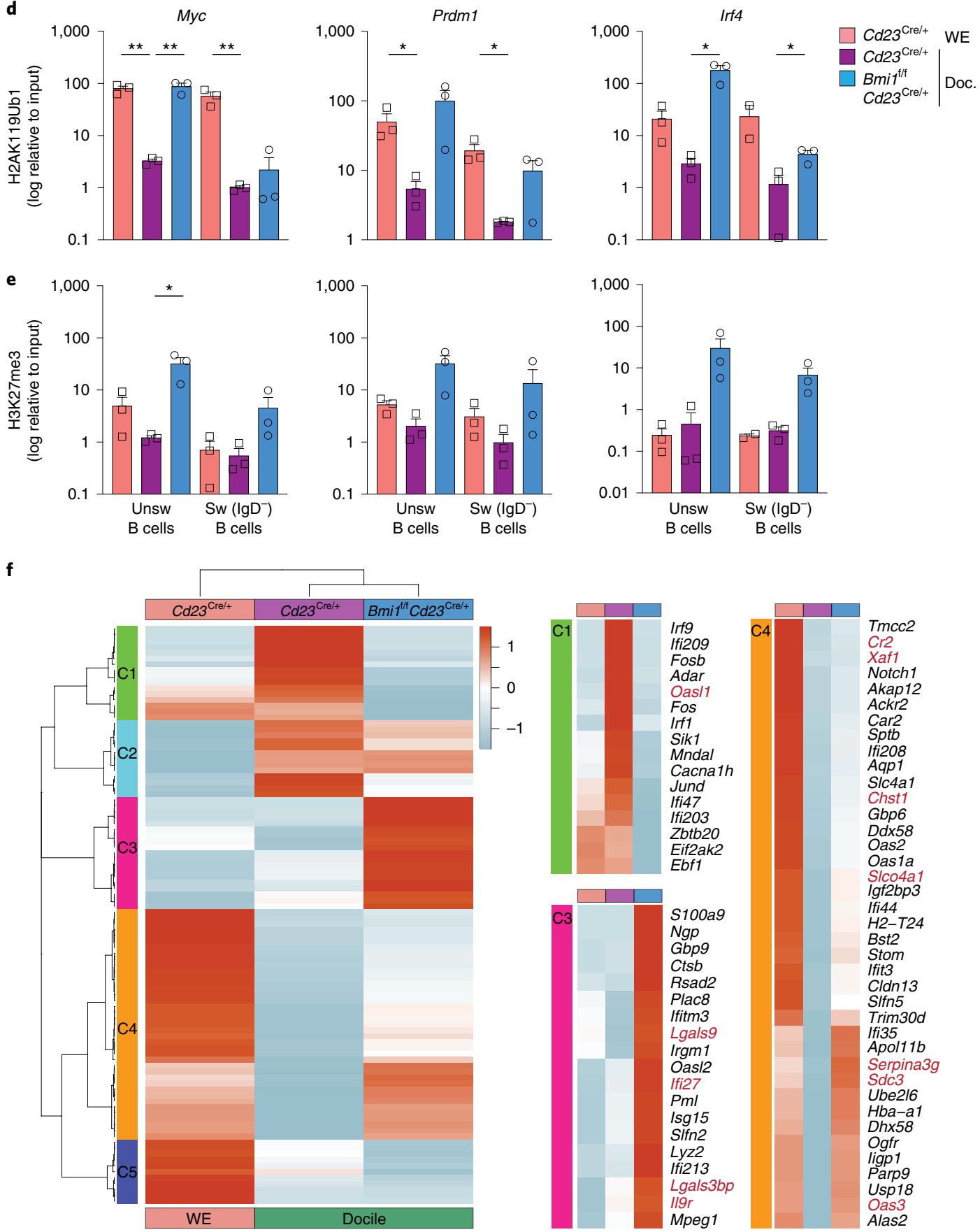

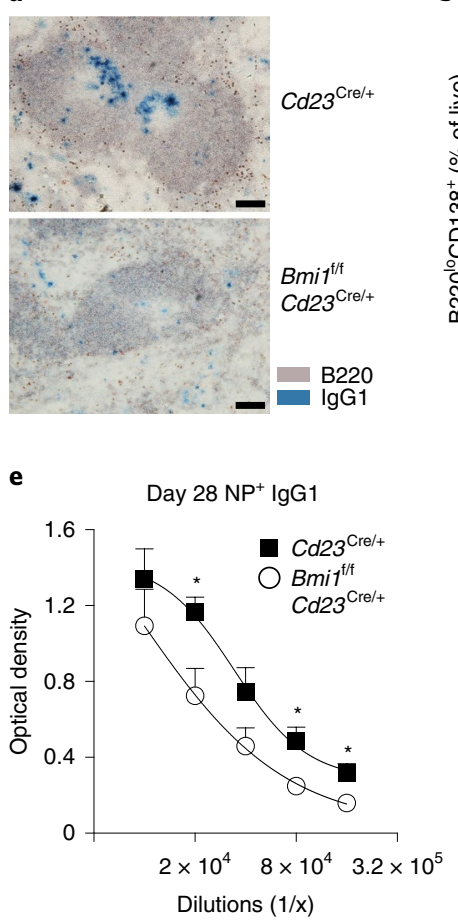

b

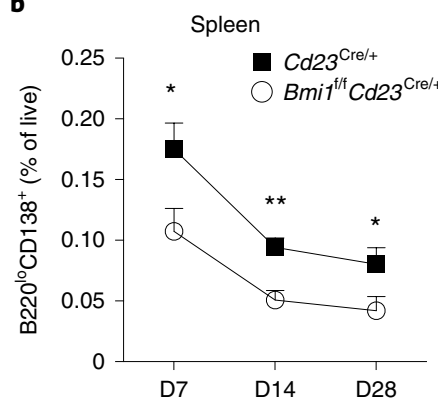

c

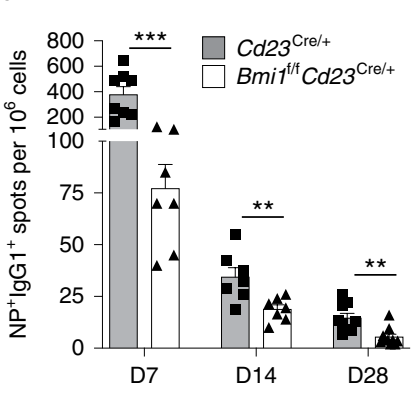

d

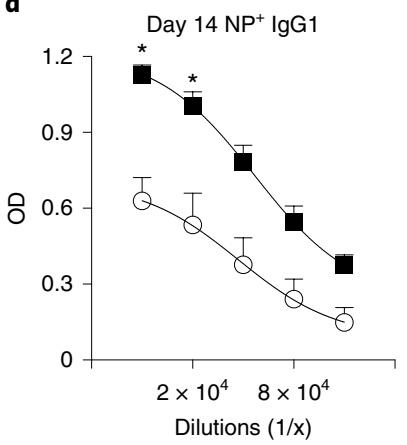

$\mathbf{f}$

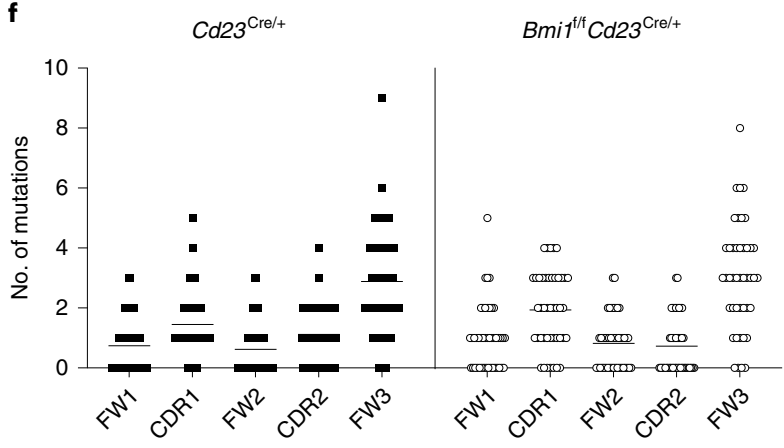

g $\quad V_{h} 186.2$ pos.33 (GC B cells)

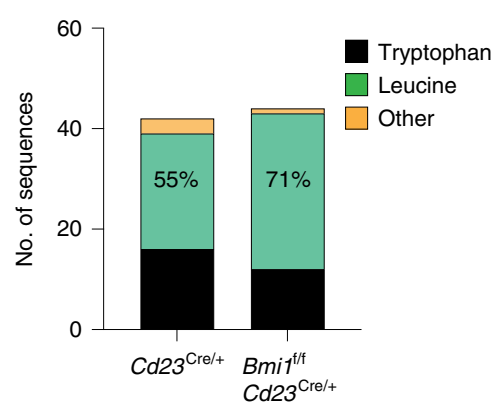

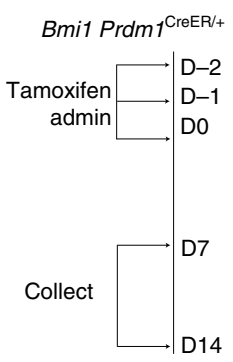

i

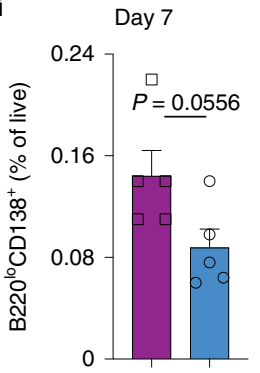

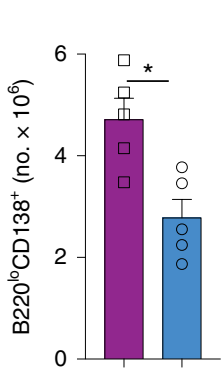

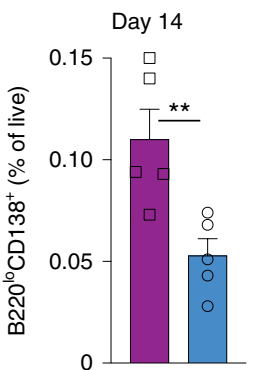

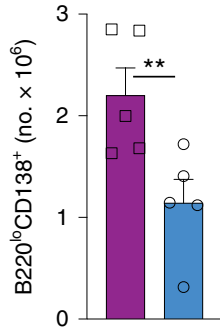

Prdm $1^{\mathrm{CreER} /+}$

$\mathrm{Bmit}^{\mathrm{f} / \mathrm{f}}$

Prdm 1 CreER/+

Fig. 6 | BMI-1 regulates plasma cell survival. a, $\mathrm{Cd} 23^{\mathrm{Cre} /+}$ and $\mathrm{Bmi} \mathrm{T}^{\mathrm{t} / \mathrm{f}} \mathrm{Cd} 23^{\mathrm{Cre} /+}$ mice were immunized with $\mathrm{NP}-\mathrm{KLH}$ in alum. Histological analyses of spleens at $7 \mathrm{~d}$ after immunization, stained with B220 (red) and IgG1 (blue), representative of two individual experiments. Scale bar, $100 \mu \mathrm{m}$. b, Cd23Cre/+ and $B \mathrm{mi}^{\mathrm{f} / \mathrm{f}} \mathrm{Cd} 23^{\mathrm{Cre} /+}$ mice were immunized with NP-KLH in alum and the frequency of $\mathrm{B} 22 \mathrm{O}^{\mathrm{lo}} \mathrm{CD} 138^{\text {hi }}$ cells was assessed by flow cytometry; $\mathrm{d} 7, n=8 \mathrm{Cd} 23^{\mathrm{Cre} /+}$ and $n=7 \mathrm{Bmil}^{\mathrm{t} / \mathrm{f}} \mathrm{Cd} 23^{\mathrm{Cre} /+}$ mice; d14, $n=5$ mice per group; $\mathrm{d} 28, n=9 \mathrm{Cd} 23^{\mathrm{Cre} /+}$ and $n=10 \mathrm{Bmi} 7^{\mathrm{t} / \mathrm{f}} \mathrm{Cd} 23^{\mathrm{Cre} /+}$ mice; combined from 2-3 individual experiments per time point. Data represent mean \pm s.e.m. $d 7,{ }^{\star} P=0.0427 ; \mathrm{d} 14,{ }^{\star}{ }^{\star} P=0.0079 ; \mathrm{d} 28,{ }^{\star} P=0.0211$ (Mann-Whitney $U$-test, two-tailed $P$ value). c, ELISpot analyses of $\mathrm{NP}^{+} \operatorname{lgG} 1^{+} \mathrm{ASCs}$ at indicated time points after immunization; $\mathrm{d} 7, n=8 \mathrm{Cd} 23^{\mathrm{Cre} /+}$ and $n=7 \mathrm{Bmit//f} C d 23^{\mathrm{Cre} /+}$ mice; $\mathrm{d} 14, n=7$ mice per group; $\mathrm{d} 28$,

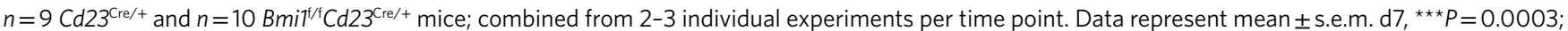
$\mathrm{d} 14,{ }^{\star \star} P=0.0076 ; \mathrm{d} 28,{ }^{\star \star} P=0.0020$ (Mann-Whitney $U$-test, two-tailed $P$ value). $\mathbf{d}, \mathbf{e}, \mathrm{NP}^{+}$IgG1 ${ }^{+}$serum antibody at d14 (d) and d28 (e) after immunization; $\mathrm{d} 14, n=3 \mathrm{Cd} 23^{\mathrm{Cre} /+}$ and $n=4 \mathrm{Bmi} 7^{\mathrm{t} / \mathrm{C}} \mathrm{Cd} 23^{\mathrm{Cre} /+}$ mice; $\mathrm{d} 28, n=4$ mice per group; representative of two individual experiments per time point. Data represent mean \pm s.e.m. ${ }^{\star} P<0.05$ (Mann-Whitney $U$-test, two-tailed $P$ value). f, Single NP+IgG1+CD95 ${ }^{\text {hi }} \mathrm{CD} 38^{\text {lo }} \mathrm{CD} 138^{-}$GC B cells were sort-purified from Cd23Cre/+ and $B m i 7^{f / f} \mathrm{Cd} 23^{\mathrm{Cre} /+}$ mice immunized with NP-KLH in alum (three mice pooled per group) at d21 after immunization. The Vh186.2 gene was sequenced; shown is the number of mutations per sequence across CDR and FW regions. $\mathbf{g}$, Trp-to-Leu mutations at position 33 of Vh186.2 in GC B cells sort-purified

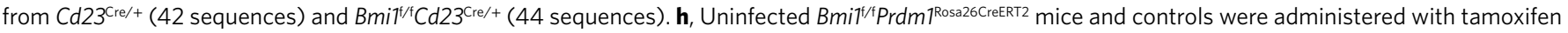
and assessed for ASC frequency. i, Frequency of ASCs assessed by flow cytometric analyses at d7 and d14 after tamoxifen analyses; $n=5$ mice per group, combined from two individual experiments per time point. Data represent mean \pm s.e.m. ${ }^{\star} P<0.05,{ }^{\star \star} P<0.01$ (Mann-Whitney $U$-test, two-tailed $P$ value).

during an immune response to regulate GC and ASC biology, respectively. Here, H2AK119Ub1 was decreased at key loci in GC B cells in chronic infection, compared to acute, suggesting a deregulation in PRC function. BMI-1 deletion increased H2AK119Ub1, in a seemingly paradoxical manner as BMI-1 is known to support the ubiquitin ligase activity of RING1B ${ }^{29}$. This suggests that the aberrant recruitment of BMI-1 into the PRC1 in chronic GCs disrupts the non-canonical function of the PRC1, concomitant with downregulation of BCOR, a regulator of GC biology ${ }^{26}$. It also suggests that this dynamic process is regulated by microenvironmental signals within the GC. Understanding the relationship between cytokine signaling and resultant biochemical changes in the composition of the PRCs may implicate other chronic inflammatory mediators that lead to detrimental B cell differentiation.

Small molecule inhibitors of epigenetic regulators are rapidly emerging as important therapeutic tools and as such are in clinical trials for a number of disorders ${ }^{67,68}$. Excessive IC deposition induces substantial tissue damage in chronic infections and other antibody-mediated diseases in which depleting pre-existing ASCs is a therapeutic goal ${ }^{69,70}$. We propose that BMI-1 could be targeted with a small molecule inhibitor to deplete pre-existing detrimental plasma cells. This strategy may also be used to tackle pathogenic 


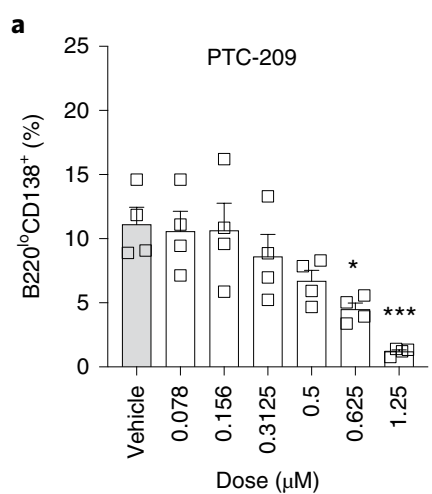

b

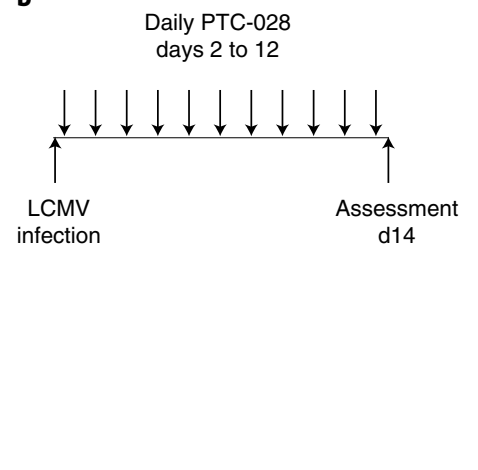

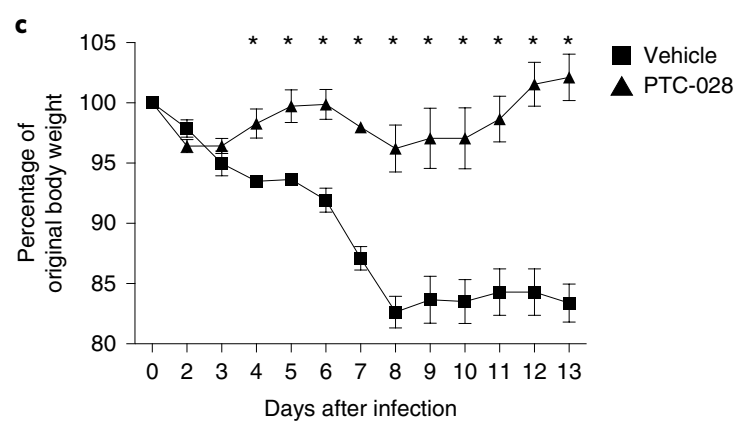

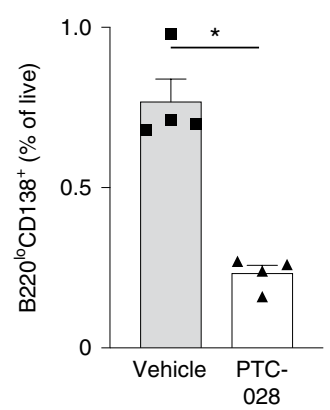

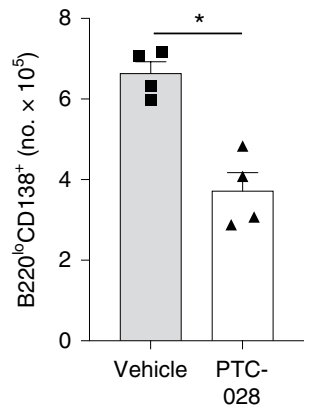

028

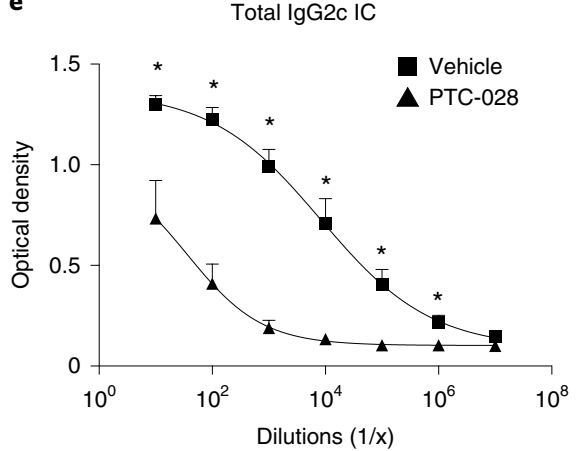

LCMV-specific IgG2c IC

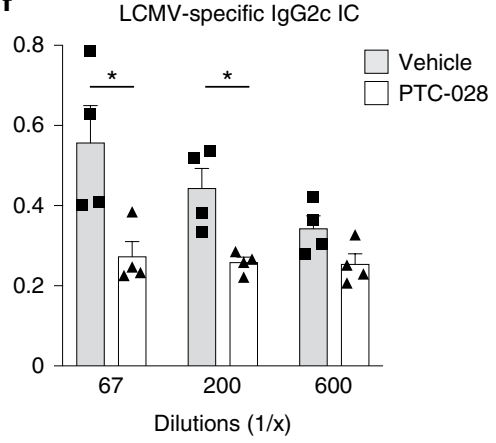

Fig. 7 | BMI-1 can be targeted to deplete plasma cells in vitro and in vivo. a, B cells were stimulated in vitro with LPS and IL-4 and in the presence or PTC209 or dimethylsulfoxide (DMSO) at the indicated concentrations. B220 ${ }^{10} \mathrm{CD} 138^{\text {hi }} \mathrm{ASC}$ s were assessed after $4 \mathrm{~d}$ by flow cytometry. Data are representative of three individual experiments; ${ }^{\star} P=0.0117,{ }^{\star \star \star} P=0.0002$ compared to DMSO control (one-way analysis of variance). b, Schematic of PTC-028 administration in vivo. c, $\mathrm{Cd} 23^{\mathrm{Cre} /+}$ and $\mathrm{Bmi} \mathrm{i}^{1 / \mathrm{f}} \mathrm{Cd} 23^{\mathrm{Cre} /+}$ mice were infected with $\mathrm{LCMV}$-Docile and administered with PTC-028 or vehicle control. c, mouse weights assessed at the indicated time points after infection. $\mathbf{d}$, Frequency and number of ASCs assessed by flow cytometry. $\mathbf{e}$, Assessment of total lgG2 $\mathrm{C}^{+}$ $I C s$. $f$, Assessment of $L C M V$-specific $\operatorname{lgG} 2 \mathrm{c}^{+} I \mathrm{IC} ; n=4$ mice per group, data are representative of two individual experiments and represent mean \pm s.e.m. (c-f); ${ }^{\star} P<0.05$ (Mann-Whitney U-test, two-tailed $P$ value).

antibody-dependent enhancement, in which antibody produced from initial viral exposure leads to multi-organ damage upon re-exposure. In identifying BMI-1 as a critical determinant of productive antibody responses to chronic viral infection, this study has important therapeutic implications for immune disorders in which pathogenic antibodies play a role in morbidity.

\section{Online content}

Any methods, additional references, Nature Research reporting summaries, source data, extended data, supplementary information, acknowledgements, peer review information; details of author contributions and competing interests; and statements of data and code availability are available at https://doi.org/10.1038/ s41590-021-01077-y.

Received: 20 January 2021; Accepted: 20 October 2021;

Published online: 29 November 2021

\section{References}

1. Zohar, T. et al. Compromised humoral functional evolution tracks with SARS-CoV-2 mortality. Cell 183, 1508-1519 (2020).

2. Woodruff, M. C. et al. Extrafollicular B cell responses correlate with neutralizing antibodies and morbidity in COVID-19. Nat. Immunol. 21, 1506-1516 (2020).

3. Dominguez-Sola, D. et al. The proto-oncogene MYC is required for selection in the germinal center and cyclic reentry. Nat. Immunol. 13, 1083-1091 (2012).

4. Calado, D. P. et al. The cell-cycle regulator c-Myc is essential for the formation and maintenance of germinal centers. Nat. Immunol. 13, 1092-1100 (2012).
5. Finkin, S., Hartweger, H., Oliveira, T. Y., Kara, E. E. \& Nussenzweig, M. C. Protein amounts of the MYC transcription factor determine germinal center B cell division capacity. Immunity 51, 324-336 (2019).

6. Hunziker, L. et al. Hypergammaglobulinemia and autoantibody induction mechanisms in viral infections. Nat. Immunol. 4, 343-349 (2003).

7. Recher, M. et al. Deliberate removal of $\mathrm{T}$ cell help improves virus-neutralizing antibody production. Nat. Immunol. 5, 934-942 (2004).

8. Lane, H. C. et al. Abnormalities of B cell activation and immunoregulation in patients with the acquired immunodeficiency syndrome. N. Engl. J. Med. 309, 453-458 (1983).

9. Cooper, L. \& Good-Jacobson, K. L. Dysregulation of humoral immunity in chronic infection. Immunol. Cell Biol. 98, 456-466 (2020).

10. Wieland, A. et al. Antibody effector functions mediated by Fc $\gamma$-receptors are compromised during persistent viral infection. Immunity 42, 367-378 (2015).

11. Yamada, D. H. et al. Suppression of Fc $\gamma$-receptor-mediated antibody effector function during persistent viral infection. Immunity 42, 379-390 (2015).

12. Appel, G. B. Immune-complex glomerulonephritis-deposits plus interest. $N$. Engl. J. Med. 328, 505-506 (1993).

13. Oldstone, M. B. \& Dixon, F. J. Pathogenesis of chronic disease associated with persistent lymphocytic choriomeningitis viral infection. II. Relationship of the anti-lymphocytic choriomeningitis immune response to tissue injury in chronic lymphocytic choriomeningitis disease. J. Exp. Med. 131, 1-19 (1970).

14. Lu, L. L., Suscovich, T. J., Fortune, S. M. \& Alter, G. Beyond binding: antibody effector functions in infectious diseases. Nat. Rev. Immunol. 18, 46-61 (2018).

15. Straub, T. et al. Nucleoprotein-specific nonneutralizing antibodies speed up LCMV elimination independently of complement and FcyR. Eur. J. Immunol. 43, 2338-2348 (2013).

16. Chung, A. W. et al. Dissecting polyclonal vaccine-induced humoral immunity against HIV using systems serology. Cell 163, 988-998 (2015).

17. Wang, T. T. et al. Anti-HA glycoforms drive B cell affinity selection and determine influenza vaccine efficacy. Cell 162, 160-169 (2015). 
18. Caskey, M., Klein, F. \& Nussenzweig, M. C. Broadly neutralizing anti-HIV-1 monoclonal antibodies in the clinic. Nat. Med. 25, 547-553 (2019).

19. Zhang, Y. \& Good-Jacobson, K. L. Epigenetic regulation of B cell fate and function during an immune response. Immunol. Rev. 288, 75-84 (2019)

20. Kealy, L. et al. The histone methyltransferase DOT1L is essential for humoral immune responses. Cell Rep. 33, 108504 (2020).

21. Sen, D. R. et al. The epigenetic landscape of T cell exhaustion. Science 354, 1165-1169 (2016)

22. Pauken, K. E. et al. Epigenetic stability of exhausted T cells limits durability of reinvigoration by PD-1 blockade. Science 354, 1160-1165 (2016)

23. Beguelin, W. et al. EZH2 is required for germinal center formation and somatic EZH2 mutations promote lymphoid transformation. Cancer Cell 23, 677-692 (2013)

24. Caganova, M. et al. Germinal center dysregulation by histone methyltransferase EZH2 promotes lymphomagenesis. J. Clin. Invest. 123, 5009-5022 (2013).

25. Tanaka, S. et al. Tet 2 and Tet 3 in B cells are required to repress CD 86 and prevent autoimmunity. Nat. Immunol. 21, 950-961 (2020).

26. Beguelin, W. et al. EZH2 and BCL6 cooperate to assemble CBX8-BCOR complex to repress bivalent promoters, mediate germinal center formation and lymphomagenesis. Cancer Cell 30, 197-213 (2016).

27. Raaphorst, F. M. et al. Cutting edge: Polycomb gene expression patterns reflect distinct B cell differentiation stages in human germinal centers. $J$. Immunol. 164, 1-4 (2000).

28. Tarte, K., Zhan, F., De Vos, J., Klein, B. \& Shaughnessy, J. Jr. Gene expression profiling of plasma cells and plasmablasts: toward a better understanding of the late stages of B cell differentiation. Blood 102, 592-600 (2003).

29. Cao, R., Tsukada, Y. \& Zhang, Y. Role of Bmi-1 and Ring1A in H2A ubiquitylation and Hox gene silencing. Mol. Cell 20, 845-854 (2005).

30. Wang, H. et al. Role of histone H2A ubiquitination in Polycomb silencing. Nature 431, 873-878 (2004).

31. Jacobs, J. J., Kieboom, K., Marino, S., DePinho, R. A. \& van Lohuizen, $\mathrm{M}$. The oncogene and Polycomb-group gene BMI-1 regulates cell proliferation and senescence through the ink4a locus. Nature $\mathbf{3 9 7}$, 164-168 (1999).

32. Cantor, D. J. et al. Impaired expression of rearranged immunoglobulin genes and premature p53 activation block B cell development in BMI1 null mice. Cell Rep. 26, 108-118 (2019).

33. Yamashita, M. et al. Bmil regulates memory CD4 T cell survival via repression of the Noxa gene. J. Exp. Med. 205, 1109-1120 (2008).

34. Jagani, Z. et al. The Polycomb group protein BMI-1 is essential for the growth of multiple myeloma cells. Cancer Res. 70, 5528-5538 (2010).

35. Lessard, J. \& Sauvageau, G. Bmi-1 determines the proliferative capacity of normal and leukaemic stem cells. Nature 423, 255-260 (2003)

36. Oguro, H. et al. Poised lineage specification in multipotential hematopoietic stem and progenitor cells by the Polycomb protein Bmil. Cell Stem Cell 6, 279-286 (2010).

37. Haupt, Y., Alexander, W. S., Barri, G., Klinken, S. P. \& Adams, J. M. Novel zinc finger gene implicated as myc collaborator by retrovirally accelerated lymphomagenesis in E mu-myc transgenic mice. Cell 65, 753-763 (1991).

38. van Lohuizen, $\mathrm{M}$. et al. Identification of cooperating oncogenes in $\mathrm{E}$ mu-myc transgenic mice by provirus tagging. Cell 65, 737-752 (1991).

39. Dierks, C. et al. Essential role of stromally induced hedgehog signaling in B cell malignancies. Nat. Med. 13, 944-951 (2007).

40. De Vos, J. et al. Comparison of gene expression profiling between malignant and normal plasma cells with oligonucleotide arrays. Oncogene 21, 6848-6857 (2002).

41. Teijaro, J. R. et al. Persistent LCMV infection is controlled by blockade of type I interferon signaling. Science 340, 207-211 (2013).

42. Louten, J., van Rooijen, N. \& Biron, C. A. Type 1 IFN deficiency in the absence of normal splenic architecture during lymphocytic choriomeningitis virus infection. J. Immunol. 177, 3266-3272 (2006)

43. Odermatt, B., Eppler, M., Leist, T. P., Hengartner, H. \& Zinkernagel, R. M. Virus-triggered acquired immunodeficiency by cytotoxic T cell-dependent destruction of antigen-presenting cells and lymph follicle structure. Proc. Natl Acad. Sci. USA 88, 8252-8256 (1991).

44. Bergthaler, A. et al. Impaired antibody response causes persistence of prototypic T cell-contained virus. PLoS Biol. 7, e1000080 (2009)

45. Mahan, A. E. et al. Antigen-specific antibody glycosylation is regulated via vaccination. PLoS Pathog. 12, e1005456 (2016).
46. Francica, J. R. et al. Innate transcriptional effects by adjuvants on the magnitude, quality, and durability of HIV envelope responses in NHPs. Blood Adv. 1, 2329-2342 (2017).

47. Hessell, A. J. et al. Fc receptor but not complement binding is important in antibody protection against HIV. Nature 449, 101-104 (2007).

48. Nimmerjahn, F. \& Ravetch, J. V. Divergent immunoglobulin g subclass activity through selective Fc receptor binding. Science 310, 1510-1512 (2005)

49. Shinkawa, T. et al. The absence of fucose but not the presence of galactose or bisecting $\mathrm{N}$-acetylglucosamine of human IgG1 complex-type oligosaccharides shows the critical role of enhancing antibody-dependent cellular cytotoxicity. J. Biol. Chem. 278, 3466-3473 (2003).

50. Wieland, A. et al. Enhancing Fc $\gamma$ R-mediated antibody effector function during persistent viral infection. Sci. Immunol. https://doi.org/10.1126/ sciimmunol.aao3125 (2018).

51. Kao, D. et al. IgG subclass and vaccination stimulus determine changes in antigen specific antibody glycosylation in mice. Eur. J. Immunol. 47 2070-2079 (2017).

52. Zotos, D. et al. IL-21 regulates germinal center B cell differentiation and proliferation through a B cell-intrinsic mechanism. J. Exp. Med. 207, 365-378 (2010).

53. Good, K. L., Bryant, V. L. \& Tangye, S. G. Kinetics of human B cell behavior and amplification of proliferative responses following stimulation with IL-21. J. Immunol. 177, 5236-5247 (2006).

54. Sarosiek, K. A. et al. Novel IL-21 signaling pathway up-regulates c-Myc and induces apoptosis of diffuse large B-cell lymphomas. Blood 115, 570-580 (2010).

55. Elsaesser, H., Sauer, K. \& Brooks, D. G. IL-21 is required to control chronic viral infection. Science 324, 1569-1572 (2009).

56. Bhattacharya, D. et al. Transcriptional profiling of antigen-dependent murine B cell differentiation and memory formation. J. Immunol. 179, 6808-6819 (2007)

57. Kong, Y. et al. Targeting of BMI-1 with PTC-209 inhibits glioblastoma development. Cell Cycle 17, 1199-1211 (2018).

58. Dey, A. et al. Evaluating the mechanism and therapeutic potential of PTC-028, a novel inhibitor of BMI-1 function in ovarian cancer. Mol. Cancer Ther. 17, 39-49 (2018).

59. Hangartner, L., Zinkernagel, R. M. \& Hengartner, H. Antiviral antibody responses: the two extremes of a wide spectrum. Nat. Rev. Immunol. 6, 231-243 (2006).

60. Lofano, G. et al. Antigen-specific antibody Fc glycosylation enhances humoral immunity via the recruitment of complement. Sci. Immunol. https://doi.org/10.1126/sciimmunol.aat7796 (2018)

61. Wang, H. B. et al. Sp1 and c-Myc regulate transcription of BMI1 in nasopharyngeal carcinoma. FEBS J. 280, 2929-2944 (2013).

62. Huang, R. et al. MYCN and MYC regulate tumor proliferation and tumorigenesis directly through BMI1 in human neuroblastomas. FASEB J. 25, 4138-4149 (2011).

63. Cho, J. H., Dimri, M. \& Dimri, G. P. A positive feedback loop regulates the expression of polycomb group protein BMI1 via WNT signaling pathway. J. Biol. Chem. 288, 3406-3418 (2013).

64. Harker, J. A., Lewis, G. M., Mack, L. \& Zuniga, E. I. Late interleukin-6 escalates $\mathrm{T}$ follicular helper cell responses and controls a chronic viral infection. Science 334, 825-829 (2011).

65. Wilson, E. B. et al. Blockade of chronic type I interferon signaling to control persistent LCMV infection. Science 340, 202-207 (2013).

66. Fallet, B. et al. Chronic viral infection promotes efficient germinal center B cell responses. Cell Rep. 30, 1013-1026 (2020).

67. Arrowsmith, C. H., Bountra, C., Fish, P. V., Lee, K. \& Schapira, M. Epigenetic protein families: a new frontier for drug discovery. Nat. Rev. Drug Discov. 11, 384-400 (2012).

68. Morera, L., Lubbert, M. \& Jung, M. Targeting histone methyltransferases and demethylases in clinical trials for cancer therapy. Clin. Epigenetics 8, 57 (2016).

69. Hiepe, F. \& Radbruch, A. Plasma cells as an innovative target in autoimmune disease with renal manifestations. Nat. Rev. Nephrol. 12, 232-240 (2016).

70. Low, M., Infantino, S., Grigoriadis, G. \& Tarlinton, D. Targeting plasma cells: are we any closer to a panacea for diseases of antibody-secreting cells? Immunol. Rev. 270, 78-94 (2016).

Publisher's note Springer Nature remains neutral with regard to jurisdictional claims in published maps and institutional affiliations.

(c) The Author(s), under exclusive licence to Springer Nature America, Inc. 2021 


\section{Methods}

Mice. All animal experimentation was performed following the Australian National Health and Medical Research Council Code of Practice for the Care and Use of Animals for Scientific Purposes guidelines and in accordance with institutional regulations. The Monash Animal Ethics Committee approved all procedures. $\mathrm{Bmil} \mathrm{f}^{\mathrm{f} / \mathrm{f}} \mathrm{Cd} 23^{\text {cre }}$ mice were generated by crossing $\mathrm{Cd} 23^{\text {cre }}$ mice provided by M. Busslinger (Institute of Molecular Pathology) ${ }^{71}$ with $\mathrm{Bmil}^{\mathrm{f} / \mathrm{f}}$ mice provided by S. Morrison (University of Texas Southwestern) $)^{72}$. Bmi1 ${ }^{\text {CreER }}$ mice (010531; Jackson Laboratories) ${ }^{73}$ were crossed with Rosa26 ${ }^{\mathrm{EYFP}}$ mice $^{74} . \mathrm{Bmil}^{\mathrm{f} / \mathrm{f}} \mathrm{Prdm} 1^{\text {Rosa26CreERT2 }}$ mice were generated by crossing $B m i 1^{\mathrm{f} / \mathrm{f}}$ with $\operatorname{Prdm} 1^{\text {Rosa26CreERT2 }}$ mice provided by D. Tarlinton (Monash University). Ly5.1 mice were kindly provided by C. Zaph (Monash University). All mice were on a C57BL/6 background, backcrossed and maintained at the Monash Animal Research Platform. Both male and female mice were used in the experimental research project, between $42 \mathrm{~d}$ and 4 months for intact mice; up to 6 months for bone-marrow chimera experiments.

For immunization, mice were injected intraperitoneally (i.p.) with $100 \mu \mathrm{g} 100 \mu \mathrm{l}^{-1}$ per mouse of $\mathrm{NP}_{13}-\mathrm{KLH}$ precipitated in adjuvant alum. For LCMV infection, $100 \mu \mathrm{l}$ of LCMV-WE $\left(3 \times 10^{3}\right.$ p.f.u. $)$ or LCMV-Docile $\left(2 \times 10^{6}\right.$ p.f.u. $)$ was given intravenously (i.v.) per mouse tail vain. For tamoxifen administration, $\mathrm{Bmil}^{\mathrm{CreERT} 2} \mathrm{Ros}^{\mathrm{EYFP}}$ and $\mathrm{Bmil}^{\mathrm{f} / \mathrm{f}} \mathrm{Prdm} \mathrm{1}^{\text {Rosa26CreERT2 }}$ mice were treated with tamoxifen (Sigma) dissolved in peanut oil and ethanol at $5 \mathrm{mg} \mathrm{ml}^{-1}$. Then, $90 \mu \mathrm{l}$ of tamoxifen or vehicle control (peanut oil and ethanol) was administered to each mouse for $3 \mathrm{~d}$ consecutively via oral gavage at indicated time points.

Flow cytometry, cell sorting and antibodies. Single-cell suspensions were resuspended in PBS 2\% FCS and stained for flow cytometric analysis. Live or fixed cells were analyzed on the Fortessa or Canto (BD); cytometry data were acquired with FACSDiva software (BD) and analyzed with FlowJo (TreeStar). Fc $\gamma$ RII/III (2.4G2; supernatant) and Normal Rat Serum (Sigma-Aldrich) were used to block nonspecific binding. For sort purification, cells were stained with fluorochrome-labeled antibodies (Supplementary Table 1) and purified by FACSAria or Influx (BD). Gating strategies used are shown in Extended Data Fig. 8.

Histology. Immunofluorescence. Splenic portions were fixed using periodatelysine-paraformaldehyde fixative for $6-8 \mathrm{~h}$ at $4^{\circ} \mathrm{C}$. Tissues were transferred to a $30 \%$ sucrose solution and incubated overnight at $4^{\circ} \mathrm{C}$. Spleens were then embedded in OCT (Tissue-Tek) and kept frozen at $-80^{\circ} \mathrm{C}$ until staining. Seven-micrometer tissue sections were cut via microtome (Leica) and mounted on Superfrost Plus slides. Sections were fixed with cold acetone (Sigma) for $10 \mathrm{~min}$, blocked with PBS$5 \%$ FCS and stained using the indicated antibodies (Supplementary Table 2). Slides were observed under $\times 4$ and $\times 10$ magnification using an Olympus IX71 inverted microscope. Images were captured with a mounted high-sensitivity cooled SPOT RT KE CCD camera; white balance and exposure were set using SPOT 5.1 imaging software. Confocal microscopy images were acquired on a Leica SP8 laser scanning confocal microscope on a DMi8 inverted stand. Overview images were acquired with a multi-immersion objective HC PL APO $\times 20 / 0.75$ IMM CS2 objective with oil immersion. For higher resolution images an HC PL APO ×63/1.40 CS2 oil immersion objective was used. Image resolution was $1,024 \times 1,024$. Quantitation of $\mathrm{PNA}^{+} \mathrm{Myc}^{+}$cells within $\mathrm{IgD}^{\text {lo }}$ regions, as well as $100 \mu \mathrm{m}$ scale bars and pseudo-colors, were assigned to raw images using ImageJ software. Brightness and contrast were applied equally to each image. Threshold and despeckle tools were used for quantification analysis.

Immunohistochemistry. Splenic portions were frozen in OCT (Tissue-Tek). Seven-micrometer sections were cut using a microtome (Leica) at $-20^{\circ} \mathrm{C}$ and fixed with acetone. Staining was performed using described antibodies (Supplementary Table 3 ). Slides were viewed under $\times 4$ and $\times 10$ magnification using an Olympus CKX41 microscope and images were captured with a mounted Nikon DP-12 camera. Raw images were taken using the Nikon NIS-Element software platform and ImageJ was used to add $100-\mu \mathrm{m}$ scale bars to each image.

Deletion analysis. Sort-purified subsets were processed using the NucleoSpin Tissue kit (Macherey-Nagel, 740952.250). Genomic DNA was amplified using the following primers: Bmi1 LoxP forward (5'-GCTAGCATTCCTGGTTTTGC-3'), Bmil LoxP reverse (5'-GGCACAGTGATGAGGTGTTG'3) and Bmil excised (5'-CACGAGGTGCTTCTTTCCTC-3').

RNA purification and quantification. Sort-purified cell subsets were centrifuged, lysed in RLT buffer (QIAGEN) and passed through a gDNA eliminator spin column (QIAGEN) to remove gDNA. Total RNA was extracted using the RNeasy Plus Micro kit (QIAGEN, cat. no. 74034) according to manufacturer's instructions. First-strand complementary DNA synthesis was performed with a High-Capacity cDNA Reverse Transcription kit (Applied Biosystems, cat. no. 4368814). RT-qPCR was performed with Rotor-Gene Q using the QuantiNovaSYBR Green PCR kit (QIAGEN, cat. no. 208054). The forward and reverse primers for Bmil (ref. ${ }^{75}$ ) were $5^{\prime}$-AATTAGTCCCAGGGCTTTTCAA-3' and 3'-TCTTCTCCTCATCTGCAACTTCTC-5'; $M y c$ : 5'-GCTGTTTG AAGGCTGGATTTC-3' and 3'-GATGAAATAGGGCTGTACGGAG-5'; Bcl2l11:
5'-CGACAGTCTCAGGAGGAACC-3' and 3'-CCTTCTCCATACCAGACGGA-5' and Pmaip 1: 5'-GAACGCGCCAGTGAACCCAA-3' and 3'-CTTTGTCTCC AATCCTCCGG-5'. The housekeeping $K u 70$ gene was used as an internal control for normalization. To assess $K u 70$ expression, the following set of primers was used: 5'-TCGCCTTTACTGAGAAGGTGAC-3' and 3'-TGCTGCAGG ACTGGATTCTC-5'. The $2^{-\Delta \Delta C t}$ method was used to determine relative changes in gene expression.

ChIP-qPCR. Sort-purified subsets were processed as published ${ }^{76}$. Briefly, sorted cells were incubated with $0.6 \%$ formaldehyde for $10 \mathrm{~min}$. Crosslinking was stopped by addition of glycine to a final concentration of $0.25 \mathrm{M}$ and cross-linked chromatin was sonicated to reduce DNA size to 200-500 base pairs (bp). Sonicated chromatin was then used for ChIP analysis. Immunoprecipitation was undertaken with mouse antibodies against H3K27me3 (Millipore, 07-449) and H2AK119Ub1 (Cell Signaling Technology, 8240). RT-qPCR was performed as described above. Primers used to amplify a fragment including the transcription start site of indicated genes were: Prdm 1 5'-GAGTAGTCAGTCGCTCGCTC-3' and 3'GGTCCCTCCTTTTCTACGGC-5'; Irf4 5'-GAGCTGAAGAAAGCCAGGGT-3' and 3'-CTTTATAGAGCCGGAGGCGG; and $M y c$ 5'-GCGCGAGCAA GAGAAAATGG-3' and $3^{\prime}$ - GCTCCGGGGTGTAAACAGTA-5'. Data were normalized by dividing the total copies of no-antibody control, H3K23me3 or H2AK119Ub1 to copies of the total input. Each value was then multiplied by a factor of 100 to obtain the frequency (\%) of input.

ELISA and ELISpot. For ELISA, LCMV-WE and Docile viral lysates were used to coat 96-well high-binding plates (Sarstedt) overnight at $4{ }^{\circ} \mathrm{C}$. Plates were then blocked with PBS $1 \%$ BSA for $1 \mathrm{~h}$, washed and loaded with serially diluted serum for a $4 \mathrm{~h}$ incubation at $37^{\circ} \mathrm{C}$. Plates were washed again and incubated for $1 \mathrm{~h}$ at $37^{\circ} \mathrm{C}$ with IgG2c conjugated to horseradish peroxidase (HRP; Southern Biotech), followed by washing and development with OPD-substrate solution (Sigma-Aldrich). For ELISPOT and ELISA of NP-KLH samples, multiscreen HA plates (Millipore) were coated overnight with $\mathrm{NP}_{12} \mathrm{BSA}$ or $\mathrm{NP}_{1} \mathrm{BSA}$ for quantification of NP-specific IgG1 ${ }^{+}$ASCs. Plates were blocked, washed and loaded with samples prepared in RPMI 5\% FCS, $50 \mu \mathrm{M} 2$-mercaptoethanol and $2 \mathrm{mM}$ glutamine before an overnight incubation at $37^{\circ} \mathrm{C}$. Plates were washed and subsequently incubated for $1 \mathrm{~h}$ at $37^{\circ} \mathrm{C}$ with secondary antibody (IgG1) conjugated to alkaline phosphatase (Southern Biotech) for $1 \mathrm{~h}$. Plates were washed and developed with the BCiP/NBT reaction (Sigma-Aldrich). For ELISA analysis, high-binding plates were coated with $\mathrm{NP}_{12} \mathrm{BSA}$, serum samples followed by IgG1-HRP incubated as described above, before detection with OPD-substrate solution. A non-linear fit is shown (GraphPad Prism).

IC precipitation. ICs were precipitated from mouse sera ${ }^{11,77}$. Briefly, serum was incubated with a 1:1 ratio of PBS 5\% PEG6000 solution overnight at $4{ }^{\circ} \mathrm{C}$. The serum-PEG samples were mixed with RPMI 2.5\% PEG6000 in a 1:3 ratio and spun down at $2,000 \mathrm{~g}$ for $30 \mathrm{~min}$ at $4^{\circ} \mathrm{C}$. PEG precipitates were resuspended to the initially used serum volume in cold PBS and then quantified by ELISA.

T cell cytotoxicity assay and IFN- $\boldsymbol{\gamma}$ production. Cytotoxicity capacity of $\mathrm{CD}^{+} \mathrm{T}$ cells were assessed as previously described ${ }^{78}$. Briefly, CD8 ${ }^{+} \mathrm{T}$ cells were negatively enriched using the $\mathrm{CD} 8 \alpha^{+} \mathrm{T}$ cell (mouse) isolation kit (Miltenyi Biotec). Splenocytes from Ly5.1 mice were used as targets, labeled with cell trace violet (CTV; Molecular Probes) and loaded with $\mathrm{gp}_{33-41}$ peptide at $0.1 \mu \mathrm{M}$. Enriched $\mathrm{CD}^{+} \mathrm{T}$ cells were plated with peptide-pulsed (CTV high) or unpulsed (CTV low) splenocyte target cells from Ly5.1 mice in either a 1:1 ratio of 2.5:1 ratio and incubated for $5 \mathrm{~h}$ at $37^{\circ} \mathrm{C}$, stained for surface markers, propidium iodide (Molecular Probes), anti-CD45.1:APC-Cy7 (A20; BioLegend) and anti-CD45.2:PE (104; BioLegend) and assessed by flow cytometry. For cytokine production, approximately $1 \times 10^{6}$ splenocytes were stimulated in vitro for $5 \mathrm{~h}$ with IL-2 $10 \mathrm{U} \mathrm{ml}^{-1}$ (Peprotech) and brefeldin A (BD Cytofix/Cytoperm) in the presence or absence of $1 \mu \mathrm{M} \mathrm{H} 2-\mathrm{Db}$ gp $_{33-41}$ peptide. Cells were surface stained with anti-CD8:BUV395 (53-6.7, BD Biosciences), then fixed and permeabilized for intracellular expression of IFN- $\gamma$ :FITC (XMG1.2, BD Biosciences) and analyzed by flow cytometry.

Bone-marrow chimeras. Lethally irradiated Ly5.1 mice $(2 \times 4.5 \mathrm{~Gy})$ were reconstituted with $50 \%$ Ly5.1 and $50 \%$ Ly5.2-Cd23 ${ }^{\mathrm{Cre} /+}$ or $50 \%$ Ly5.2-Bmi ${ }^{\mathrm{f}}$ ${ }^{\mathrm{f}} \mathrm{C} d 23^{\mathrm{Cre} /+}$ bone marrow.

Plaque-forming unit assay and infectivity reduction assay. Livers were weighed and the calculated volume of DMEM (Gibco) was added to obtain $500 \mathrm{mg} \mathrm{ml}^{-1}$ of suspension. One stainless steel bead (QIAGEN) was added per sample and liver tissues were homogenized using the TissueLyser LT (QIAGEN) for $5 \mathrm{~min}$ at 50 oscillations s ${ }^{-1}$. Beads were removed and samples were spun for $10 \mathrm{~min}$ at 15,000 r.p.m. $\left(4^{\circ} \mathrm{C}\right)$ to pellet cell debris. For the p.f.u. assay, homogenized liver suspensions were serially diluted and added onto MC57G cells. An overlay mixture of $2 \%$ methylcellulose solution and $2 \times$ DMEM (Gibco) was added after virus adsorption and plates incubated $\left(37^{\circ} \mathrm{C}\right.$ for $\left.48 \mathrm{~h}\right)$. Plates were then stained with primary VL-4 antibody (previously described ${ }^{79}$ ) and the secondary HRP goat 
anti-rat IgG (Jackson ImmunoResearch). Plaques were developed (HRP Substrate kit; Vector) and counted to quantify viral load. For infectivity reduction assays, sera from LCMV-infected experimental mice were inactivated at $56^{\circ} \mathrm{C}$ for $30 \mathrm{~min}$ to eliminate pre-existing virus. Sera were then diluted and incubated for $90 \mathrm{~min}$ at $37^{\circ} \mathrm{C}$ with a known quantity of LCMV (30 p.f.u.). The antibody-virus mixtures were added onto MC57G cells and plaques were calculated. The neutralization capacity of the serum was expressed in percentage of plaque reduction, referring to the no-serum control sample.

ADCC. Target cells MC57G were cultured in complete DMEM (DMEM, 10\%, NaPyr, L-Glu, NEAa, 2-ME and HEPES, pH 7.2-7.5), labeled with CTV and infected with LCMV-Docile at a multiplicity of infection of $1,24 \mathrm{~h}$ before the cytotoxicity assay. Splenic NK cells were isolated from naive C57BL/6 mice using nylon wool filters (Polysciences) and seeded in complete RPMI-1640 (RPMI-1640, $5 \%$ FCS, $1 \%$ penicillin, streptomycin and $2 \mathrm{mM}$ glutamine) supplemented with $250 \mathrm{ng} \mathrm{ml}^{-1} \mathrm{IL}-2$ for $5 \mathrm{~d}$. ADCC was initiated by the addition of serum, previously collected from mice infected with LCMV-Docile, to the target cells. NK cells were combined in a 10:1 effector:target ratio. The plate was further incubated for $2 \mathrm{~h}$ at $37^{\circ} \mathrm{C}$. Cells were collected and stained with Fixable Viability Stain (BD Biosciences) to evaluate the frequency of dead cells by FACS.

IgG purification. IgG antibodies were purified from plasma according to manufacturer's protocol (Melon Gel IgG Purification kit, Thermo Fisher Scientific). Purified IgG antibody samples were centrifuged through $100 \mathrm{kDa}$ Amicon Ultra filters (Merck) at $14,000 \mathrm{~g}$ for $10 \mathrm{~min}$ to remove excess serum proteins and buffer was exchanged into PBS. Purity was confirmed via SDS-PAGE (Bio-Rad) and IgG concentrations were measured using a nanodrop spectrophotometer (Bio-Rad).

IgG $N$-linked glycan profiling. IgG $N$-linked glycosylation patterns were measured ${ }^{80,81}$ according to ProfilerPro glycan profiling LabChip GXII Touch protocol on the LabChip GXII Touch instrument (PerkinElmer). Microchip capillary electrophoresis laser-induced fluorescence (CE-LIF) analysis of digested and labeled $N$-linked glycans was performed. The relative prevalence of major $\mathrm{N}$-linked glycan profiles of IgG was analyzed using the LabChip GX Reviewer (PerkinElmer) software. Peaks were assigned based on the migration of known standards and glycan digests ${ }^{45}$. Peak area and relative prevalence of each glycan pattern were calculated.

In vitro B cell stimulation. $B$ cells were isolated using a B cell negative enrichment kit (STEMCELL). Cells were resuspended in RPMI 5\% FCS, $50 \mu \mathrm{M}$ 2-mercaptoethanol and $2 \mathrm{mM}$ glutamine. Then, $5 \times 10^{4}$ labeled B cells were cultured with CD40L (R\&D Systems) in combination with IL-4 and IL-5 (R\&D Systems) and in the presence of increasing IL-21 (Peprotech) at the indicated ng $\mathrm{ml}^{-1}$ concentrations.

Small molecule inhibitors. In vitro, $5 \times 10^{4} \mathrm{CTV}$-labeled B cells were cultured with LPS (Sigma) in combination with $50 \mathrm{ng} \mathrm{ml}^{-1} \mathrm{IL}-4$ (R\&D Systems) in the presence of DMSO or PTC-209 (Sapphire Bioscience) at the indicated concentrations. In vivo, mice were infected with LCMV-Docile and administered with $15 \mathrm{mg} \mathrm{kg}^{-1}$ body weight per mouse of PTC-028 (Sapphire Bioscience) small molecule inhibitor or vehicle control ( $0.5 \%$ hydroxypropyl methylcellulose and $1 \%$ Tween 80$)$ via oral gavage every $24 \mathrm{~h}$.

ATAC sequencing. Briefly, 50,000 cells were pelleted and washed with PBS. One-step permeabilization and tagmentation method was used by resuspending the cell pellets in Digitonin (EZSolution), Tween-20 (Sigma) buffer. High-molecular-weight tagmented DNA was then removed by incubating samples with a $0.7 \times$ ratio of Agencourt AMPureXP beads (Invitrogen). The same process was applied using a $1.2 \times$ ratio of beads to exclude low-molecular-weight DNA. Purified DNA was then pre-amplified with indexed primers and HiFi HotStart Polymerase Ready Mix (KAPA Biosystems). After estimation of addition PCR cycles required $^{82}$, the genomic library was fully amplified using the SYBR qPCR Master Mix with primers included in the Illumina Library Quantification kit for Bio-Rad iCycler (KAPA Biosystems). Libraries were sequenced on a HiSeq2500 using 50-bp paired-end Illumina chemistry. For data processing, reads were aligned to the NCBI37/mm10 build of the Mus musculus genome using Bowtie2 (ref. ${ }^{83}$ ) and PCR duplicate reads were flagged using the Picard MarkDuplicates tool. Enriched accessible regions were determined using MACS2 (ref. ${ }^{84}$ ) and reads overlapping peaks were annotated for each sample using GenomicRanges ${ }^{85}$ tool in R. DARs were determined using DESeq2 (ref. ${ }^{86}$ ). PCA was performed using the vegan package in $R$

RNA sequencing. Briefly, 250,000 cells were pelleted and washed with PBS. RNA purification was performed using the RNeasy Micro kit (QIAGEN) or Direct-zol RNA Microprep kit (Zymo Research), according to the manufacturer's instructions. Total mRNA was quantified with the Qubit Fluorometer (Invitrogen) and RNA integrity number values were generated for quality assignment by using the Agilent Bioanalyzer. Quality control-assessed libraries were then sequenced at the Illumina NextSeq500. For data processing, reads were aligned to the NCBI $37 / \mathrm{mm} 10$ build of the M. musculus genome using the Subread aligner. Library counts were obtained using featureCounts and $\log _{2}$ fold change were processed applying the DeSeq2 function. A PCA plot was generated using the PCAplot tool included in the DeSeq2 library. Volcano plot and quality control analysis were acquired using the Degust tool ${ }^{87} . K$-means analysis and heat maps were carried out using the kmeans and heatmap. 2 tools in RStudio. PRC and Myc target analyses plots were generated using information about targets from published datasets ${ }^{88-93}$.

IPA and GSEA. QIAGEN's IPA software was used for functional pathway analysis of DEGs identified in this study. Analysis was performed using expression cutoff of 0.58 -fold and FDR of 0.05 . GSEA was performed on unfiltered normalized counts to identify signaling pathway that are differentially activated in GC B cells between acute and chronic infection. Analysis was executed by using the MSigDB collection of the Hallmark gene set covering principal molecular functions.

Vh sequencing. Splenocytes from NP-KLH-immunized mice were pooled and single GC B cells were sort-purified into 96-well plates containing PBS on a BD FACSAria equipped with a plate sorter and prepared for sequencing using nested primers for $V h 186.2$ and $C \gamma 1$ as previously described ${ }^{94}$. DNA Sanger sequencing was performed by Macrogen, Singapore, using 3' primers from the second round of PCR. Vh186.2 sequences were aligned to germline using IMGT V-Quest and sequences of poor quality, those not identified as Vh186.2, miscalls, incomplete sequences or those containing stop codons were excluded from further analysis. The number and frequency of mutations was identified by comparison to the germline sequence. The number of sequences with the position 33 mutation, $\operatorname{tgg}(\operatorname{Trp})->$ ttg, ctt or tta (Leu), was counted.

LCMV BCR sequencing. Methods were adapted from previous work ${ }^{95}$. Sort-purified bulk GC B cells (B220 $\left.{ }^{+} \mathrm{IgD}^{\text {lo }} \mathrm{CD} 38^{-} \mathrm{CD}^{-} 5^{+} \mathrm{CD} 138^{-}\right)$were processed with a NucleoSpin Tissue mini kit for DNA (Macherey-Nagel, 740952), according to manufacturer's instructions. Genomic DNA was pre-amplified for mouse antibody heavy-chain library construction (using primers listed in Supplementary Table 4), amplicons were purified and Illumina NexteraXT adaptors were added to the Igh library ${ }^{95}$. Paired-end sequencing using Illumina MiSeq V2 chemistry and 251-bp paired-end reads was performed (Hudson Institute). For data processing, high-throughput BCR data of raw sequences from eight mice along with their metadata were stored, annotated and analyzed with ImmuneDB ${ }^{96} . \mathrm{V}$ and J gene assignment was performed using the Anchoring $\operatorname{method}^{97}$. For clone assignment, sequences in each mouse were divided into bins of common Vh and Jh gene assignment and the same CDR3 length. All of the sequences with $85 \%$ or more similarity in their CDR3 amino acids were grouped into the same clone. For mutation analysis, the number of unique mutations per clone were calculated in CDRs and framework regions, defined previously ${ }^{98}$. We considered both the overall levels of non-synonymous and synonymous mutations and the overall ratio of non-synonymous to synonymous mutations in each region of each mouse. For selection pressure analysis, the overall selection pressure in CDRs and framework regions was assessed across all clones of each mouse. Selection pressure analysis was performed with BASELINe (Bayesian Estimation of Antigen-driven Selection in Ig Sequences) $)^{99}$, part of the Shazam package ${ }^{100}$.

Immunoblot. Sort-purified GC B cells were resuspended in RIPA buffer (Sigma, R0278) supplemented with Roche complete mini protease inhibitor cocktail (Roche, 11836170001). Protein lysates were prepared with $4 \times$ Laemmli Sample Buffer (Bio-Rad, 1610747) supplemented with $\beta$-mercaptoethanol. Samples were run on 12\% SDS-PAGE gels (Bio-Rad, 1610174). Transfer blotting on nitrocellulose membranes was performed $(40 \mathrm{~min}$ at $90 \mathrm{~V})$. Membranes were blocked in 5\% milk. Primary antibodies were: BMI-1 (D20B7; Cell Signaling Technology, 6964) and histone H3 (D1H2; Cell Signaling Technology, 4499). Secondary antibodies were peroxidase AffiniPure goat anti-rabbit IgG $(\mathrm{H}+\mathrm{L})$ (Jackson ImmunoResearch, 111-035-144). H3 controls of samples were run in parallel due to technical limitations of developing both H3 and BMI-1 on the same blot. Membranes were developed using Clarity Western ECL Substrate (Bio-Rad, 1705060) and images were taken at the ChemiTouch (Bio-Rad) at different exposure times. Intensity of bands was quantified using the 'lane and bands' tool in Image Lab software (Bio-Rad, v.6.1).

Statistical analysis. The Mann-Whitney nonparametric two-tailed test, unpaired Student's $t$-test, Wilcoxon matched-pairs signed-rank test or a one-way analysis of variance was used to analyze the significance of data (GraphPad Prism). Statistical values are ${ }^{\star * *} P<0.0001,{ }^{\star * \star} P<0.001,{ }^{* \star} P<0.01$ and ${ }^{\star} P<0.05$. Data are represented as mean \pm s.e.m. No statistical methods were used to predetermine sample sizes but our sample sizes are similar to those reported in previous publications $\mathrm{s}^{20,101}$. Data distribution was assumed to be normal but this was not formally tested. There was no randomization to data collection or organization of experimental conditions. Animals were assigned to experimental groups based on genotype, sex and age matching. Mice assessed to be nonresponders to stimuli were excluded from analyses. Data collection and analysis were not performed blind to the conditions of the experiments. 
Reporting Summary. Further information on research design is available in the Nature Research Reporting Summary linked to this article.

\section{Data availability}

RNA-seq, ATAC-seq and LCMV BCR sequencing data has been deposited to the Gene Expression Omnibus under accession code GSE163365. Source data are provided with this paper

\section{Code availability}

Code for RNA-seq and ATAC-seq analysis followed typical pipelines from public $\mathrm{R}$ packages. RNAsik pipeline ${ }^{102}$ was used to analyze RNA-seq data, Bowtie2/MACS2 was used to analyze ATAC-seq data. All codes are available upon request.

\section{References}

71. Kwon, K. et al. Instructive role of the transcription factor E2A in early B lymphopoiesis and germinal center B cell development. Immunity 28, 751-762 (2008).

72. Mich, J. K. et al. Prospective identification of functionally distinct stem cells and neurosphere-initiating cells in adult mouse forebrain. eLife 3, e02669 (2014).

73. Sangiorgi, E. \& Capecchi, M. R. Bmil is expressed in vivo in intestinal stem cells. Nat. Genet. 40, 915-920 (2008).

74. Srinivas, S. et al. Cre reporter strains produced by targeted insertion of EYFP and ECFP into the ROSA26 locus. BMC Dev. Biol. 1, 4 (2001).

75. Nowak, K. et al. BMI1 is a target gene of E2F-1 and is strongly expressed in primary neuroblastomas. Nucleic Acids Res. 34, 1745-1754 (2006)

76. Russ, B. E. et al. Distinct epigenetic signatures delineate transcriptional programs during virus-specific $\mathrm{CD} 8\left(^{+}\right) \mathrm{T}$ cell differentiation. Immunity 41, 853-865 (2014).

77. Lux, A., Yu, X., Scanlan, C. N. \& Nimmerjahn, F. Impact of immune complex size and glycosylation on IgG binding to human Fc $\gamma$ Rs. J. Immunol. 190, 4315-4323 (2013).

78. Quinn, K. M. et al. Metabolic characteristics of CD8 $\left(^{+}\right) \mathrm{T}$ cell subsets in young and aged individuals are not predictive of functionality. Nat. Commun. 11, 2857 (2020).

79. Battegay, M. et al. Quantification of lymphocytic choriomeningitis virus with an immunological focus assay in 24- or 96-well plates. J. Virol. Methods 33, 191-198 (1991).

80. Lopez, E. et al. Low $\mathrm{pH}$ exposure during immunoglobulin $\mathrm{G}$ purification methods results in aggregates that avidly bind fcy receptors: implications for measuring Fc dependent antibody functions. Front. Immunol. 10, 2415 (2019).

81. Mahan, A. E. et al. A method for high-throughput, sensitive analysis of IgG Fc and Fab glycosylation by capillary electrophoresis. J. Immunol. Methods 417, 34-44 (2015)

82. Scharer, C. D. et al. ATAC-seq on biobanked specimens defines a unique chromatin accessibility structure in naive SLE B cells. Sci. Rep. 6 , 27030 (2016)

83. Langmead, B. \& Salzberg, S. L. Fast gapped-read alignment with Bowtie 2. Nat. Methods 9, 357-359 (2012).

84. Zhang, Y. et al. Model-based analysis of ChIP-Seq (MACS). Genome Biol. 9 , R137 (2008).

85. Lawrence, $\mathrm{M}$. et al. Software for computing and annotating genomic ranges PLoS Comput. Biol. 9, e1003118 (2013).

86. Love, M. I., Huber, W. \& Anders, S. Moderated estimation of fold change and dispersion for RNA-seq data with DESeq2. Genome Biol. 15, 550 (2014).

87. Powell, D. Degust: interactive RNA-seq analysis. Zenodo https://doi org/10.5281/zenodo.3258932 (2015).

88. Kim, J. et al. A Myc network accounts for similarities between embryonic stem and cancer cell transcription programs. Cell 143, 313-324 (2010).

89. Schuhmacher, $M$. et al. The transcriptional program of a human B cell line in response to Myc. Nucleic Acids Res. 29, 397-406 (2001).

90. Gargiulo, G. et al. In vivo RNAi screen for BMI1 targets identifies TGF- $\beta$ / BMP-ER stress pathways as key regulators of neural- and malignant glioma-stem cell homeostasis. Cancer Cell 23, 660-676 (2013).

91. Douglas, D. et al. BMI-1 promotes Ewing sarcoma tumorigenicity independent of CDKN2A repression. Cancer Res. 68, 6507-6515 (2008)

92. Wiederschain, D. et al. Contribution of Polycomb homologues Bmi-1 and Mel-18 to medulloblastoma pathogenesis. Mol. Cell. Biol. 27, 4968-4979 (2007).

93. Nuytten, M. et al. The transcriptional repressor NIPP1 is an essential player in EZH2-mediated gene silencing. Oncogene 27, 1449-1460 (2008).

94. Piovesan, D. et al. c-Myb regulates the T-Bet-dependent differentiation program in B cells to coordinate antibody responses. Cell Rep. 19, 461-470 (2017).
95. Staupe, R. P. et al. Chronic viral infection promotes early germinal center exit of B cells and impaired antibody development. Preprint at bioRxiv https://doi.org/10.1101/849844 (2019).

96. Rosenfeld, A. M., Meng, W., Luning Prak, E. T. \& Hershberg, U. ImmuneDB: a system for the analysis and exploration of high-throughput adaptive immune receptor sequencing data. Bioinformatics 33, 292-293 (2017).

97. Zhang, B., Meng, W., Luning Prak, E. T. \& Hershberg, U. Discrimination of germline $\mathrm{V}$ genes at different sequencing lengths and mutational burdens: a new tool for identifying and evaluating the reliability of $\mathrm{V}$ gene assignment. J. Immunol. Methods 427, 105-116 (2015).

98. Giudicelli, V., Brochet, X. \& Lefranc, M. P. IMGT/V-QUEST: IMGT standardized analysis of the immunoglobulin (IG) and T cell receptor (TR) nucleotide sequences. Cold Spring Harb. Protoc. 2011, 695-715 (2011).

99. Yaari, G., Uduman, M. \& Kleinstein, S. H. Quantifying selection in high-throughput Immunoglobulin sequencing data sets. Nucleic Acids Res. 40, e134 (2012).

100. Gupta, N. T. et al. Change-O: a toolkit for analyzing large-scale B cell immunoglobulin repertoire sequencing data. Bioinformatics 31 , 3356-3358 (2015)

101. Good-Jacobson, K. L., O’Donnell, K., Belz, G. T., Nutt, S. L. \& Tarlinton, D M. c-Myb is required for plasma cell migration to bone marrow after immunization or infection. J. Exp. Med. 212, 1001-1009 (2015).

102. Tsyganov, K., Perry, A. J., Archer, S. K. \& Powell, D. RNAsik: a pipeline for complete and reproducible RNA-seq analysis that runs anywhere with speed and ease. J. Open Source Softw. 3, 583 (2018)

\section{Acknowledgements}

We thank J. Groom (Walter and Eliza Hall Institute), I. Parish (Peter MacCallum Cancer Centre), C. Zaph and J. Rossjohn for critical reading of this manuscript and/or discussions; M. Pellegrini (Walter and Eliza Hall Institute), M. Degli-Esposti (Monash University) and A. Papa (Monash University) for generously providing, respectively, LCMV stocks, IL-2 and c-Myc antibody; J. Sun and members of the Good-Jacobson laboratory for technical assistance; O. Chernyavskiy and the staff of Monash Micro Imaging for the provision of instrumentation training and technical support; Monash FlowCore, Bioinformatics and Animal Research Platforms; and MHTP Medical Genomics Facility. This work was supported by a Bellberry-Viertel Senior Medical Research Fellowship (K.L.G.-J.); National Health and Medical Research Council (NHMRC) Career Development Fellowships 1108066 (K.L.G.-J.) and 1140509 (A.W.C.); American Association of Immunologists Careers in Immunology Fellowship and Travel for Techniques program (A.D.P. and K.L.G.-J.); Australian Research Council Future Fellowship FT170100174 and Discovery Project DP200102776, NHMRC Ideas grant 1182086 (N.L.L.G.); NHMRC Program grant 1054925 and Investigator award 1175411 (D.M.T. and K.O.D.); Australian Research Council Discovery Project DP170102020 and NHMRC Ideas grant 1183478 (S.J.T.); Monash University Biomedicine Discovery Institute Scholarship (L.C.); Monash University Scholarship for Excellence (J.P.); Monash University Graduate Scholarship and Monash International Postgraduate Research Scholarship (T.H.); Postgraduate Scholarship from the Bonn University - Melbourne University joining PhD program (V.U.); National Institutes of Health P01 AI106697 and the European Union's Horizon 2020 Research and Innovation program 825821 (U.H. and A.S.). The contents of this document can under no circumstances be regarded as reflecting the position of the European Union.

\section{Author contributions}

K.L.G.-J. conceived the study. K.L.G.-J., A.D.P., N.L.L.G. and A.W.C. designed research. A.D.P., J.P., L.C., L.H., T.D., V.U., K.O.D. and T.H. performed the research. S.J.T., N.L.L.G., A.W.C., C.D.S. and D.M.T. provided additional intellectual input. T.M., A.S., U.H., A.D.P. and C.D.S. analyzed deep-sequencing data. S.P. provided reagents and technical expertise. D.M.T. provided mice. K.L.G.-J. wrote the manuscript.

\section{Competing interests}

K.L.G.-J. has received funding from GSK for a separate project. The remaining authors declare no competing interests.

\section{Additional information}

Extended data is available for this paper at https://doi.org/10.1038/s41590-021-01077-y. Supplementary information The online version contains supplementary material available at https://doi.org/10.1038/s41590-021-01077-y.

Correspondence and requests for materials should be addressed to Kim L. Good-Jacobson.

Peer review information Nature Immunology thanks Deepta Bhattacharya, Tri Phan and the other, anonymous, reviewer(s) for their contribution to the peer review of this work. L. A. Dempsey was the primary editor on this article and managed its editorial process and peer review in collaboration with the rest of the editorial team.

Reprints and permissions information is available at www.nature.com/reprints. 

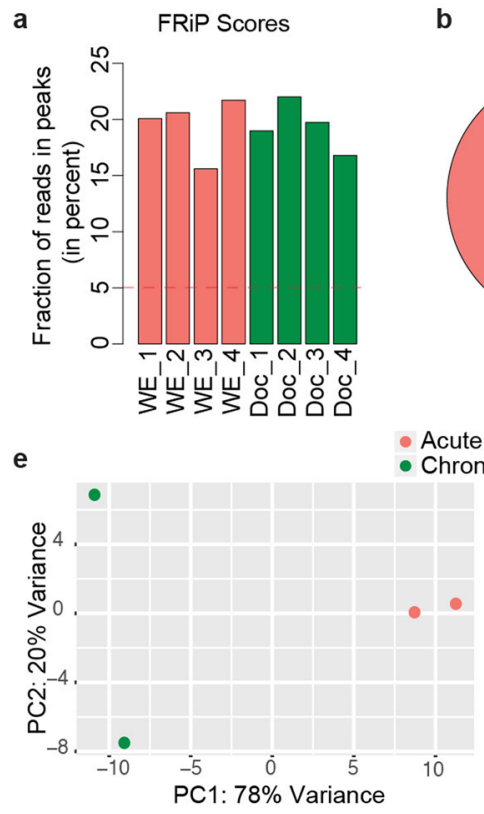

b

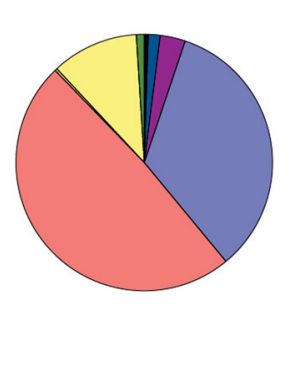

Intron $49 \%$

Intergenic 34\%

Promoter-TSS $11 \%$

Exon $3.2 \%$

5'UTR $1.5 \%$

TTS $1 \%$

3'UTR 0.5\%

Non-coding $0.3 \%$

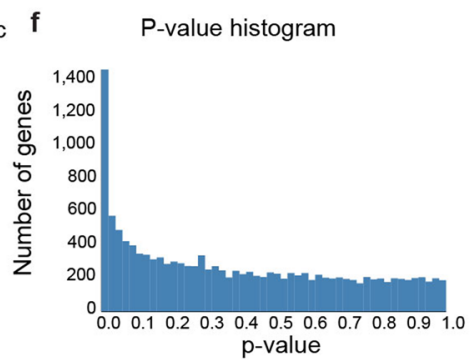

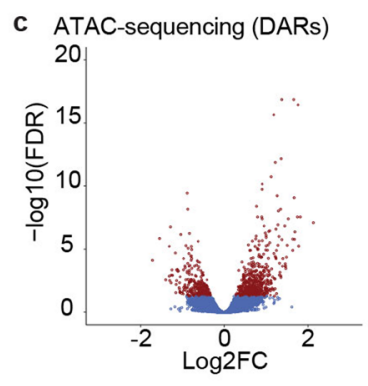

g

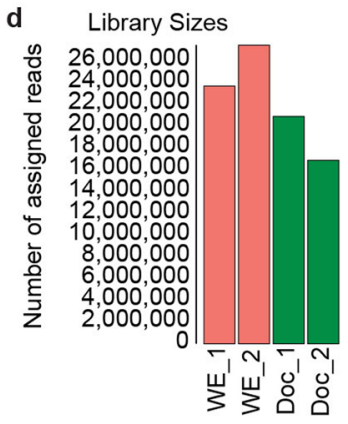

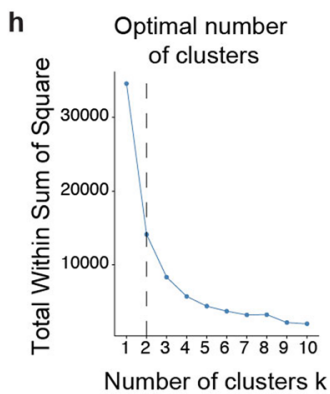
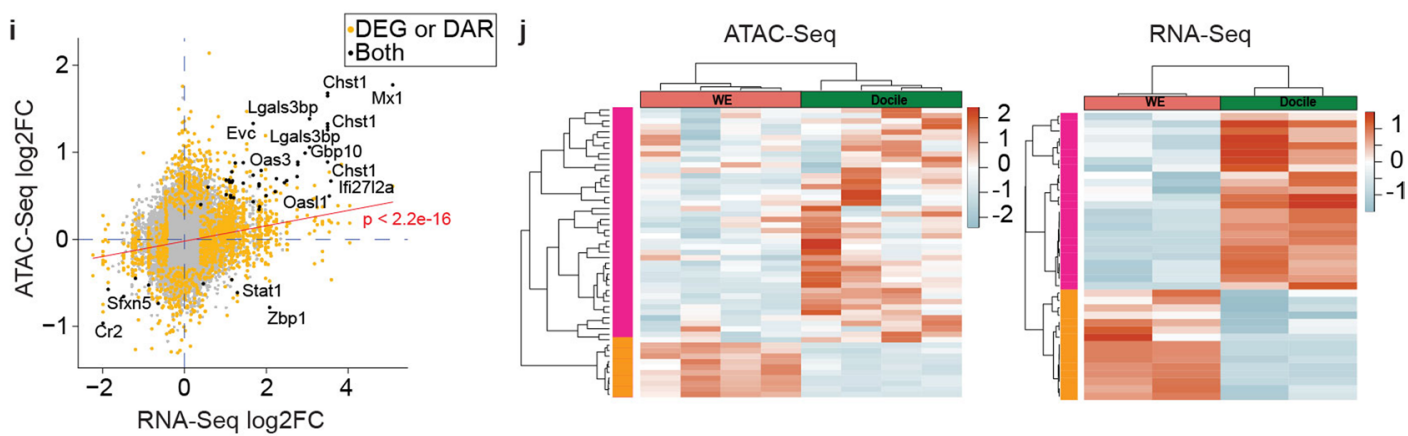

k PRC2 Targets
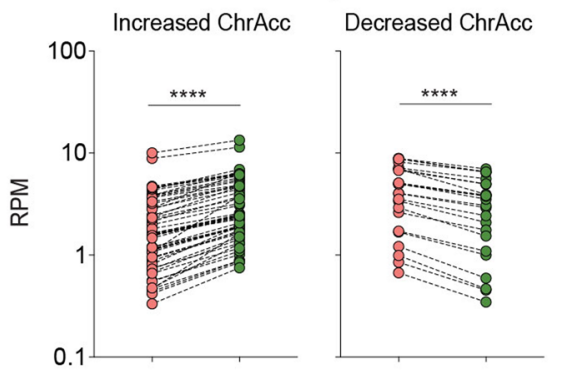

$\uparrow \begin{array}{r}2500 \\ 200 \\ 1500 \\ 1000 \\ 500\end{array}$
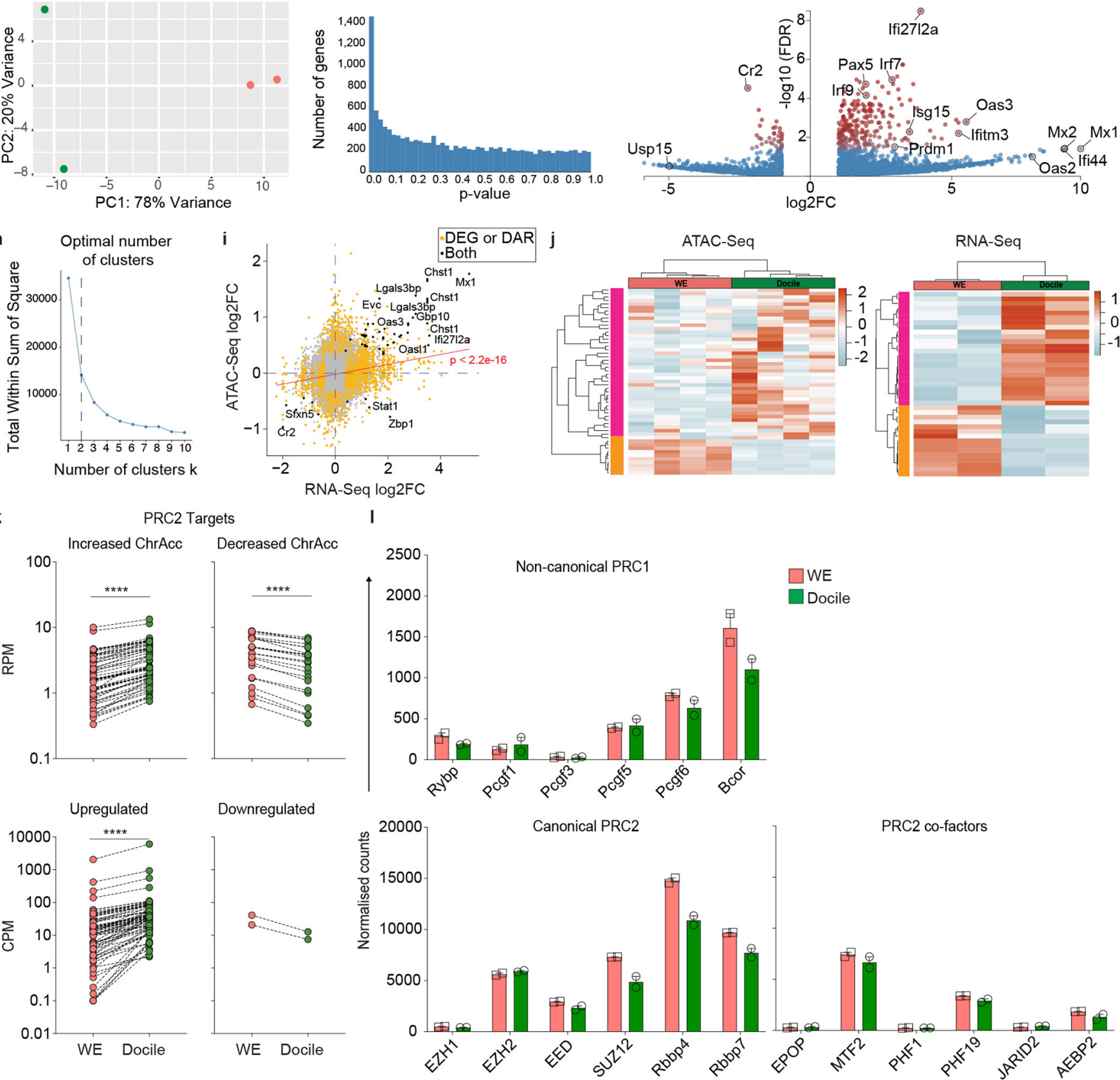

Extended Data Fig. 1 | See next page for caption. 


\section{NATURE IMMUNOLOGY}

Extended Data Fig. 1 | Quality control for deep-sequencing dataset and overlap between differentially chromatin accessible regions and differentially expressed genes. a, Data quality for the ATAC-seq was evaluated by calculating the Fraction of read in peaks (FRIP Score). b, Chromatin accessibility regions pie chart. c, Volcano plot for all significantly differentially accessible regions (DARs). d, Metrics for RNA-seq showing the sequencing library size of assigned reads. e, PCA plot in two dimensions of differential expressed genes in acute (salmon) and chronic (green) GC B cells. $\mathbf{f}$, Histogram of the nominal p-values calculated by DESeq for synthetic data RNA-seq. g, Volcano plot for differentially expressed genes (DEGs) identified by RNA-seq. h. Within Sum of Square (WSS) plot for the optimal number of clusters determined by the K-mean analysis. i, Dot plot showing differential chromatin accessibility regions (DARs) or expressed genes (DEGs) (yellow dots) and the overlap between the two datasets (black dots). $\mathbf{j}$, Heat maps for overlapped DARs (ATAC-Seq, left panel) and DEGs (RNA-Seq, right panel). k, PRC2 targets assessed within DARs (upper panels) or DEGs (lower panels); ${ }^{\star \star \star \star} \mathrm{P}<0.0001$, Wilcoxon matched-pairs signed rank test, two-tailed $\mathrm{p}$-value. I, Plots of normalised counts for non-canonical PRC1 (top), PRC2 and PRC2 co-factors (bottom); $\mathrm{n}=2$ mice per group, data represent mean \pm SEM. 


\section{ARTICLES}
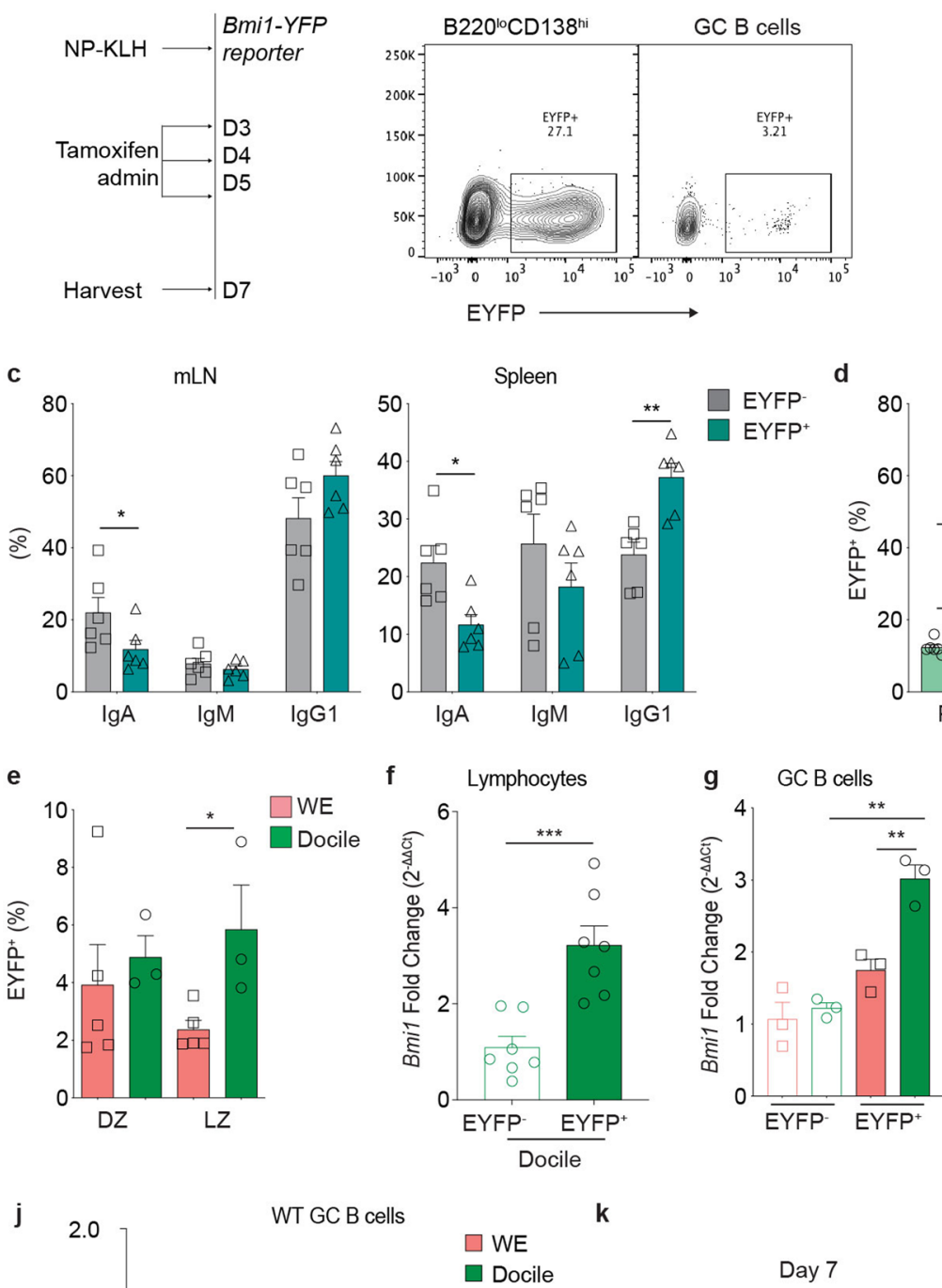

k

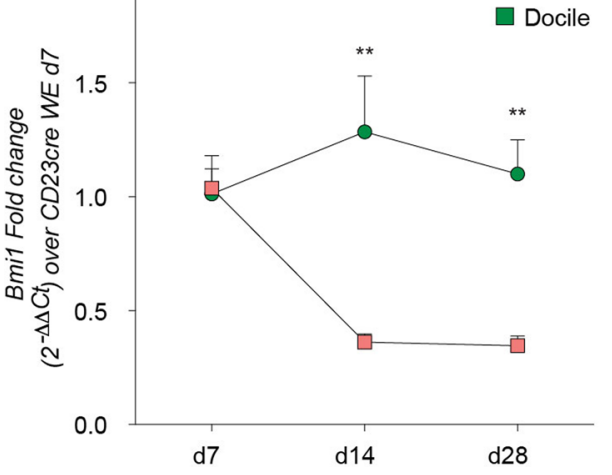

Day 7
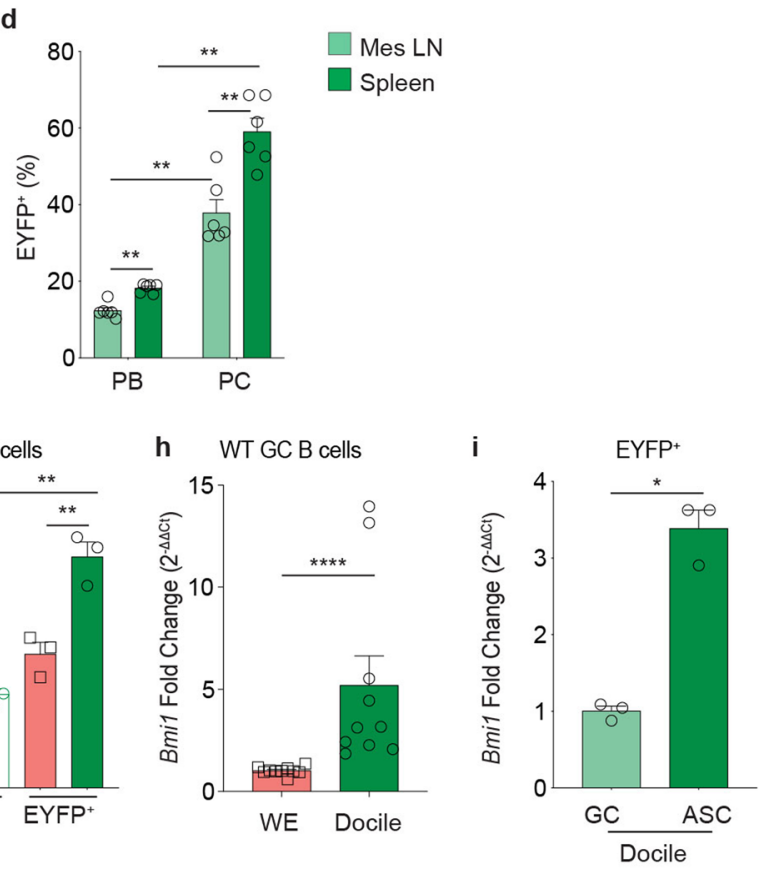

WT GC B cells

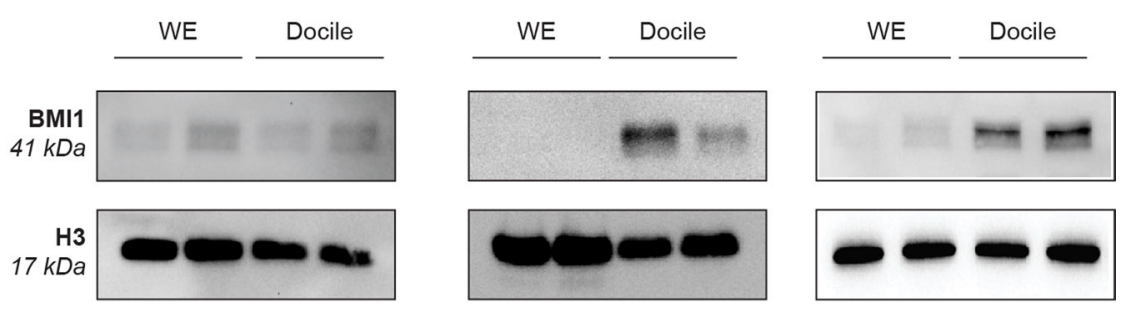

Extended Data Fig. 2 | See next page for caption. 
Extended Data Fig. 2 | BMI-1 expression in B cell subsets. a, Schematic of NP-KLH in alum immunization and tamoxifen administration of

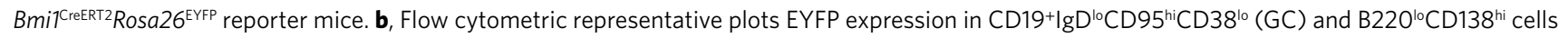
from immunized BmilRosa26eYFP reporter mice. c, EYFP- and EYFP+ frequencies within B220 ${ }^{\circ} \mathrm{CD}^{-} 138^{\text {hi }}$ ASC of either $\operatorname{lgG}$, IgA or $\operatorname{lgM}$ immunoglobulin isotypes were assessed by flow cytometry; $n=6$ mice per group; data represent mean $\pm S E M ; m L N$ : ${ }^{\star} P=0.0411, S p l e e n:{ }^{*} P=0.04152$, ${ }^{\star \star} P=0.0043$ (Mann-Whitney $U$ test, two-tailed p-value). d, Frequency of EYFP+ $P B\left(B 220^{\text {int }} C D 138^{\text {hi }}\right)$ and $P C\left(B 220^{-} C D 138^{\text {hi }}\right)$ in mesenteric lymph nodes and spleen in immunized mice; $n=6$ mice per group, combined from two independent experiments; data represent mean $\pm S E M$; ${ }^{\star *} P<0.01$ (Mann-Whitney $U$ test, twotailed p-value). e-i, Bmi ${ }^{\text {CreeRT2}}$ Rosa26 $6^{\mathrm{EYP}}$ reporter mice and wild-type controls were infected with either LCMV-WE or LCMV-Docile as per schematic in Fig. 1. e, GC B cells were segregated into DZ and $L Z$ subsets and assessed for EYFP+ frequency; WE: $n=5$ mice, Docile: $n=3$ mice; Data represent mean $\pm S E M$. ${ }^{*} \mathrm{P}=0.0357$ (Mann-Whitney U test, two-tailed p-value). $\mathbf{f - i}$, Assessment of Bmil by RT-qPCR in sort-purified populations as follows: $\mathbf{f}$, EYFP-and EYFP+ lymphocytes in LCMV-Docile-infected mice ( $2^{-\Delta 4 C t}$ method relative to EYFP- $) ; n=7$ mice per group; data represent mean $\pm S E M ;{ }^{\star \star \star} P=0.0006(M a n n-$ Whitney $U$ test, two-tailed p-value). g, EYFP-and EYFP+ GC B cells responding to either LCMV-WE or LCMV-Docile (relative to acute EYFP- GC B cells); $\mathrm{n}=3$ mice per group; data represent mean $\pm S E M$; ${ }^{\star \star} \mathrm{P}<0.01$ (Welch's $U$ test, two-tailed $p$-value). $\mathbf{h}, \mathrm{GC} B$ cells from wild-type mice infected with either LCMV-WE or LCMV-Docile (relative to acute GC B cells), d14 post-infection; $n=10$ mice per group; data represent mean $\pm S E M$; ${ }^{\star \star \star \star} P<0.0001$ (MannWhitney U test, two-tailed p-value). $\mathbf{i}, E Y F{ }^{+} \mathrm{GC} B$ cells and ASCs (relative to GC B cells); $n=3$ mice per group; data represent mean $\pm S E M$. ${ }^{*} \mathrm{P}=0.0211$ (Welch's $U$ test, two-tailed p-value). $\mathbf{j}$-k, Kinetics of (j) Bmi1 and (k) BMI-1 expression in GC B cells isolated from wild-type mice infected with either LCMV-WE or LCMV-Docile. H3 loading control in bottom panel. RT-qPCR values for (j) combined from 1-3 experiments per timepoint (d7: WE $n=5$, Docile $n=6$; d14: $n=10$ per group; d28: WE $n=4$, Docile $n=3$; d14 data also shown in $\mathbf{h}$ ). Data represent mean $\pm S E M$. ${ }^{\star \star} P<0.01$ (Mann-Whitney $U$ test, two-tailed $p$-value). Gels and blots for ( $k$ ) were processed in parallel, using the same samples. 


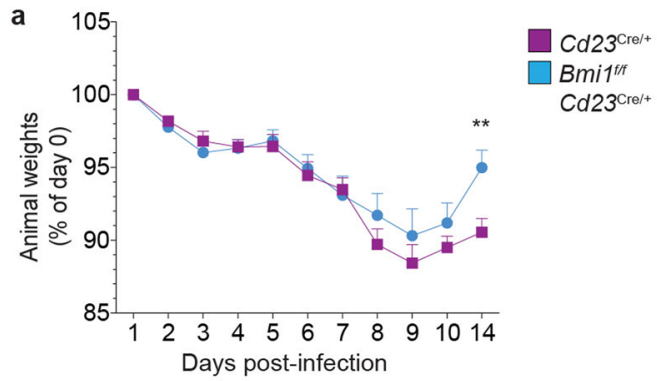

b D7 Innate subsets
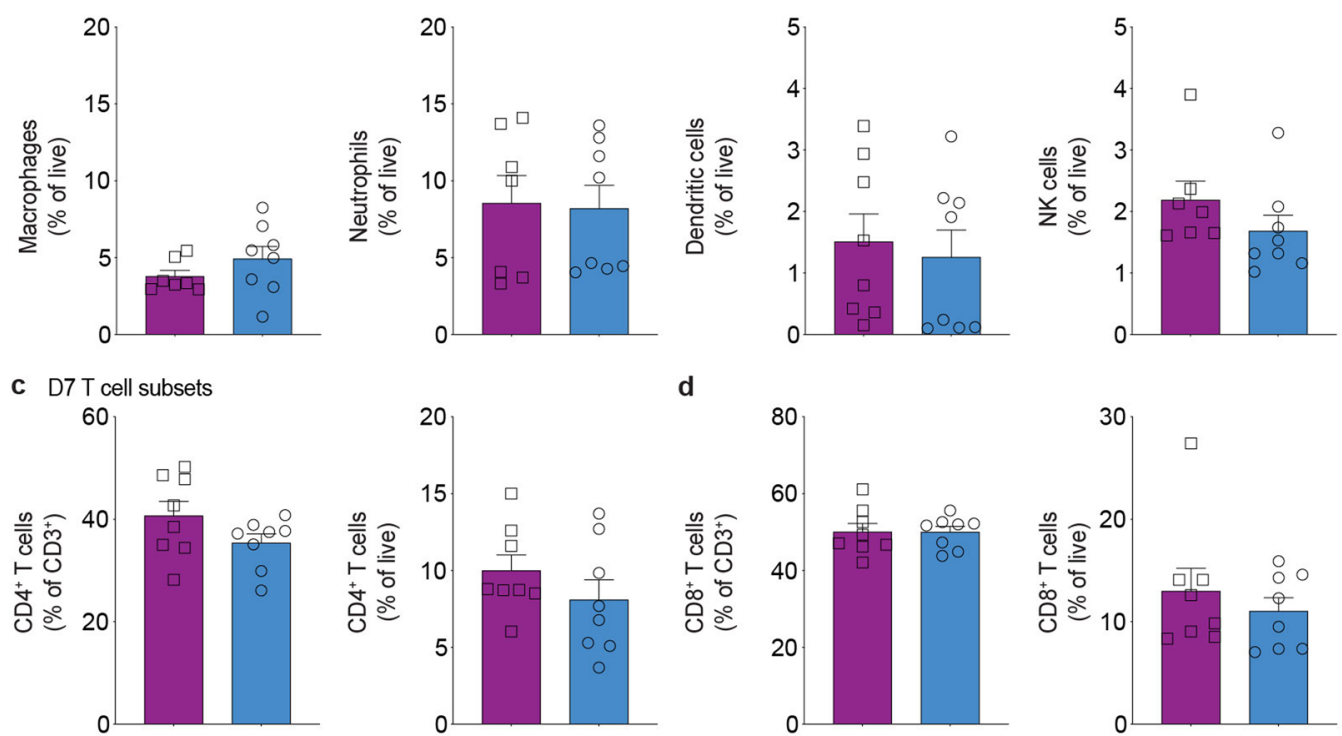

d
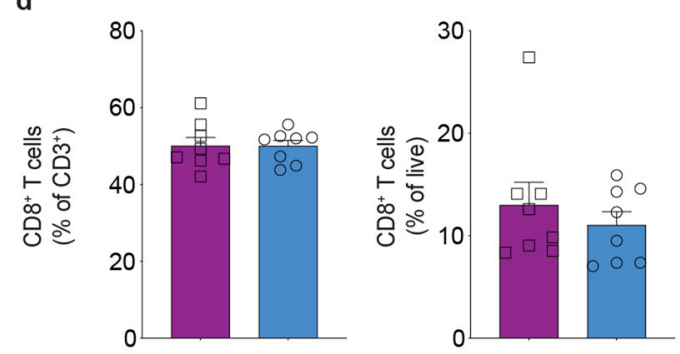

e D21 T cell subsets
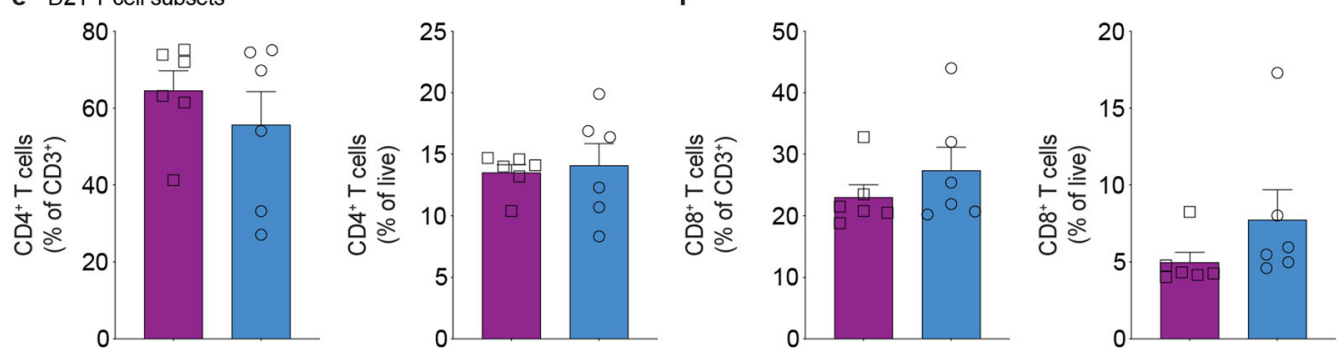

g

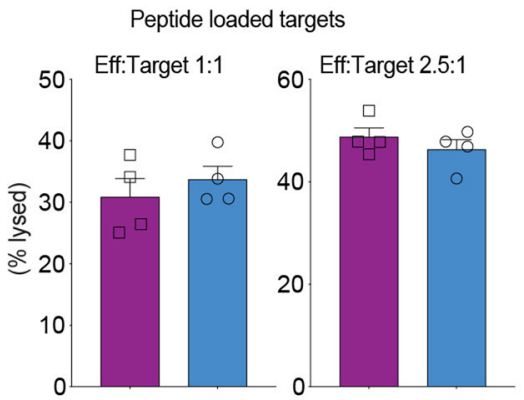

h $\quad$ gp33+CD8 ${ }^{+} \mathrm{T}$ cells

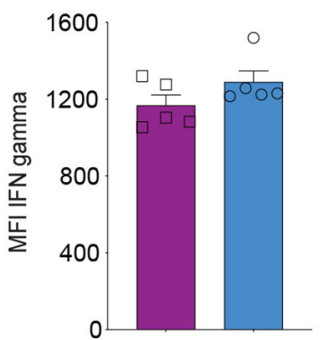

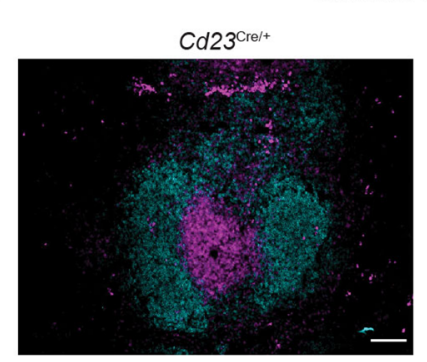

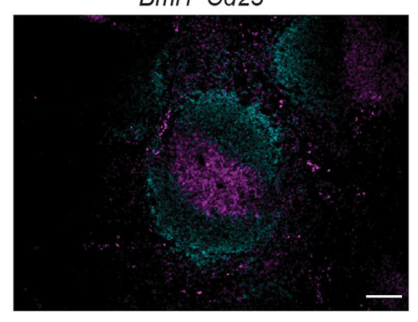

Extended Data Fig. 3 | Quantitation of innate and adaptive cell subsets. Cd23 weights assessed at the indicated time points post-infection ( $n=18 \mathrm{Cd} 23^{\mathrm{Cre} /+}$ and $n=19 \mathrm{Bmi} 7^{1 / / 4} \mathrm{Cd} 23^{\mathrm{Cre} /+}$ mice; data represent mean $\pm \mathrm{SEM}$; ${ }^{* \star} \mathrm{P}=0.0058$, Mann-Whitney $\mathrm{U}$ test, two-tailed $\mathrm{p}$-value). $\mathbf{b}$, Innate immune cell subsets; $\mathbf{c}, \mathrm{CD} 4^{+} \mathrm{T}$ cells; $\mathbf{d}, \mathrm{CD} 8^{+} \mathrm{T}$ cells were assessed at $\mathrm{d} 7$. $\mathbf{b}-\mathbf{d}, \mathrm{n}=8 \mathrm{mice}$ per group, combined from two independent experiments (Mann-Whitney $U$ test, two-tailed $p$-value). e, CD4 ${ }^{+} T$ cells and $\mathbf{f}, C D 8^{+} T$ cells were assessed at $d 21$. $\mathrm{n}=6$ mice per group, combined from two independent experiments (Mann-Whitney $U$ test, two-tailed p-value). $\mathbf{g}$, Sort-purified CD44hi CD8 ${ }^{+}$cells from

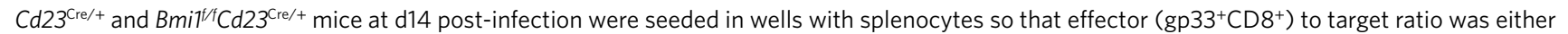
2.5:1 or 1:1; $n=4$ mice per group (Mann-Whitney $U$ test, two-tailed $p$-value). $\mathbf{h}$, Mean fluorescence intensity of IFN $\gamma$ in gp33+CD $8^{+} T$ cells; $n=5$ mice per group (Mann-Whitney $\mathrm{U}$ test, two-tailed p-value). i, Histological analysis of uninfected spleens from $\mathrm{Cd} 23^{\mathrm{Cre} /+}$ and $\mathrm{Bmi} 7^{1 / f} \mathrm{Cd} 23^{\mathrm{Cre} /+}$ mice from an individual experiment; B220 (cyan), CD3 (magenta). Scale bar $=100 \mu \mathrm{m}$. 


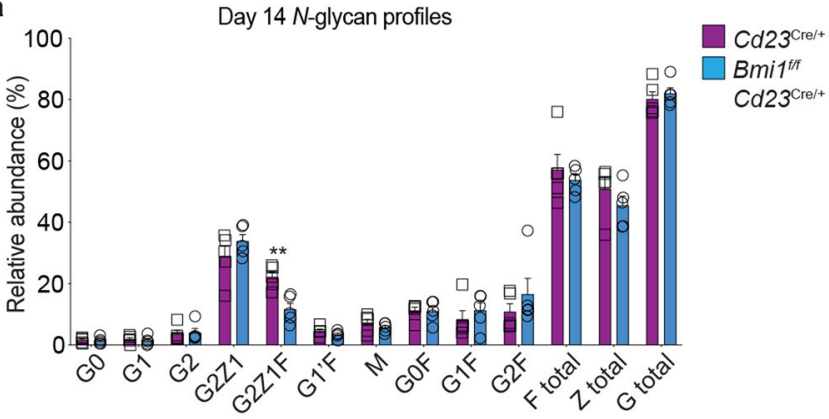

d

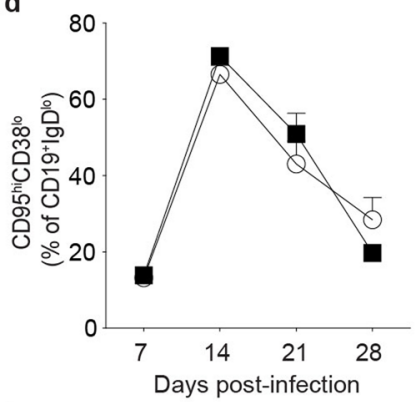

h

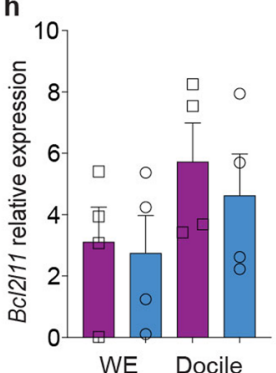

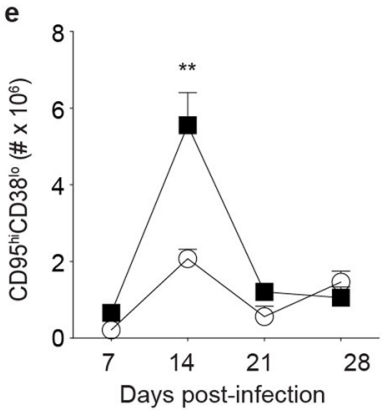

b

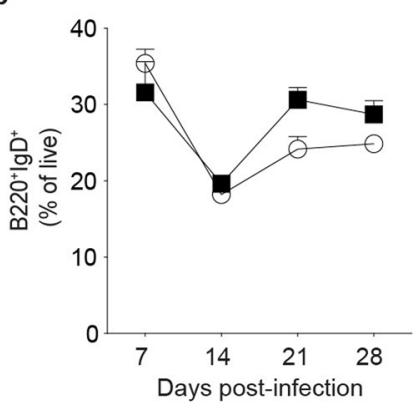

f

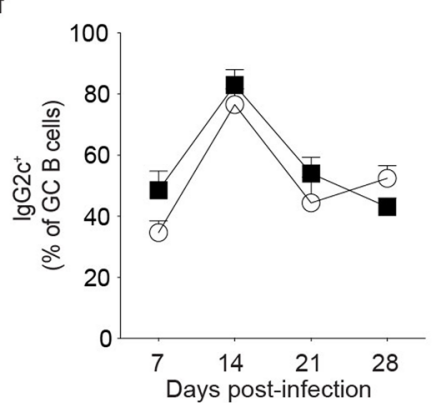

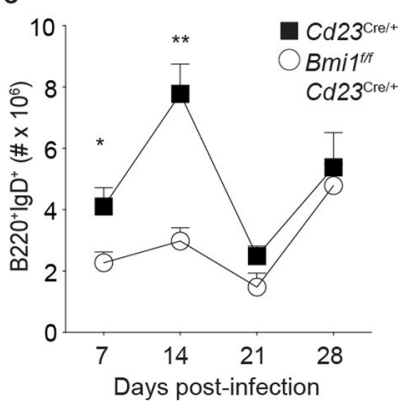

g

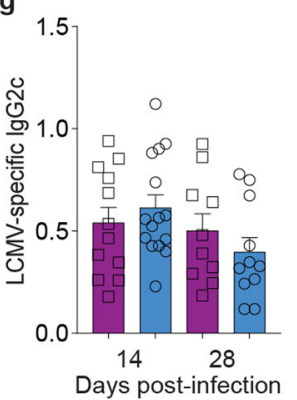

Extended Data Fig. 4 | Humoral responses to infection of BMI-1-deficient B cells. Cd23 $3^{\mathrm{Cre} /+}$ and $B m i 1^{7 / f} \mathrm{Cd} 23^{\mathrm{Cre} /+}$ mice were infected with LCMV-Docile. a, Relative abundance of specific types of $\mathrm{N}$-glycan structures (GO, agalactosylated; G1, monogalactosylated; G2, digalactosylated; F, fucosylated; $Z$, sialylated; $M$, mannose) of serum antibody at d14 post-infection. Data represent mean $\pm S E M, n=5$ per group, combined from two independent experiments. b, Frequency and $\mathbf{c}$, number of unswitched B cells at the indicated time points; d, Frequency of GC B cells within the CD19+lgD'o population and $\mathbf{e}$, number of GC B cells in LCMV-Docile-infected mice at indicated time points. f, Frequency of IgG2 $\mathrm{c}^{+}$cells within the GC B cell population in LCMV-Docile-infected mice at the indicated time points. $b$-f, Data represent mean \pm SEM; $d 7: n=6-10$ mice per group, d14: $n=12-16$ Cd23Cre/+ and

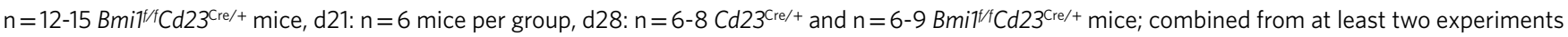
per time point; ${ }^{\star} \mathrm{P}<0.05$, ${ }^{\star \star} \mathrm{P}<0.01$ (Mann-Whitney $\mathrm{U}$ test, two-tailed $\mathrm{p}$-value). $\mathbf{g}$, LCMV-specific serum IgG2c at d14 and d28 post-infection with

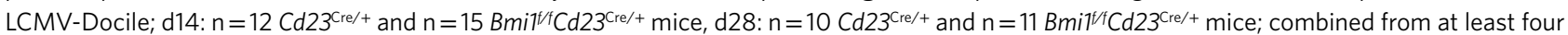
experiments per time point. h, Bc/2/11 and Pmaip1 expression in GC B cells isolated from Cd23 Cre/+ or Bmit/f/Cd23Cre/+ mice, d14 post-infection. Data represent mean $\pm S E M, n=4$ per group. 
a $\mathrm{Cd} 23_{\mathrm{Cre} / \mathrm{t}}$
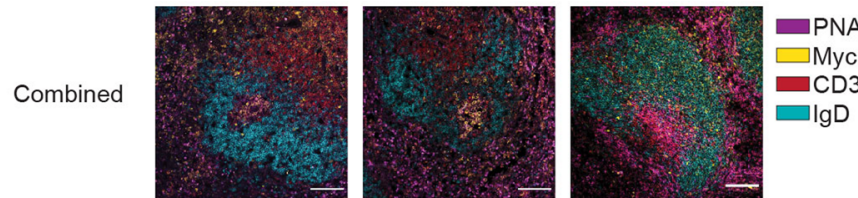

$\lg D$
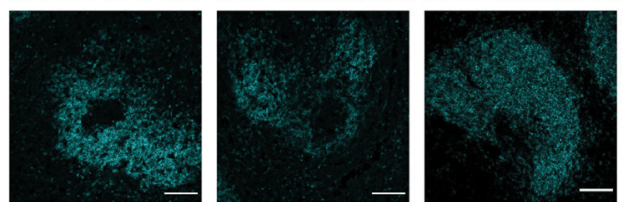

CD3
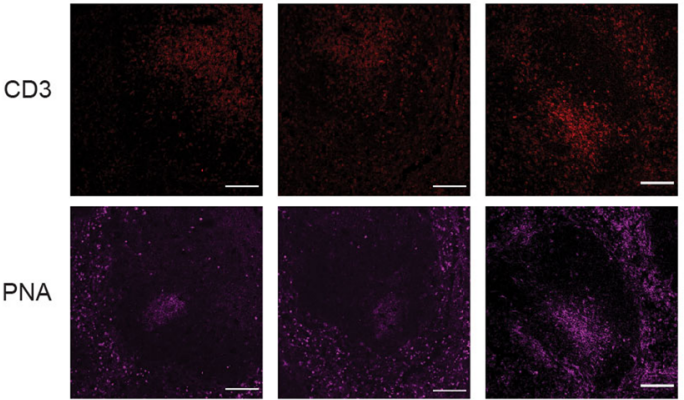

Myc
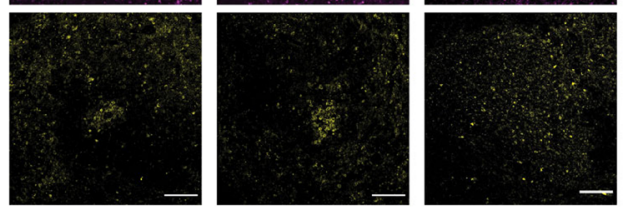

c

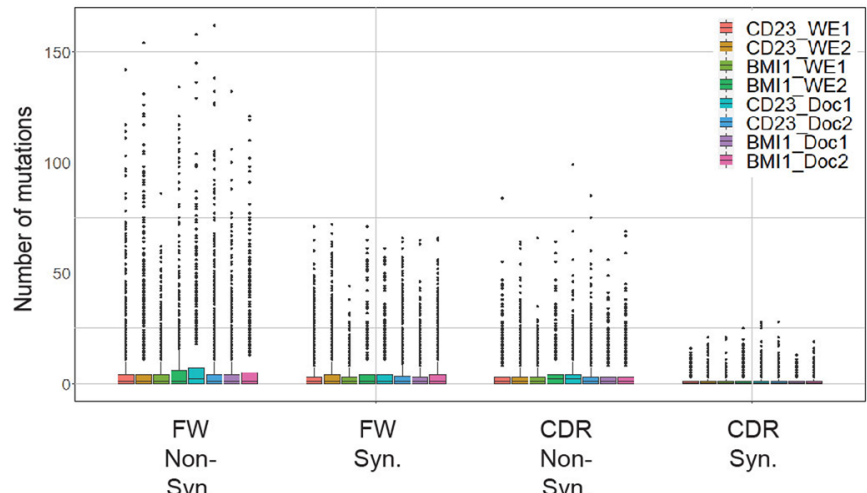

Syn.
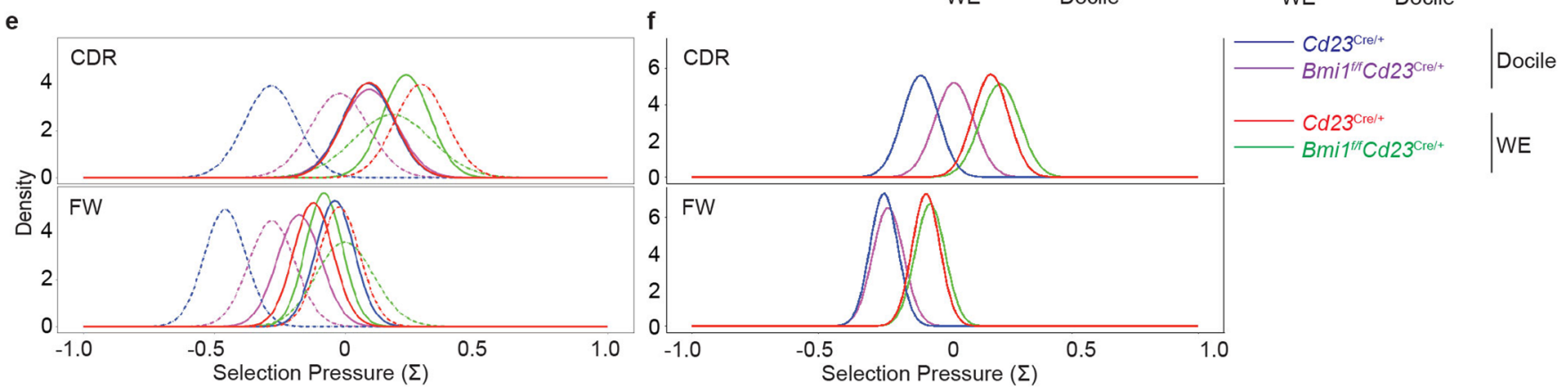

Extended Data Fig. 5 | See next page for caption.

b Bmi1 $1^{\text {iff }} \mathrm{Cd} 23^{\mathrm{Cre} /+}$
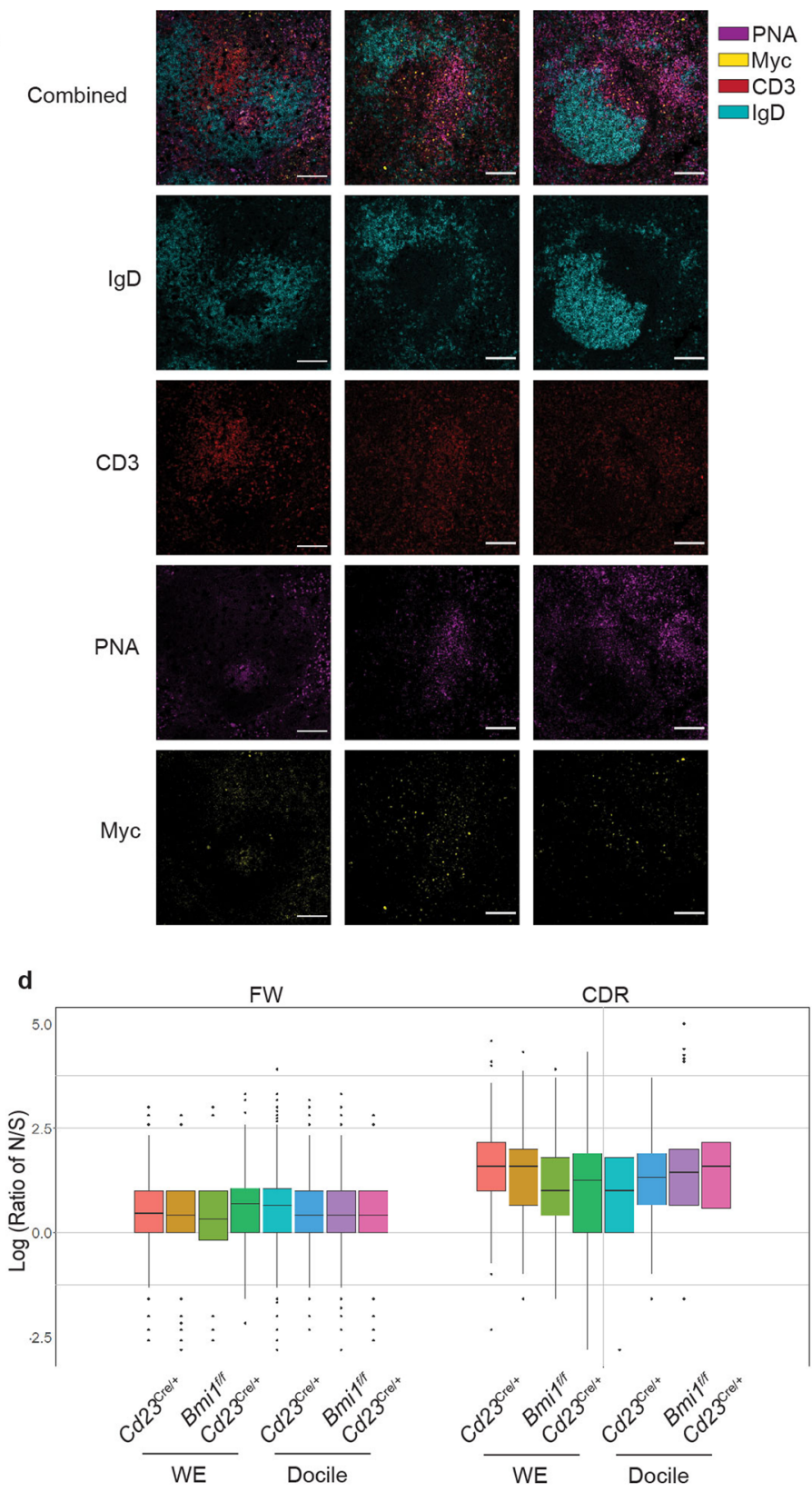
Extended Data Fig. 5 | Additional images of Myc expression within GCs. a, Cd23 $3^{\mathrm{Cr} /+}$ and $\mathbf{b}, \mathrm{Bmi} 7^{\mathrm{f} / \mathrm{C}} \mathrm{Cd} 23^{\mathrm{Cre} /+}$ mice were infected with LCMV-Docile and GCs assessed at $d 7$ post-infection as detailed in Fig. 4. Panels show individual staining (IgD, CD3, PNA and Myc; combined top row). Representative images of $n=4$ mice per genotype from two individual experiments. Scale bar $=100 \mu m$. $\mathbf{c}$, Number of unique synonymous and non-synonymous mutations per clone in CDR and FW regions of GC B cell $V_{H}$ gene repertoire. GC B cells were isolated from $C d 23^{\mathrm{Cre} /+}$ and $B$ mit $7^{\mathrm{f} / \mathrm{C}} \mathrm{C} 23^{\mathrm{Cre} /+}$ mice infected with either LCMV-WE or LCMV-Docile, d14 post-infection. $\mathbf{d}$, Log ratio of non-synonymous to synonymous mutations in total CDR and total FW regions; median values shown. The boxplots (c, d) visualize the median (middle hinge), two hinges (first and third quartiles, $25^{\text {th }}$ and $75^{\text {th }}$, respectively), two whiskers (values no larger than the inter-quartile range, $1.5^{\star} \mathrm{IQ}$ ), and all individual outlying points. e-f, Selection pressure in $\mathrm{V}_{\mathrm{H}} \mathrm{CDR}$ and $\mathrm{FW}$ regions; (e) shows individual mice, $(\mathbf{f})$ selection pressure of pooled mice per genotype and infection. 


\section{ARTICLES}
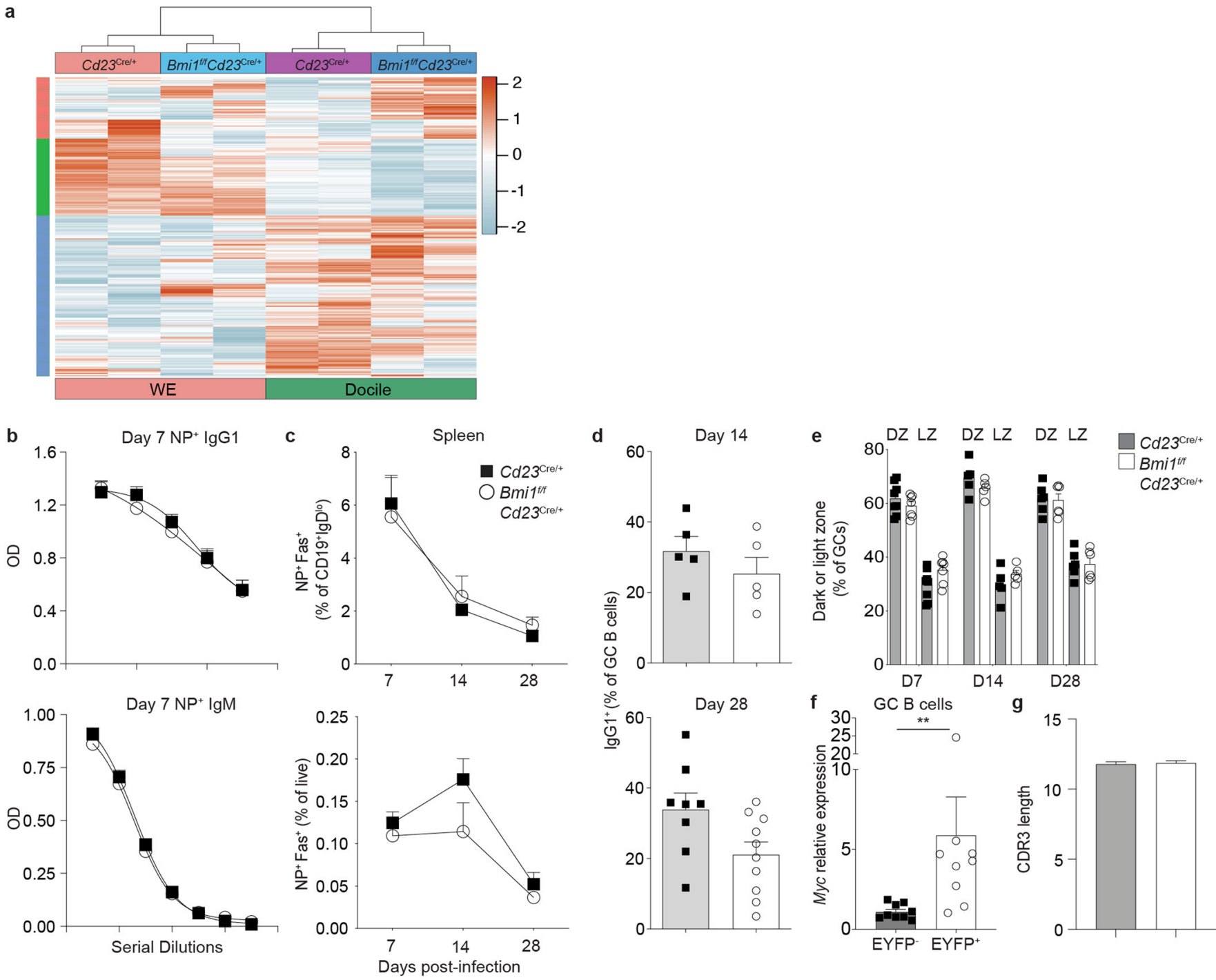

h
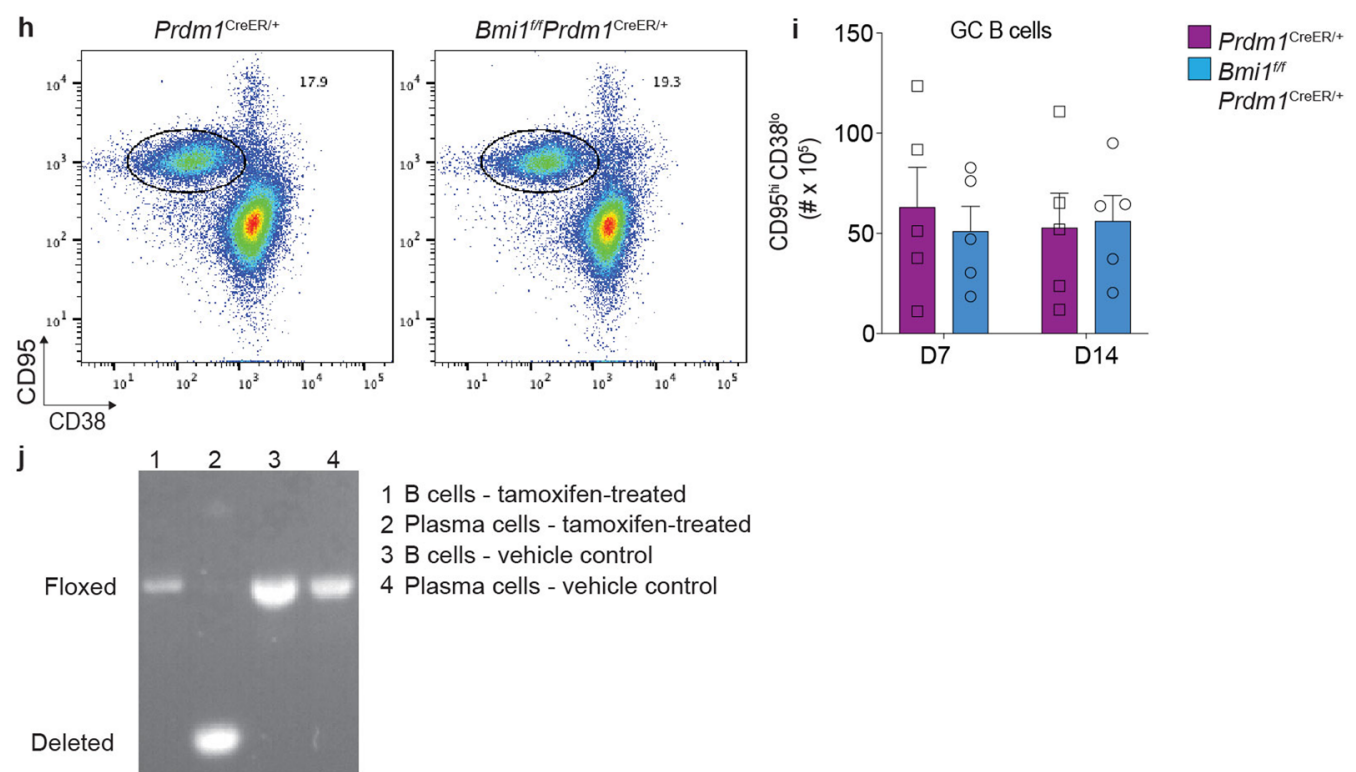

1 B cells - tamoxifen-treated

2 Plasma cells - tamoxifen-treated

3 B cells - vehicle control

4 Plasma cells - vehicle control

Extended Data Fig. 6 | See next page for caption. 


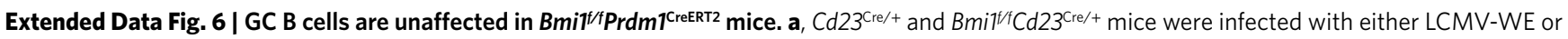
LCMV-Docile, GC B cells sort-purified 14d post-infection, and gene expression assessed by RNA-seq. Shown are DEGs identified across the four groups. b. $\mathrm{Cd} 23^{\mathrm{Cre} /+}$ and $\mathrm{Bmi} 7^{\mathrm{f} / \mathrm{C}} \mathrm{Cd} 23^{\mathrm{Cre} /+}$ mice were immunized with NP-KLH in alum and serum NP-binding IgG1 and IgM assessed at d7 post-immunization; $\mathrm{n}=8 \mathrm{Cd} 23^{\mathrm{Cre} /+}$ and $\mathrm{n}=7 \mathrm{Bmi} 7^{\mathrm{f} / \mathrm{C}} \mathrm{C} 23^{\mathrm{Cre} /+}$ mice, combined from two independent experiments. c, Antigen-specific GC B cells were assessed over time; $d 7$ : $\mathrm{n}=8 \mathrm{Cd} 23^{\mathrm{Cre} /+}$ and $\mathrm{n}=7 \mathrm{Bmi} 7^{\mathrm{ff} / \mathrm{Cd}} 23^{\mathrm{Cre} /+}$ mice, d14: $\mathrm{n}=5$ mice per group, d28: $\mathrm{n}=9 \mathrm{Cd} 23^{\mathrm{Cre} /+}$ and $\mathrm{n}=10 \mathrm{Bmi}{ }^{\mathrm{ft} / \mathrm{Cd}} 23^{\mathrm{Cre} /+}$ mice; combined from at least two experiments per time point. d, Frequency of $\operatorname{lgG} 1^{+}$within the GC B cell population at d14 and d28 post-immunization; d14: $n=5$ mice per group, d28: $n=9$

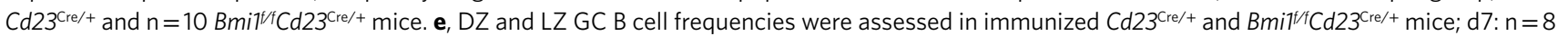

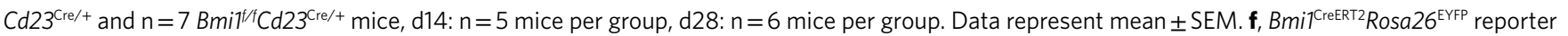
mice and wild-type controls were immunized and treated as per schematic in Extended Data Fig. 2. EYFP- and EYFP+ GC B cells were isolated and assessed for Myc as per Fig. 4; $n=9$ mice per group, combined from two independent experiments ( ${ }^{\star \star} P=0.0019$, Mann-Whitney $U$ test, two-tailed $p$-value). $\mathbf{g}$, CDR3 length of $V_{H} 186.2$ sequences from GC B cells; $n=42$ cells from Cd23Cre/+ and $n=44$ cell from Bmi $7^{\text {t/f }} \mathrm{Cd} 23^{\mathrm{Cre} /+}$ mice, combined from $n=3$ mice per group. h, Naïve Bmi7/fPrdm 7 CreeR/+ and controls were administered tamoxifen as per schematic in Fig. 6a. Representative flow cytometric plots of GC B cells in mesenteric lymph nodes. $\mathbf{i}$, Assessment of GC B cell number by flow cytometry; $n=5$ mice per group, combined from two independent experiments

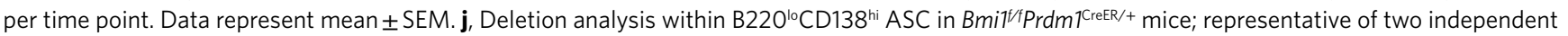
experiments. 
a
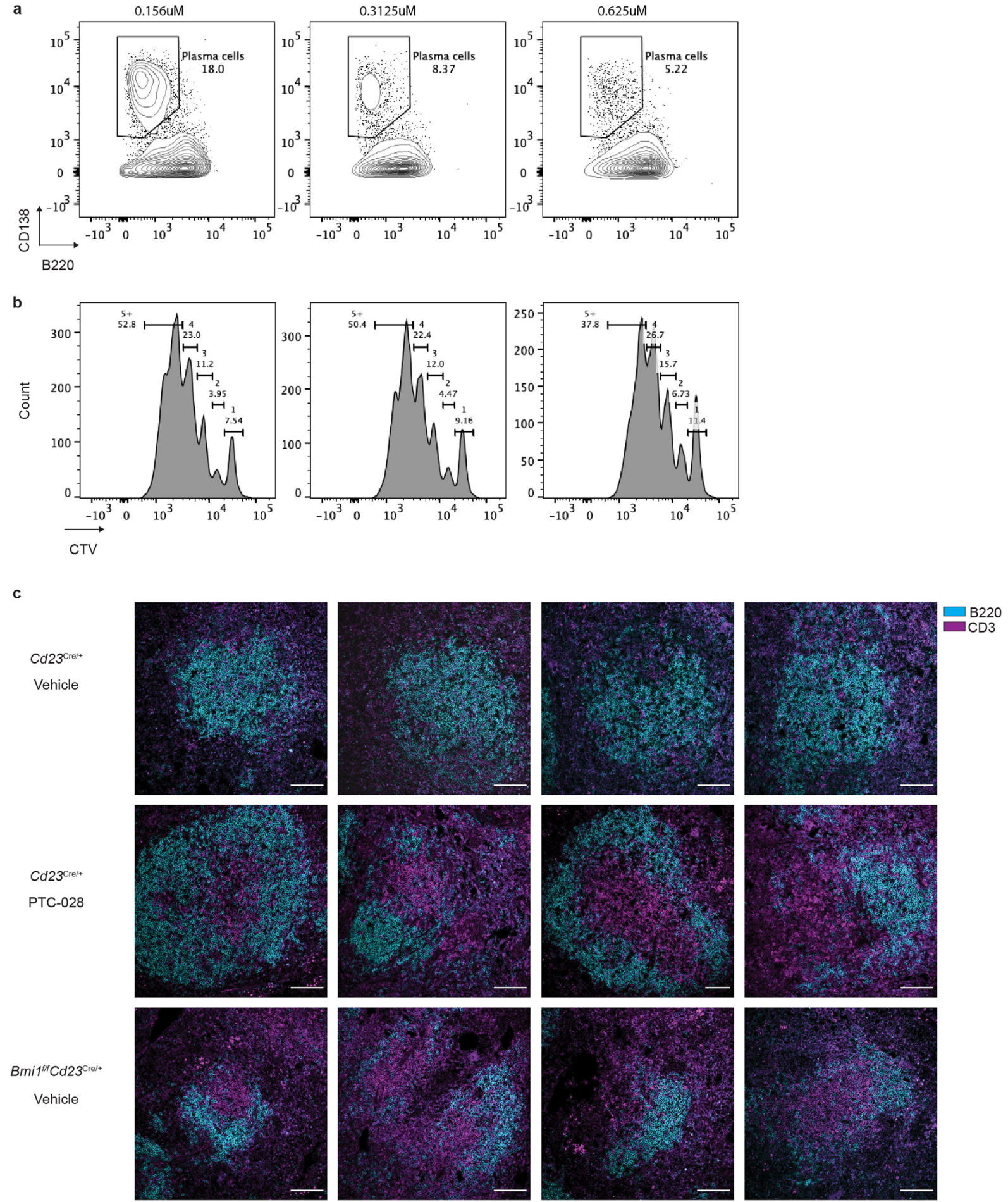

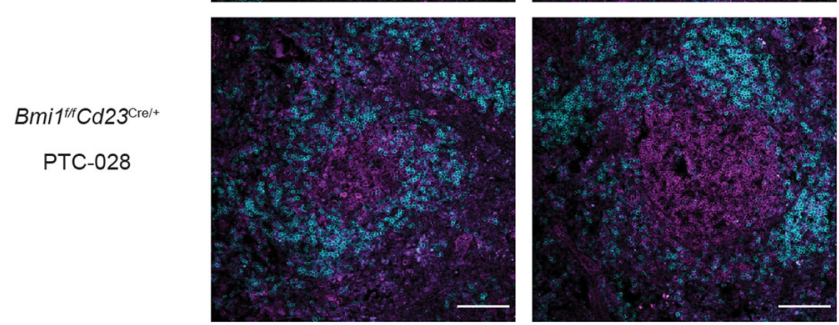

Individual mouse per experimental group

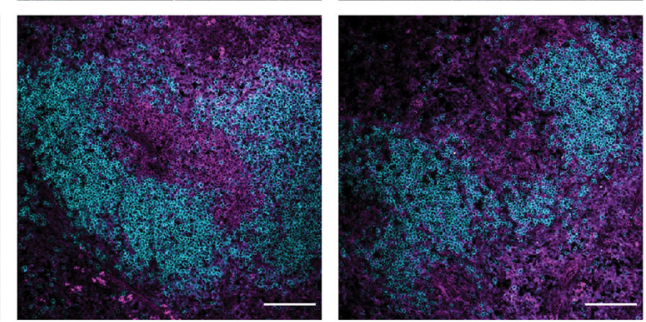

Individual mouse per experimental group

Extended Data Fig. 7 | See next page for caption. 
Extended Data Fig. 7 | PC are decreased in response to a small molecule inhibitor to BMI-1. a, b, Representative flow cytometric plots of CTV-labelled wild-type B cells cultured with LPS and IL-4, and in the presence of PTC-209 at the indicated concentrations. Cells were assessed by flow cytometry for (a) ASC markers and (b) cell division, as determined by the dilution of CTV. c, Representative images of histological analysis of spleens $12 \mathrm{~d}$ post-infection from $\mathrm{Cd} 23^{\mathrm{Cre} /+}$ and $\mathrm{Bmi7}{ }^{7 / \mathrm{C}} \mathrm{Cd} 23^{\mathrm{Cre} /+}$ mice treated with either the vehicle control or PTC-028; B220 (cyan), CD3 (magenta). Two examples of B cell follicles per individual mouse; two individual mice within each experimental group shown. Scale bar $=100 \mu \mathrm{m}$. 


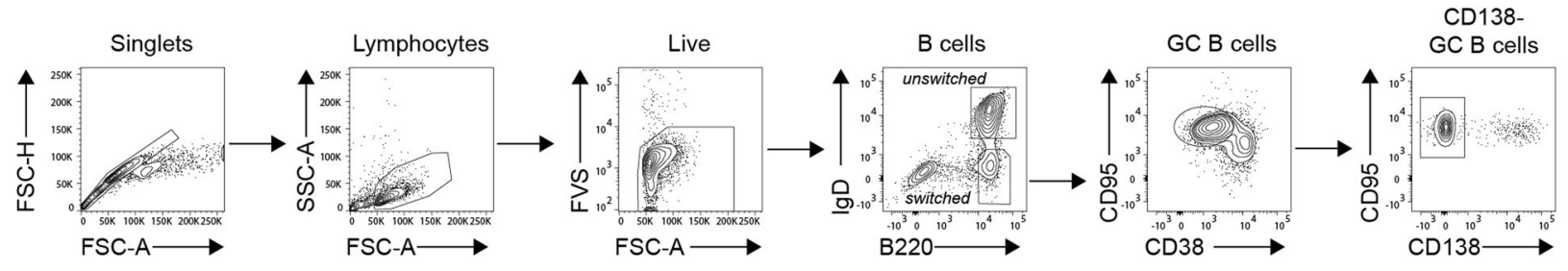

b
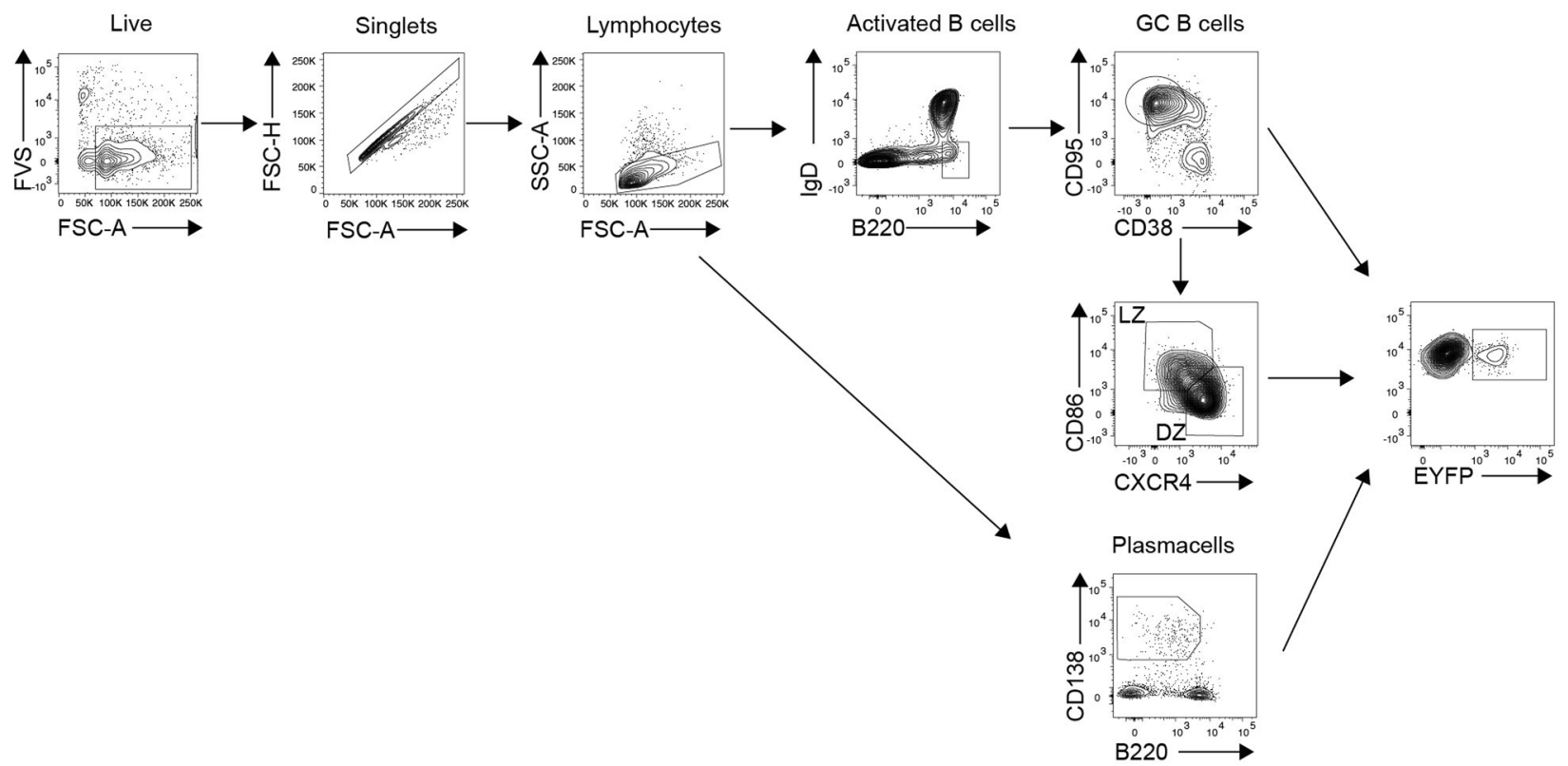

C

Gated on CD45+
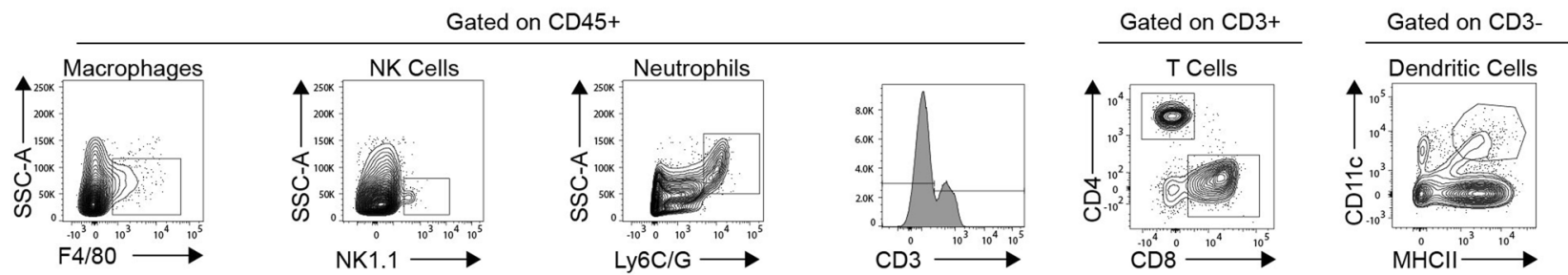

Extended Data Fig. 8 | Flow cytometry gating scheme. a, Gating strategy for sort purification of GCB for RNA-seq and ATAC-seq analysis (Figs. 1, 5; ED Figs. 1, 6). b, Gating strategy for GCB, GCB DZ and LZ distribution, and ASC ("Plasmacells") used throughout the manuscript, and EYFP gating strategy for Bmi1 reporter mice (Fig. 1; Extended Data Fig. 2). c, Gating strategy for innate cell and T cell subsets (Extended Data Fig. 3). Note either B220 or CD19 were used to gate B cells. 


\section{Reporting Summary}

Nature Research wishes to improve the reproducibility of the work that we publish. This form provides structure for consistency and transparency in reporting. For further information on Nature Research policies, see our Editorial Policies and the Editorial Policy Checklist.

\section{Statistics}

For all statistical analyses, confirm that the following items are present in the figure legend, table legend, main text, or Methods section.

$\mathrm{n} / \mathrm{a}$ Confirmed

$\bigotimes$ The exact sample size $(n)$ for each experimental group/condition, given as a discrete number and unit of measurement

$\square$ A statement on whether measurements were taken from distinct samples or whether the same sample was measured repeatedly

The statistical test(s) used AND whether they are one- or two-sided

Only common tests should be described solely by name; describe more complex techniques in the Methods section.

$\bigotimes \square$ A description of all covariates tested

$\square$ A description of any assumptions or corrections, such as tests of normality and adjustment for multiple comparisons

$\square$ A full description of the statistical parameters including central tendency (e.g. means) or other basic estimates (e.g. regression coefficient)

AND variation (e.g. standard deviation) or associated estimates of uncertainty (e.g. confidence intervals)

For null hypothesis testing, the test statistic (e.g. $F, t, r$ ) with confidence intervals, effect sizes, degrees of freedom and $P$ value noted

Give $P$ values as exact values whenever suitable.

Х $\square$ For Bayesian analysis, information on the choice of priors and Markov chain Monte Carlo settings

$\square$ For hierarchical and complex designs, identification of the appropriate level for tests and full reporting of outcomes

\ $\square$ Estimates of effect sizes (e.g. Cohen's $d$, Pearson's $r$ ), indicating how they were calculated

our web collection on statistics for biologists contains articles on many of the points above.

\section{Software and code}

Policy information about availability of computer code

Data collection BD FACSDiva Software v9.0 was used to collect flow cytometry and sorting data.

Leica LAS X v3.0, Nikon NIS-Element software 4.3, SPOT software 5.1, ChemiDoc ${ }^{\text {TM }}$ Touch Gel Imaging System (BIORAD) were used to acquire images.

OPTIMA Series v2.20 was used to acquire ELISA reads

NanoDrop 1000 software 3.71 was used to acquire DNA and RNA concentration.

Rotor-Gene software (QIAGEN) v2.3.4 was used to acquire qPCR data (Ct values).

Data analysis GraphPad Prism v9.2 was used to analyze raw data, perform statistics and create graphs.

FlowJo v10.7 was used to analyze flow citometry and sorting data.

ImageJ/FIJI v1.53c was used to analyze confocal images.

MARS Software v3.01 was used to analyze ELISA raw reads obtained with the OPTIMA Series.

LabChip GX Reviewer 5.8 used to analyze N-Glycan profiles.

Image Lab 6.1 was used to quantify band intensity in Western Blot images.

RNA-Seq data were processed using the following R/Bioconductor tools and software: RNA-sik pipeline (10.5281/zenodo.1403976),

RSubread/Featurecounts v2.6.4, DeSeq2 v1.32, Kmeans (Cluster v2.1.2), Degust (10.5281/zenodo.3258932), gplots v3.1.1, Ingenuity Pathway Analysis (QIAGEN, v01-14), GSEA v4.1.

ATAC-Seq data were processed using the following R/Bioconductor tools: Bowtie2 v2.4.1, Picard MarkDuplicates v2.26, GenomicRanges v1.44, MACS2 v2.2, DeSeq2 v1.32.

BCR-Seq data were processed using the following tools and algorithms: IMGT V-Quest v3.5, ImmuneDB v0.29.11, Shazam v1.1, BASELINE algorithm v1.2.1. 
Policy information about availability of data

All manuscripts must include a data availability statement. This statement should provide the following information, where applicable:

- Accession codes, unique identifiers, or web links for publicly available datasets

- A list of figures that have associated raw data

- A description of any restrictions on data availability

\section{Field-specific reporting}

Please select the one below that is the best fit for your research. If you are not sure, read the appropriate sections before making your selection.

Х Life sciences

Behavioural \& social sciences

Ecological, evolutionary \& environmental sciences

For a reference copy of the document with all sections, see nature.com/documents/nr-reporting-summary-flat.pdf

\section{Life sciences study design}

All studies must disclose on these points even when the disclosure is negative.

Sample size

The minimum sample size for in vivo experiments was determined based on our prior experience with statistical assessment of geneticallymodified mice compared to control mice (e.g. Kealy et al Cell Reports 2020; Good-Jacobson et al JEM 2015). The minimum sample size for in vitro experiments was determined based on our prior experience (e.g. Kealy et al Cell Reports 2020). For in vivo and in vitro experiments, a minimum of two independent experiments were performed.

For deep-sequencing experiments, a minimum of two independent biological replicates were used.

Data exclusions Mice that did not respond to LCMV, likely due to a problem encountered during tail IV injection, were excluded. Mice that did not respond to NP-KLH immunization were excluded.

Replication Data were combined from at least two independent experiments, and each experiment has at least two biological replicates. All attempts at replication were successful.

Randomization Samples were organized by mouse strain and treatment (immunization, infection). To reduce the covariates, each experiment was designed by matching age range and sex between the different experimental groups.

Blinding Blinding was not possible as the mice are tattooed with an identifying number, and are animal ethics protocols dictate monitoring and recording of each animal from infection to experiment. One researcher is responsible for the entirety of the experiment.

\section{Reporting for specific materials, systems and methods}

We require information from authors about some types of materials, experimental systems and methods used in many studies. Here, indicate whether each material, system or method listed is relevant to your study. If you are not sure if a list item applies to your research, read the appropriate section before selecting a response.

\begin{tabular}{|c|c|c|c|}
\hline \multicolumn{2}{|r|}{ Materials \& experimental systems } & \multicolumn{2}{|c|}{ Methods } \\
\hline $\mathrm{n} / \mathrm{a}$ & Involved in the study & $\mathrm{n} / \mathrm{a}$ & Involved in the study \\
\hline & $\bigotimes$ Antibodies & Х & $\square$ ChIP-seq \\
\hline L & $\bigotimes$ Eukaryotic cell lines & $\square$ & \ Flow cytometry \\
\hline$\bigotimes$ & $\square$ Palaeontology and archaeology & Х & $\square$ MRI-based neuroimaging \\
\hline 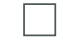 & Х Animals and other organisms & & \\
\hline Х & $\square$ Human research participants & & \\
\hline$\bigotimes$ & $\square$ Clinical data & & \\
\hline Х & $\square$ Dual use research of concern & & \\
\hline
\end{tabular}

\section{Antibodies}

Antibodies used

Validation
A detailed list of used antibodies, clones, supplier names and catalog numbers are provided in the supplementary information section.

All antibodies are commercially available and have been validated in the literature (e.g. Kealy et al Cell Reports 2020, Quinn et al Nature Communications 2020, Piovesan et al Cell Reports 2020, Russ et al Immunity 2014, Tamburri et al Molecular Cell 2020). IgD AF647, obtained from the WEHI antibody facility, is a commercially available clone and has been used previously (Kealy et al Cell 
Reports 2020). Anti-myc validation can be found here: https://www.abcam.com/c-myc-antibody-y69-ab32072.html. Reproducibility is indicated in https://www.biolegend.com/reproducibility and https://www.biocompare.com/Antibody-Manufacturing/355107Antibody-Manufacturing-Perspectives-BD-Bioscience/ and https://www.biocompare.com/Reproducibility/336225-Q-A-with-ThermoFisher-Scientific-VP-and-GM-Dara-Grantham-Wright/.

\section{Eukaryotic cell lines}

Policy information about cell lines

Cell line source(s)

MC57G cell line: The MC57G is a fibrosarcoma cell line established from a tumor arising in a C57BL/6 mouse after treatment with methylcholanthrene.

VL4 Hybridoma: hybrid cells generated with YM3 myeloma cells and spleen cells from LCMV-WE immunized rats.

Authentication

None of the cell lines used were authenticated

Mycoplasma contamination

Cell lines were not tested for Mycoplasma contamination

Commonly misidentified lines

(See ICLAC register)

Name any commonly misidentified cell lines used in the study and provide a rationale for their use.

\section{Animals and other organisms}

Policy information about studies involving animals; ARRIVE guidelines recommended for reporting animal research

Laboratory animals

All mice are on a C57BL/6 background, back-crossed and maintained at the Monash Animal Research Platform.

Strains used

- Cd23cre

- Bmi1f/f Cd23cre

- Bmi1CreERRosa26EYFP

- Prdm1Rosa26CreERT2

- Bmi1f/fPrdm1Rosa26CreERT2

- Ly5.1

Mice were maintained in housing at a temperature of $18-240 \mathrm{C}$ and a humidity of $40-70 \%$. Light/dark cycle was $12 \mathrm{hr}$ per cycle. Both males and females were used for the purposes of this project. Animals used in the experimental procedures were at least 42 days old and up to 6 months of age.

Wild animals The study did not involved the use of wild animals.

Field-collected samples The study did not involved samples collected from the field.

Ethics oversight The Monash Animal Ethics Committee approved all experimental procedures on the laboratory animals. Animal care and experimentation were conducted following the Australian National Health and Medical Research Council Code of Practice for the Care and Use of Animals for Scientific Purposes guidelines.

Note that full information on the approval of the study protocol must also be provided in the manuscript.

\section{Flow Cytometry}

\section{Plots}

Confirm that:

Х The axis labels state the marker and fluorochrome used (e.g. CD4-FITC).

Х The axis scales are clearly visible. Include numbers along axes only for bottom left plot of group (a 'group' is an analysis of identical markers).

Х All plots are contour plots with outliers or pseudocolor plots.

Х A numerical value for number of cells or percentage (with statistics) is provided.

\section{Methodology}

Sample preparation
Murine spleens were used from the above listed mice for flow cytometric analysis, by using the following method:

- Mush spleens through strainer with a syringe plunger into Falcon tube with PBS-FCS 2\% (pre-chilled at 4 degrees Celsius);

- Rinse strainer and plunger with 2\%PBS-FCS;

- Spin at 1500 rpm for 5 min and discard supernatant;

- Add $1 \mathrm{ml} \mathrm{RBC}$ buffer (per spleen) for 3 min with gentle agitation (pipette up and down with serological pipette to try and break up some clumps or use transfer pipette to get rid of big clumps);

- Add $9 \mathrm{ml} \mathrm{PBS-2 \%} \mathrm{FCS,} \mathrm{spin} \mathrm{at} 1500$ rpm for 5 min and discard supernatant (keep everything at 4 degrees Celsius)

- Resuspend in PBS-2\%FCS, filter through mesh (to get rid of clumps) and perform cell count

- Add 5 million cells per FACS tube and wash again, aspirate off supernatant for a dry pellet;

- Cells are then ready for viability stain and stained with anti-mouse antibodies as described in the methods. 
Instrument

Software

Cell population abundance

Gating strategy

\section{BD LSRFortessa ${ }^{\mathrm{TM}}$ X-20 cell analyzer, BD FACSAria ${ }^{\mathrm{TM}}$ Fusion Cell Sorter}

BD FACSDiva Software v9.0 for data collection and FlowJo v10.7 for data analysis.

For flow cytometry analysis, a total of 5,000,000 cells (purified splenocytes) per sample was used for staining with the listed antibodies.

For cell sorting, depending on the type of experiment, we used to stain at least 20,000,000 cells. A small fraction (usually $20 \mu \mathrm{l}$ ) of the sorted samples was run on the BD LSRFortessa ${ }^{\mathrm{TM}} \mathrm{X}-20$ cell analyzer to check the purity of the sorted population. Our sorted samples showed a frequency of 98-99\% purity.

For all the samples used in this project, the initial gating strategy was used as follows:

1. Live/Dead cells, by using the BD HorizonTM Fixable Viability Stain (FVS). Positive stained dead cells were excluded from the gate.

2. Single cell gate. This gate was obtained by using FSC-A on the X-axis and FSC-H on the Y-axis. The cells laying on the diagonal, representing the single cell population, were gated.

3. Lymphocytes. This population is gated by using FSC-A on the X-axis and SSC-A on the Y-axis.

Example downstream gating strategies are shown in Supplementary Information.

The various cell populations described in the paper were gated by using the antibodies listed in the Supplementary Information.

Each antibody was previously tested to discriminate between the negative and positive population. To do so, each antibody was serially diluted and used to stain the same number of splenocytes $\left(5 \times 10^{\wedge} 6\right)$. The titer of each antibody was assessed by using the geometric mean analysis of the different dilutions.

$\bigotimes$ Tick this box to confirm that a figure exemplifying the gating strategy is provided in the Supplementary Information. 